\title{
RECENT PROGRESS IN NON-NATIVE NUCLEIC ACID MODIFICATIONS
}

\author{
Luke K. McKenzie, ${ }^{\mathrm{a}, 1}$ Roberto El-Khoury, ${ }^{\mathrm{b}, 1}$ James D. Thorpe, ${ }^{\mathrm{b}}$ Masad J. Damha, ${ }^{\mathrm{b} *}$ and Marcel Hollenstein ${ }^{\mathrm{a}^{*}}$
}

While Nature harnesses RNA and DNA to store, read and write genetic information, the inherent programmability, synthetic accessibility and wide functionality of these nucleic acids make them attractive tools for use in a vast array of applications. In medicine, antisense oligonucleotides (ASOs), siRNAs, and therapeutic aptamers are explored as potent targeted treatment and diagnostic modalities, while in the technological field oligonucleotides have found use in new materials, catalysis, and data storage. The use of natural oligonucleotides limits the possible chemical functionality of resulting technologies while inherent shortcomings, such as susceptibility to nuclease degradation, provide obstacles to their application. Modified oligonucleotides, at the level of the nucleobase, sugar and/or phosphate backbone, are widely used to overcome these limitations. This review provides the reader with an overview of nonnative modifications and the challenges faced in the design, synthesis, application and outlook of novel modified oligonucleotides.

\section{Introduction}

Nucleic acids are the fundamental molecules of life, carrying the genetic blueprints for all living things on Earth. Refined through billions of years of evolution, they achieve an ideal balance between complexity and elegance, a perfect marriage of form and function. Their main functions consist of the reliable storage and transmission of hereditary information. The structural basis behind these functions was first unravelled by Franklin, Wilkins, Watson, and Crick in 1953 who highlighted the double helical nature of DNA. Well-defined hydrogen bonding patterns combined with hydrophobic and stacking forces maintain DNA in this iconic double stranded helical structure. In the context of RNA, the functional diversity assumed by this biopolymer is reflected by an important structural plasticity covering numerous secondary and tertiary conformations. The high degree of programmability of nucleic acids, along with synthetic accessibility has led to applications that markedly deviate from their natural functions. For instance, these biopolymers can serve as convenient bricks for the construction of nanomaterials with novel intrinsic properties, ${ }^{1,2}$ complex functional biochips, ${ }^{3}$ potent catalysts, ${ }^{4,}$ 5,6 and media for data storage applications. ${ }^{7,8}$ Despite these assets, the efficiency of nucleic acids in natural settings, but also in numerous practical (in vivo) applications is often hampered by intrinsic limitations. These include facile degradation by endo- and exo-nucleases, rapid renal clearance and poor pharmacokinetic properties, limited accessibility to

\footnotetext{
a. Institut Pasteur, Department of Structural Biology and Chemistry, Laboratory for Bioorganic Chemistry of Nucleic Acids, CNRS UMR3523, 28, rue du Docteur Roux, 75724 Paris Cedex 15, France.

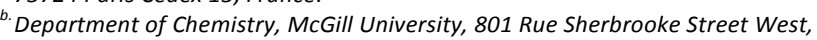
Montréal, Canada H3AOB8

${ }^{1}$ these authors contributed equally to this work

*marcel.hollenstein@pasteur.fr; masad.damha@mcgill.ca
}

more complex functional patterns and a dearth of functional groups capable of mediating binding or catalysis, especially when compared to proteinaceous counterparts. Nature remediates some of these shortcomings by introducing additional chemical modifications into the scaffold of nucleic acids, mainly at the level of the nucleobase. ${ }^{9,10}$ For instance, all RNAs contain modified nucleobases predominantly in tRNAs with an average of 13 modified nucleotides per molecule. These modifications assume a variety of functions including increasing the stability of local structures or assisting in the formation of functional secondary and tertiary structures. ${ }^{11}$ While some of the modified nucleotides such as 5carboxymethylcytidine ${ }^{12}$ or $N^{1}$-methyladenosine ${ }^{13}$ bear only small alterations to the scaffold of the canonical nucleobases, other patterns such as those found in wybutosine ${ }^{14}$ or in other hypermodified bases equipped with various amino acids ${ }^{15}$ are rather complex. Inspired by Nature's efforts, a myriad of synthetic analogues of nucleosides and oligonucleotides have been prepared in order to enhance their properties and further alleviate the aforementioned drawbacks. In this context, a prime example is the conjugation of $\mathrm{N}$ acetylgalactosamine (GalNAc) residues to siRNAs which has massively improved their targeted delivery to hepatocytes and culminated in the regulatory approval of the drug patisiran (brand name Onpattro). ${ }^{16}$

The seminal discovery of the gene silencing capacity of antisense oligodeoxynucleotides by Zamecnik and Stephenson ${ }^{17,18}$ combined with the realisation of the inherent in vivo instability of canonical nucleic acids ${ }^{19}$ have spurred tremendous efforts to modify the chemical architecture of nucleic acids and their constituting building blocks. The first type of oligonucleotide modification is the widely used phosphorothioate (PS) internucleotide linkage, where one of the phosphate non-bridging oxygens was substituted by a bulkier sulfur atom. This rather conservative change in the 
backbone led to a marked improvement in nuclease resistance and bioavailability of the ensuing oligonucleotides. Despite
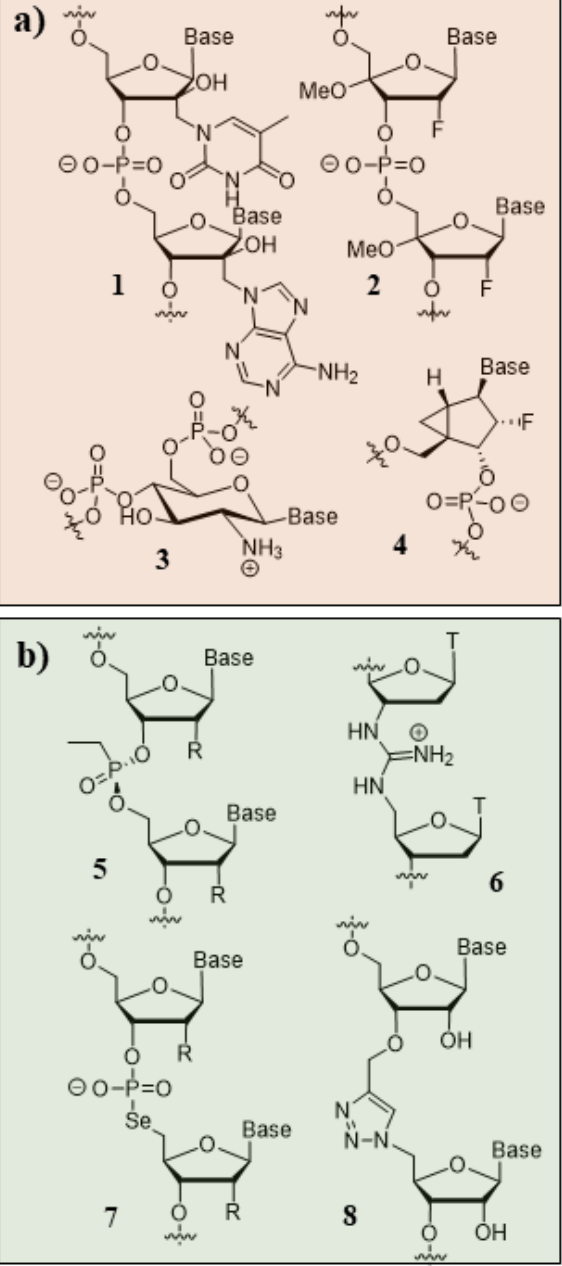

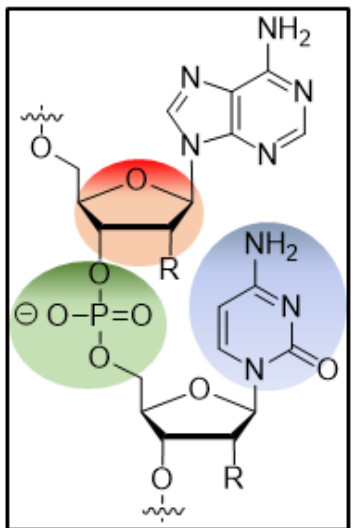

d)
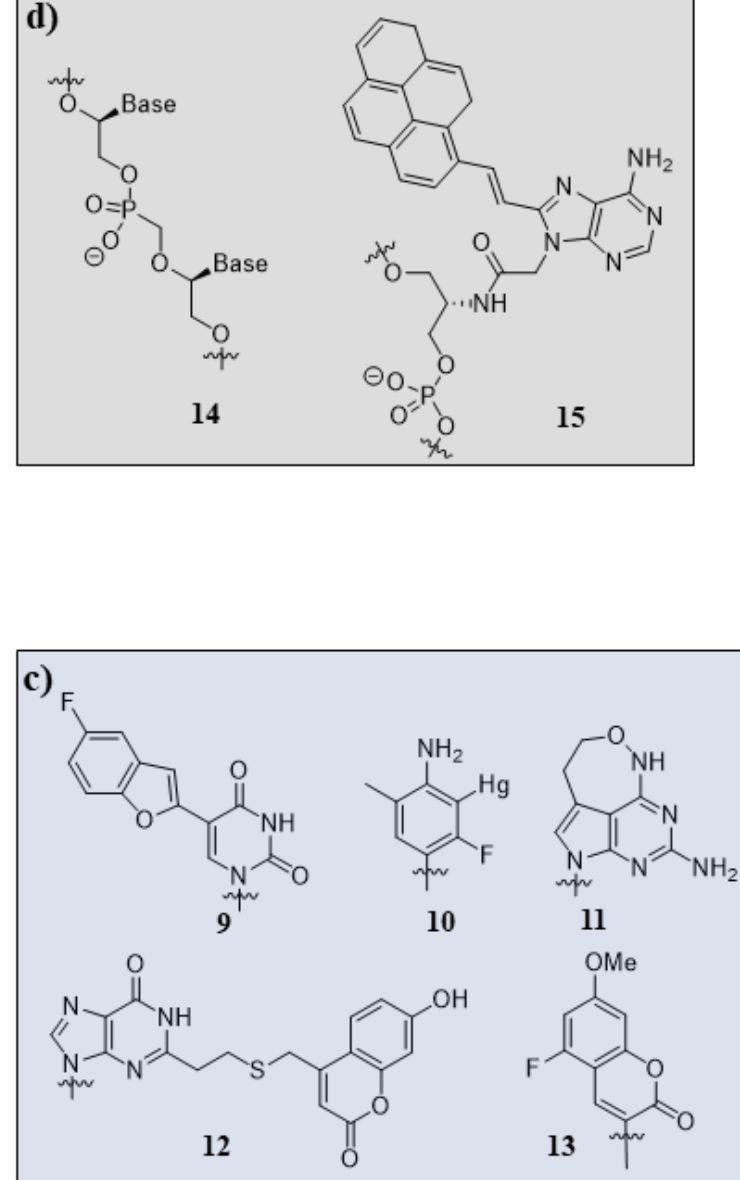

Figure 1. Selected recent examples of chemical modifications introduced in nucleic acids. a) sugar-modified nucleic acids including double-headed nucleotides (1) ${ }^{20}$ $2^{\prime}$-OMe,4'-F-modified ribobinonucleotides (2), ${ }^{21} 4^{\prime}, 6^{\prime}$-glucosamino nucleic acids (GANA) (3), ${ }^{22}$ and 2'-F-methanocarbacyclic nucleotides (4); ${ }^{23}$ b) backbone-modified nucleic acids including $(S)_{\mathrm{P}}-P$-ethyl-phosphonate nucleic acids (5), ${ }^{24}$ deoxynucleic guanidine DNG (6), ${ }^{25}$ phosphoroselenolate nucleic acid analogues (7), ${ }^{26}$ and triazolemodified RNA (8); ${ }^{27}$ c) nucleobase modifications including 5-fluorobenzofuran-2'-deoxyuridine (9), ${ }^{28}$ 3-fluoro-6-methylanilinenucleotide (10) involved in Hg(II)mediated base pairing, ${ }^{29}$ biversal pyrimidine analogueue (11) ${ }^{30}$ 2-vinylhypoxanthine (12) further modified by the thiol-ene reaction, ${ }^{31}$ and the fluorescent mimic of deoxycytidine containing a 5-fluoro-7-methoxy-coumarin moiety (13); ${ }^{32}$ d) nucleic acid analogues bearing modifications at multiple sites such as $(S)$-ZNA (14) that contains an acyclic methylphosphonate backbone ${ }^{33}$ and serinol nucleic acid (SNA) bearing a pyrene-modified adenine nucleobase (15). ${ }^{34}$

these advantages, the PS modification does not completely protect oligonucleotides from nuclease-mediated degradation and increases non-specific binding to proteins while concomitantly reducing the binding affinity for complementary RNA. ${ }^{35}$ Hence, novel chemistries were developed to introduce additional functionalities in the sugar-phosphate backbone. As highlighted in Fig. 1, any site of the sugar moiety, phosphodiester backbone, nucleobase or combinations thereof is amenable to the introduction of chemical modifications. In this Section, we discuss the different synthetic methods for introducing these modifications into oligonucleotides.

Considering the importance of chemical functionalization of nucleic acids, we have decided to focus this review on the current and emerging methods for the synthesis of DNA and RNA analogues and to discuss their main applications. We will discuss the sites of possible 


\section{ARTICLE}

a)

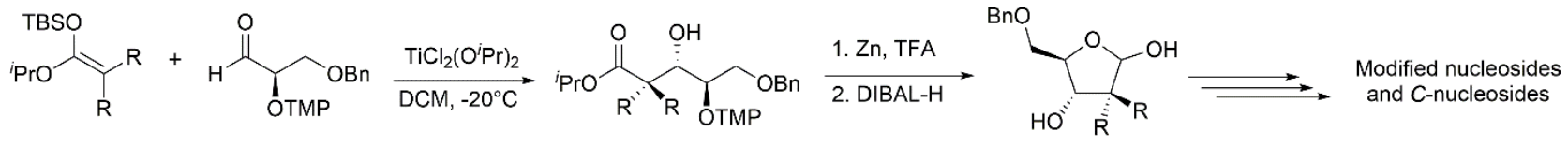

b)

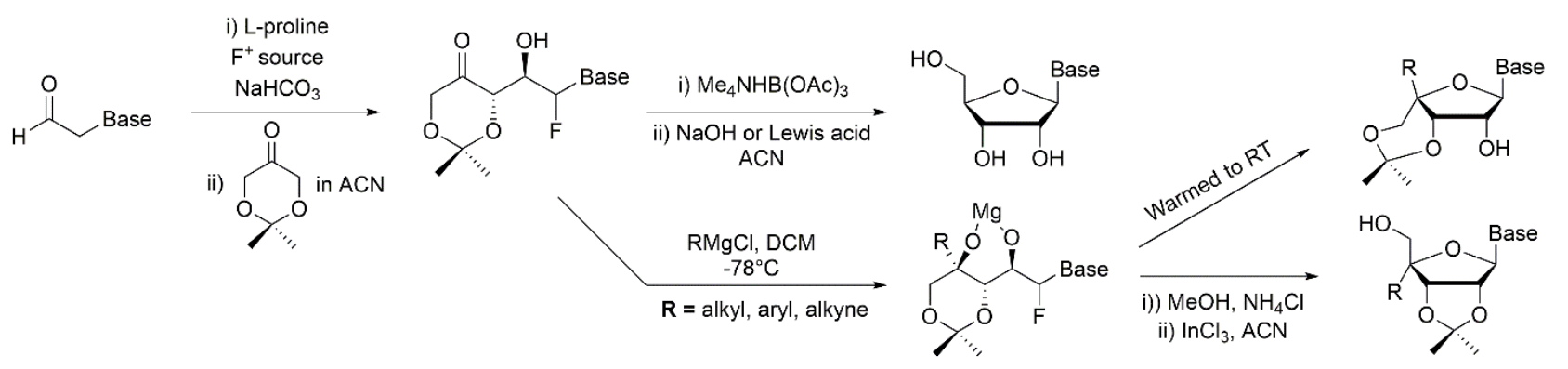

c)

$$
\begin{aligned}
& \text { Base } \begin{array}{c}
\begin{array}{c}
\mathrm{Cp} \text { (allyl) } \mathrm{Pd}(10 \mathrm{~mol} \%) \\
\mathrm{Chiral} \mathrm{ligand} \mathrm{L6}(10 \mathrm{~mol} \% \\
4^{\circ} \mathrm{C}, 12 \mathrm{hrs}
\end{array} \\
\text {-iodosuccinimide, } \mathrm{DCM}
\end{array} \\
& n=1-8 \\
& \mathbf{R}=\mathrm{H} \text {, vinyl silane, } \mathrm{NTs}
\end{aligned}
$$

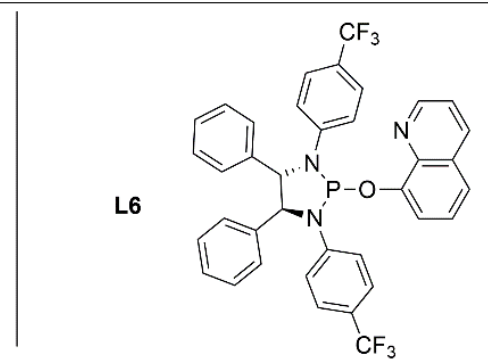

Figure 2. Selected asymmetric syntheses of nucleosides and their analogues. a) MacMillan's Mukaiyama aldol addition followed by ring closure and reduction. ${ }^{36}$ b Britton's electrophilic $\alpha$-fluorination and aldol condensation followed by annulative fluoride displacement. ${ }^{37} \mathrm{c}$ ) Trost's palladium catalyzed formation of oxygen and nitrogen containing heterocycles bearing pyrimidine nucleobases.

modification, how new functional groups can be inserted into nucleoside and nucleotide building blocks, and how these can be assembled to form oligonucleotides. The scope of this review is not to provide a comprehensive survey of all modifications made on nucleic acids, nor to describe naturally occurring modified nucleotides. Rather, recent selected examples of applications are presented to highlight the possibilities and limitations of the main chemical methods available for modifying the structure of nucleic acids. As such, we will describe therapeutic oligonucleotides, stabilized noncanonical RNA and DNA structures, aptamers, catalytic DNA and RNA molecules and synthesis of DNA and RNA analogues via photolithographic methods. Finally, we provide an insight into the challenges facing nucleic acid analogues especially in the context of therapeutic agents.

\section{Synthetic methodologies of nucleosides and oligonucleotides}

Interest in the synthesis of nucleoside analogues was spurred by the quest for potent antiviral drugs. ${ }^{39}$ The chemistry developed in this context was then rapidly integrated for the construction of macromolecular drugs based on oligonucleotides. To do so, the nucleoside analogues had to be converted into activated building blocks which could then be assembled to form modified DNA and RNA oligonucleotides. An overview of important nucleoside modifications, including some recent developments, will be given, followed by an elaboration of the different chemical and chemoenzymatic methods that have been devised for the synthesis of modified oligonucleotides, as well as their modus operandi.

\section{Important modifications and recent developments}

\section{Sugar modification}

Methods for introducing modifications to the sugar have traditionally required long syntheses with significant manipulation of protecting groups. To this end, we will not dwell on those synthetic routes as the current strategies for sugar modifications have evolved significantly in the past decade and will instead focus on the more recent and salient methods.

In 2014, MacMillan and colleagues developed a strategy for the synthesis of 5-carbon furanose sugars bearing nucleobases at the anomeric position. ${ }^{36}$ The key steps in the reaction sequence began with an enantiomerically rich $\alpha, \beta$ dioxygenated aldehyde ${ }^{40}$, a Lewis acid-catalyzed Mukaiyama 
aldol addition and cyclization by treatment with $\mathrm{Zn}$ and trifluoroacetic acetic acid. Finally, reduction with DIBAL-H yielded ribose rings bearing hydroxyl groups at the anomeric position for further manipulation (Fig. 2a). This 3-step process enabled synthesis of 5-membered ring ribose, deoxyribose, and 2 '-modified ribose sugars in high yields (>80\%) and high enantioselectivity (e.e. $\sim 90 \%$ ). Furthermore, the lactone intermediate, prior to reduction, could be further exploited towards $C$-nucleosides or other therapeutic nucleoside analogues such as PSI-6130 (precursor Sofosbuvir, hepatitis C) ${ }^{41}$ and gemcitabine (cancer). ${ }^{42}$ While this strategy allowed for efficient synthesis of various functionalized riboses, the poor selectivity of the glycosylation of nucleobases remains a major issue. In this regard, inspired by a "ribose-last approach", Britton and colleagues recently demonstrated an efficient synthesis of a modified ribose core bearing nucleobases with the correct stereochemistry. ${ }^{37}$ This approach takes advantage of a tandem $\alpha$-fluorination followed by proline catalyzed aldol addition of an aldehyde and a dioxanone; then an annulative fluoride displacement yields modified ribose $\alpha$ - or $\beta$ nucleosides in good yields and enantioselectivity. This strategy also allows for easy access to $\mathrm{C4}^{\prime}$ modified nucleosides including bicyclic and certain $C$-nucleosides via treatment with Grignard reagents (Fig 2b). Impressively, they synthesized an ethylene LNA analogue in 4 steps which had previously required 23 steps. $^{43}$

Direct stereoselective glycosylation of nucleobases, with 5-fluorouracil, deazapurines, and the four major nucleobases of natural RNA, was achieved by Hocek and coworkers in 2017. ${ }^{44}$ A modified Mitsunobu reaction results in formation of the intermediate anhydrase with subsequent nucleophilic epoxide ring opening resulting in nucleoside formation. The reaction conditions require only mono-triphenylmethyl protection of the sugar and neutral reaction conditions with good yields maintained up to a gram scale. Merck recently developed a biocatalytic cascade starting from acyclic reagents for the synthesis of islatravir, a potential nucleoside HIV treatment, with a $4^{\prime}$ modified ribose core. ${ }^{45}$ Their approach took advantage of five enzymes engineered for non-natural substrates and required fewer than half as many steps as any previously reported route.

Inspired by earlier work for palladium-catalyzed synthesis of acyclic amido ethers ${ }^{46}$, Trost and coworkers developed a method for synthesis of nucleoside analogues via novel chiral diamidophosphite ligands (Fig 2c). ${ }^{38}$ Most of their efforts focused on the synthesis of 5 to 12-membered rings containing oxygen and nitrogen with pyrimidines at the anomeric position. These novel macrocyclizations open the door for new studies on even larger and more conformationally flexible rings in nucleic acids.

Both 6-membered ${ }^{47-50}$ and 7-membered ${ }^{51-53}$ ring nucleic acids have been explored. Hexose nucleic acids (HNA) are among most notable. ${ }^{54}$ Recently, fluorinated ${ }^{55}$ and unsaturated ${ }^{56}$ HNA analogues have been prepared and were found to increase duplex stability. ${ }^{57}$ Furthermore, glucosamine based nucleic acids have been synthesized with $\beta$-oriented nucleobases at the anomeric position. ${ }^{22}$ These analogues bear charged amino groups and their affinity towards complementary targets was found to be dependent on the linkage connectivity $\left(4^{\prime}-6^{\prime}\right.$ vs $3^{\prime}$ $\left.6^{\prime}\right)$. A different ring expanded analogue acid, that has been extremely important for therapeutic applications, is the morpholino nucleic acid. ${ }^{58,59}$

Perhaps even more synthetically challengingly than 6membered sugar rings are the 7-membered ring oxepane nucleic acids (ONAs). First prepared by Damha and coworkers ${ }^{51}$ via ring expansion of cyclopropanated sugars ${ }^{60}$, ONAs were able to bind complementary RNA targets (albeit with low affinity), elicited RNase $\mathrm{H}$ degradation of the RNA strand, and exhibited high nuclease resistance.

Another interesting modification of the sugar unit results by linking a second nucleobase at $\mathrm{C2}^{\prime}$ of the sugar via a methylene group (Fig. 1a). ${ }^{61}$ Initial efforts produced a uridine linked to a thymine base $\left(U_{T}\right)$. When incorporated into an oligonucleotide, the "double headed" $U_{T}$ unit was able to base pair with two adenine bases on the complementary strand. In standard sequences $U_{T}$ was found to be destabilizing; however, it was stabilizing when a bulge was present in the complementary strand. Double-headed nucleotides of mixed base composition or arabinose sugars were also synthesized. ${ }^{62,63}$ Interestingly, while the triphosphate derivative of $U_{A}$ was not a substrate for four DNA polymerases tested, it proved possible for Therminator DNA polymerase to transfer the information of $U_{A}$ in a template sequence to natural DNA under controlled conditions. ${ }^{64}$

\section{Base modification}

Progress in heterocyclic chemistry has permitted the construction of a myriad of nucleobase analogues. In conjunction, the nucleobase has advanced as a popular site for the introduction of functional groups into nucleic acids since this often causes little disruption of the Watson-Crick recognition pattern and thus does not perturb or disrupt the genetic information carried by the DNA or RNA sequences. ${ }^{65,66}$ Simultaneously, modified nucleobases can increase the thermal stability of duplexes and gene silencing activities, ${ }^{67-69}$ enable the introduction of fluorescent ${ }^{70-72}$ or redox labels, ${ }^{73,74}$ convey additional reactivity, ${ }^{75,76}$ or expand the genetic alphabet. ${ }^{77-79}$ Early examples of chemical variations of the chemical composition of nucleobases stem from synthetic efforts to develop nucleoside-based antiviral agents. ${ }^{80,81}$ These early modifications included, for instance, 2,6diaminopurine, ${ }^{82}$ or 5-vinyl pyrimidines ${ }^{83}$ and mainly represented small architectural variations of the overall structure of the canonical bases. The complexity, diversity, and nature of the applications of base-modified nucleosides and nucleotides have all rapidly expanded since these first examples.

Numerous synthetic pathways have been devised for the introduction of modifications at the level of the nucleobase and mainly involve glycosidic bond formation between an altered nucleobase and an activated sugar unit or, alternatively, by further modification of suitable synthetic precursors (Fig. 3). Direct glycosylation reactions of activated 
sugar moieties are commonly used since they grant access to a broad variety of

a)

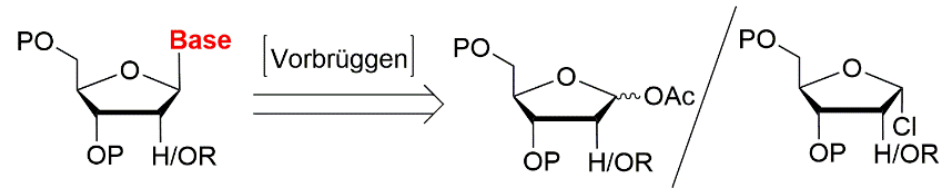

b)

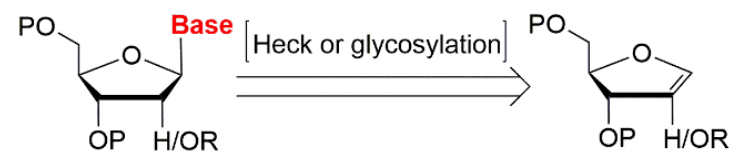

c)

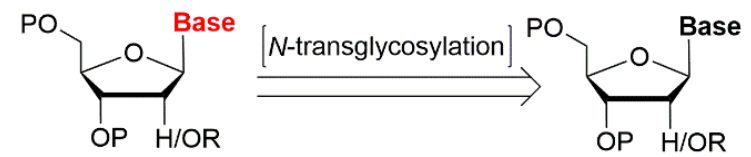

d)

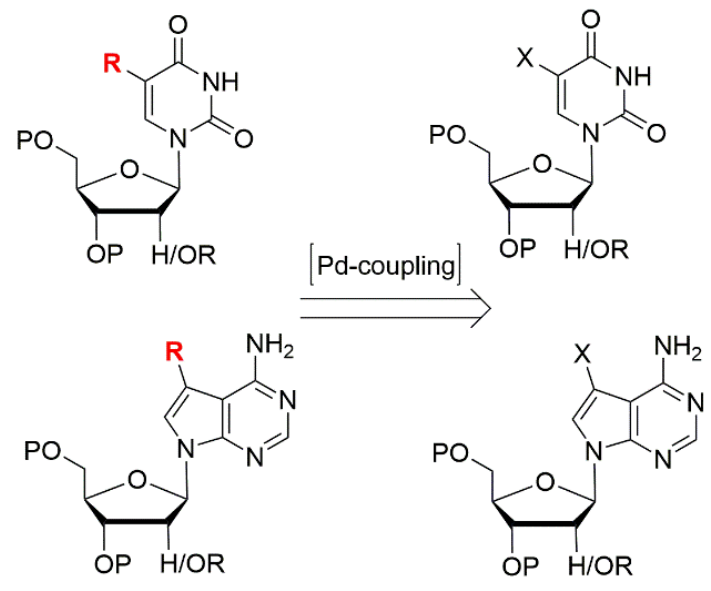

Figure 3. Main synthetic pathways to nucleobase-modified purine and pyyrimidine nucleoside analogues: a) the Vorbrüggen nucleosidation reaction involving Lewis acid activated nucleophilic attack ${ }^{84}$; b) the Pd-catalysed Heck reaction ${ }^{85}{ }^{86}$; c) Chemoenzymatic transglycosylation methods; d) Pd-assisted cross-coupling reactions with purine and pyrimidine precursors

base-modified nucleoside analogues. However, this approach is often impaired by the poor solubility and nucleophilicity of the nucleobases resulting in low yields and unfavorable stereoselective outcomes of the reactions. Consequently, most glycosylation methods require prior activation of both the sugar and the nucleobase moieties. ${ }^{88}$ In this context, the Vorbrüggen nucleosidation reaction is undoubtedly the most commonly used method for the synthesis of modified nucleosides and involves the nucleophilic attack of persilylated nucleobases on acylated sugar residues ${ }^{89}$ in the presence of a Lewis acid (Fig. 3a). ${ }^{84}$ Despite the immense success of this method. it is often impaired by moderate N7/N9 and/or poor $\alpha / \beta$ stereoselectivity as well as compatibility issues with specific functional groups due to the rather strong Lewis acid conditions. Milder variants of the Vorbrüggen reaction include the $N$-iodosuccinimide-mediated addition of persilylated nucleobases on glycals which has been successfully applied to constrained nucleic acids (Fig. 3b) ${ }^{90}$ or the use of Brønsted acid catalysts such as pyridinium triflate salts. ${ }^{91}$ A catalyst free variant of the Vorbrüggen reaction has also been reported and applied to the synthesis of various base- and sugar-modified nucleoside analogues. ${ }^{92}$ More recently, a broad scope method was reported which combines glycosyl ortho-(1phenylvinyl)benzoates donors with persilylated nucleobases (Fig. 4a). ${ }^{93}$

The glycosidic bond connecting the nucleobase with the sugar moiety can also be formed by application of metal catalyzed and organometallic reactions. For instance, the Heck coupling has been used extensively for the synthesis of $C$-nucleoside analogues such as 13 (Fig. 1) where halogenated or organometallic aryl and heterocyclic derivatives are reacted with glycals in the presence of a Pd-based catalyst (Fig. b). ${ }^{86}$ Metal catalyzed cross-coupling reactions have also been developed for the synthesis of $\mathrm{N}$-glycosidic, base-modified nucleoside analogues, mainly in the context of antiviral drugs. For instance, a two-step method involving Pd-catalyzed addition of unprotected nucleobases to alkoxyallenes followed by ruthenium-catalyzed ring-closing-metathesis has been proposed as a convenient and atom-efficient method for the isolation of a broad range of nucleobase-modified analogues
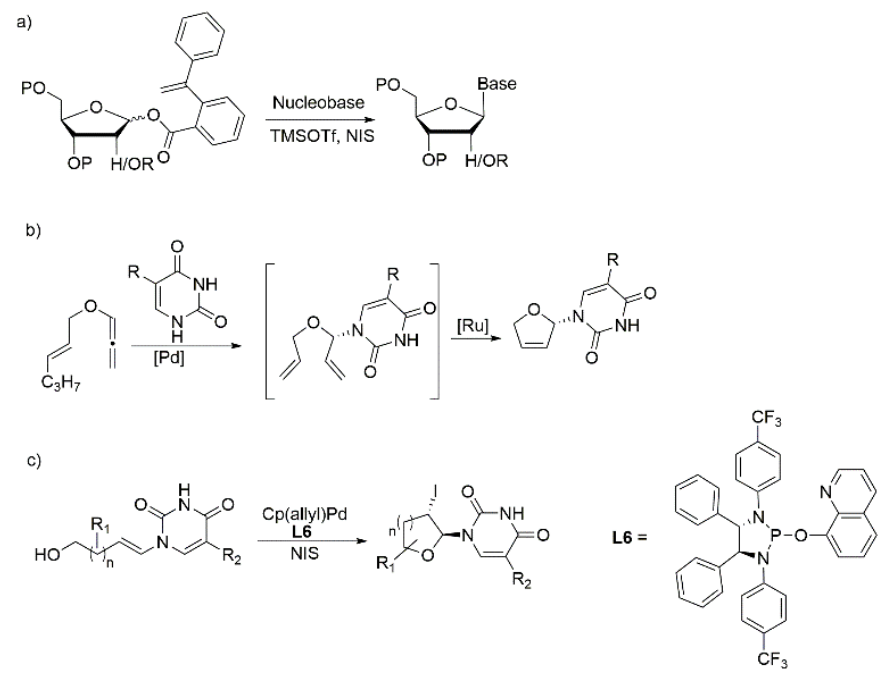

(Fig. 4b). ${ }^{46}$ Similarly, an asymmetric Pd-

Figure 4. Recent alternative glycoşylation reactions: a) Broad scope method based on a stable $O$-glycosyl donor; ${ }^{9}$ b) Sequential metal catalysis method using unproteçted nucleobases; c) Asymmetric Pd-catalyzed iodoetherification method. 


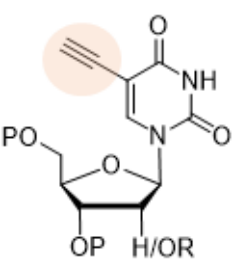

16

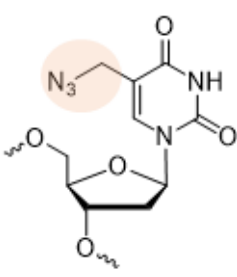

17

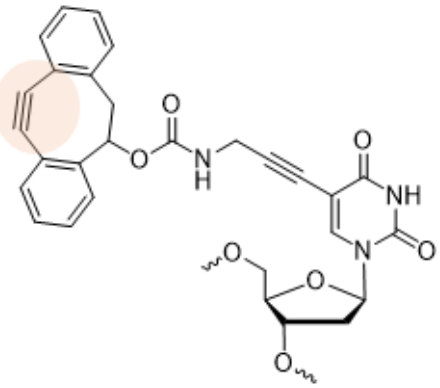

18<smiles></smiles>

19

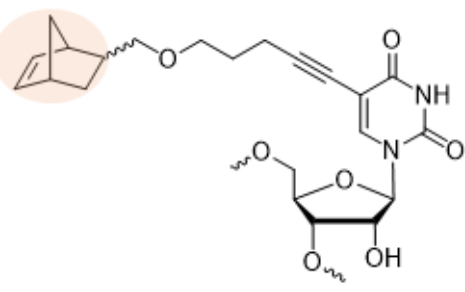

20

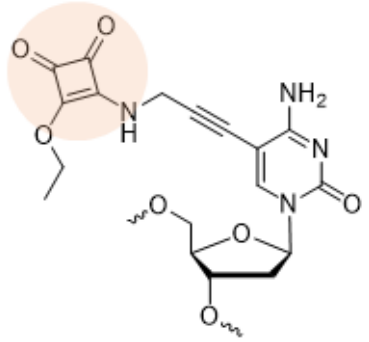

21

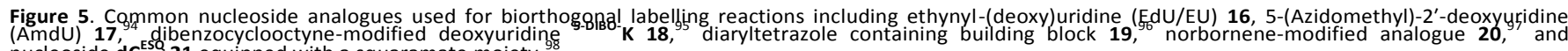
nucleoside dC $^{\text {ESQ }} \mathbf{2 1}$ equipped with a squaramate moiety.

catalyzed iodoetherification method has recently been reported for the synthesis of nucleoside analogues equipped with an iodine atom on the sugar moiety which serves as synthetic handle for the introduction of additional functional groups (Fig. 4c). ${ }^{38}$ The advantages of this iodoetherification method include high yields, mild conditions, and access to sizeexpanded sugar nucleosides which might be of interest in the context of xenobiology (see Section 3.4). ${ }^{99,} 100$ Other metal catalysts, particularly $\mathrm{Au}(\mathrm{I})$-based complexes, have also been suggested for nucleosidation reactions. ${ }^{101}$

Chemoenzymatic methods, mainly involving nucleoside phosphorylases and $N$-deoxyribosyl-transferases (NDTs), represent a solid alternative to chemical methodologies for the installation of modified nucleobases on the (deoxy)ribose unit (Fig. 3c). Compared to classical multistep chemical methods, enzyme-mediated transglycosylation reactions do not require complex protecting group patterns or harsh conditions while concomitantly ensuring high stereoselective outcomes of the reactions with respect to the anomeric configuration. This versatile method has allowed the construction of numerous nucleoside analogues including imidazole containing nucleosides, $^{102}$ base-modified therapeutic nucleosides, ${ }^{103}$ fleximers, ${ }^{104}$ and has recently been expanded to ribonucleosides. ${ }^{105}$

While direct, chemical and chemoenzymatic glycosidation reactions of nucleosides grant access to virtually any type of base-modified analogue, they often involve low-yielding, lengthy synthetic protocols with uncertain stereo- and regioselective controls. As an alternative, nucleosides bearing small modifications can serve as precursors for the introduction of additional functional groups. In this context, popular sites of heterocyclic modification are solvent-exposed locations in duplex major grooves (i.e. mainly at positions 5 of pyrimidines and 7 of purines) since they avoid inducing structural perturbations and often increase the thermal stability of duplexes. ${ }^{106}$ Modifications located at these sites are easily accessible via $\mathrm{Pd}$-assisted cross-coupling reactions (mainly Sonogashira, Heck, Suzuki, Stille, and Negishi coupling reactions) with halogenated purine and pyrimidine precursors (Fig. 3d). ${ }^{87}$ This method is very convenient since it can be directly implemented on nucleosides, ${ }^{107}$ nucleotides, ${ }^{108-110}$ and oligonucleotides, ${ }^{111}$ both in organic and aqueous media. ${ }^{112}$ The synthetic, halogenated pyrimidine precursors can easily be obtained by direct halogenation of the corresponding unmodified nucleosides or via organometallic intermediates as 
highlighted in the synthesis of analogue 9 (Fig. 1). ${ }^{113}$ Halogenated purine nucleosides are usually obtained either by stereoselective glycosylation ${ }^{114}$ or by nucleobase anion glycosylation ${ }^{115}$ using activated sugar moieties such as Hoffer's chlorosugar. $^{89}$

Besides Pd-mediated cross-coupling reactions, functional groups can be introduced on the nucleobase via the broadly applied $\mathrm{Cu}(\mathrm{I})$-catalyzed azide-alkyne cycloaddition (CUAAC) reaction of alkynyl-modified nucleoside and nucleotide precursors with azide derivatives. ${ }^{116}$ In this method, ethynyl(deoxy)uridine $(E(d) U)$ is undoubtedly one of the most popular synthons due to its ease of synthesis, ${ }^{117}$ facile functionalization by the click reaction, ${ }^{118,} 119$ and biocompatibility. ${ }^{120,} 121$ However, the requirement for cytotoxic $\mathrm{Cu}(\mathrm{l})$ restricts CuAAC reactions mainly to in vitro applications. To circumvent this, other biorthogonal click reactions have been developed including strain-promoted azide-alkyne cycloaddition (SPAAC), ${ }^{122,}{ }^{123}$ photoinduced click reactions, ${ }^{124}$ or inverse-electron-demand Diels-Alder (iEDDA) reaction. ${ }^{125}$ In order to apply these bioorthogonal reaction tools to nucleic acids, suitable nucleoside and nucleotide analogues have been synthesized and some of the most common synthons are shown in Fig. 5. Bioorthogonal click reactions will be discussed in more detail in Section 2.3.

\section{Nucleosidic scaffold modification}

The chemical nature of the nucleosidic scaffold permits the introduction of modifications at more than one defined location but this often comes at the expense of more complex synthetic pathways. Consequently, there is no unifying synthesis of such non-native analogues and therefore only the
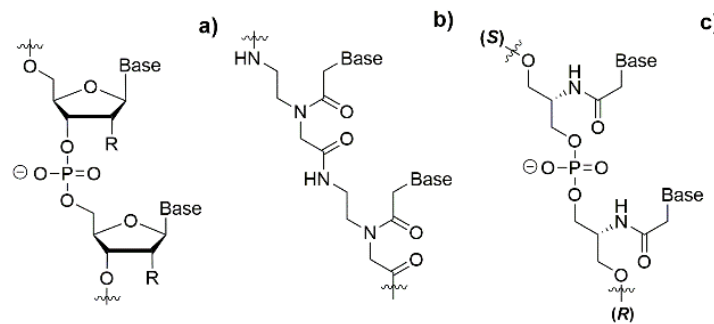

c)

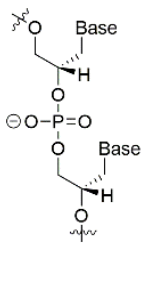

main approaches and examples will be considered in this section.

Figure 6. Chemical structure of nucleic acids containing altered sugar-backbone scaffolds compared to canonical DNA $(R=H)$ and RNA $(R=O H)$. a) PNA; b) GNA and c) (S)-SNA.

One of the earliest and most successful examples of nonnative nucleic acid analogues bearing multiple modifications is PNA (Peptide Nucleic Acid; Fig. 6a). ${ }^{126}$ In PNA, the entire sugarphosphate backbone is substituted with a neutral polyamidebased scaffold, reminiscent of the chemical architecture found in proteins. This DNA mimic forms highly stable duplex and triplex structures with PNA, DNA, and RNA oligonucleotides and was initially designed as an antisense candidate. The favorable assets of PNA have triggered a number of research areas based on this analogue including in microRNA detection, ${ }^{127}$ as a potential substitute for prebiotic RNA in research on the origin of life ${ }^{128}$ or in genome editing methods. ${ }^{129}$ PNA monomers and their structurally modified variants are mainly synthesized by coupling the desired nucleobase to an activated backbone obtained by reductive aminations of $\mathrm{N}$-protected glycinals, ${ }^{130}$ alkylation of methyl $\mathrm{N}$-(2-Boc-aminoethyl)glycinates, ${ }^{131}$ or by the Ugi reaction. ${ }^{132,}$ 133 


\section{ARTICLE}

A)

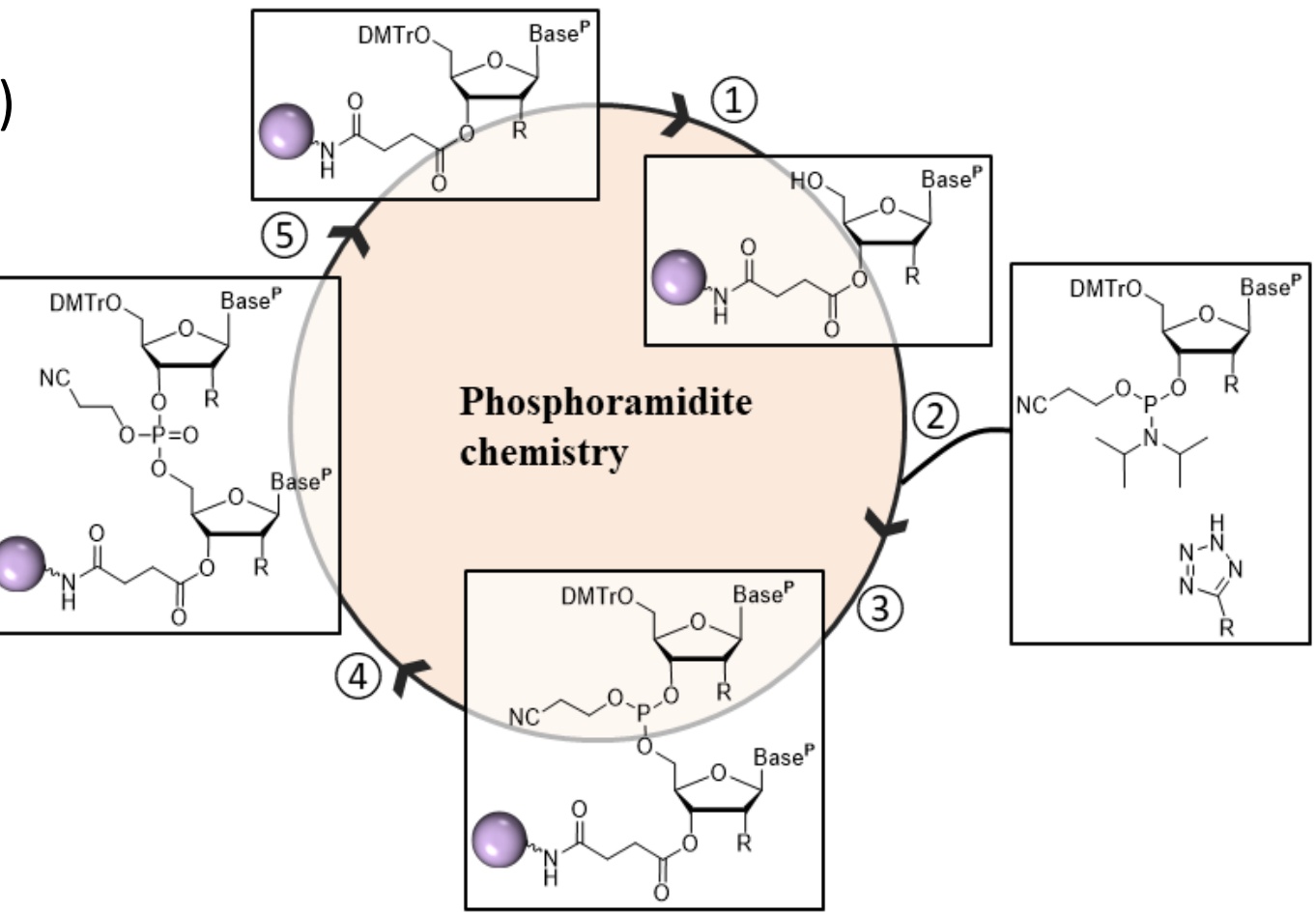

B)
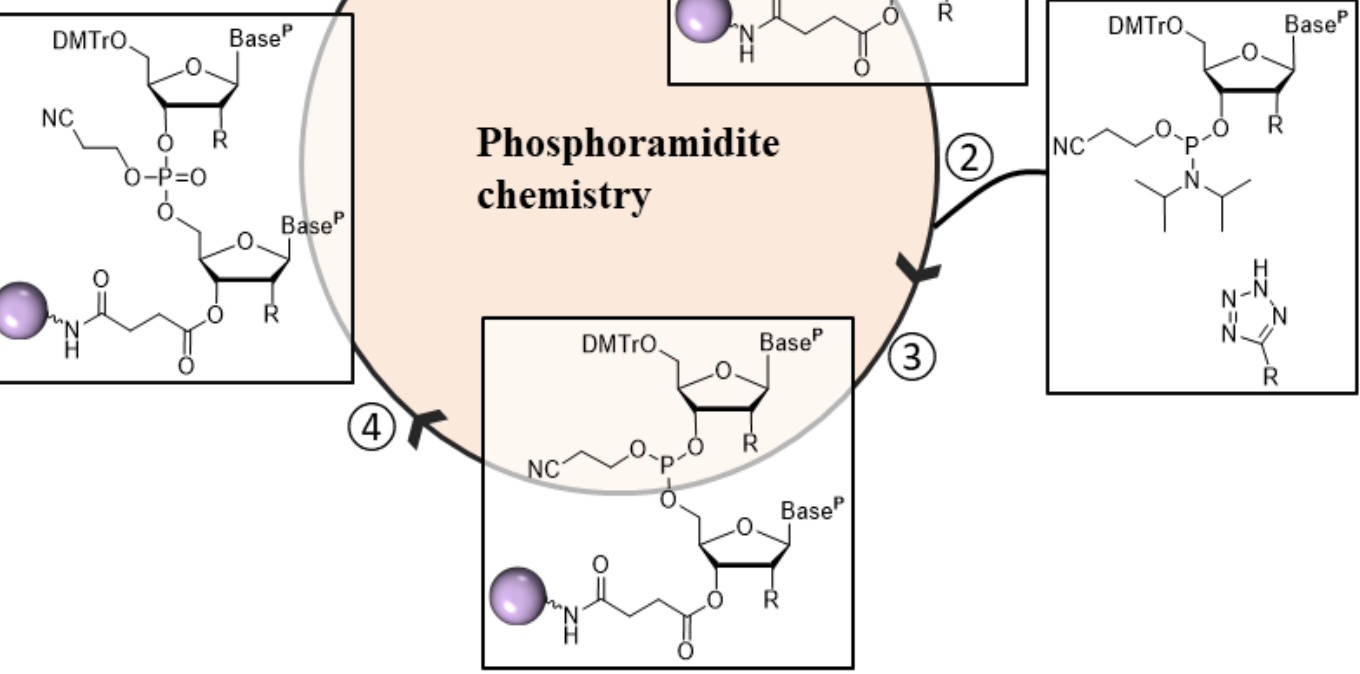

)

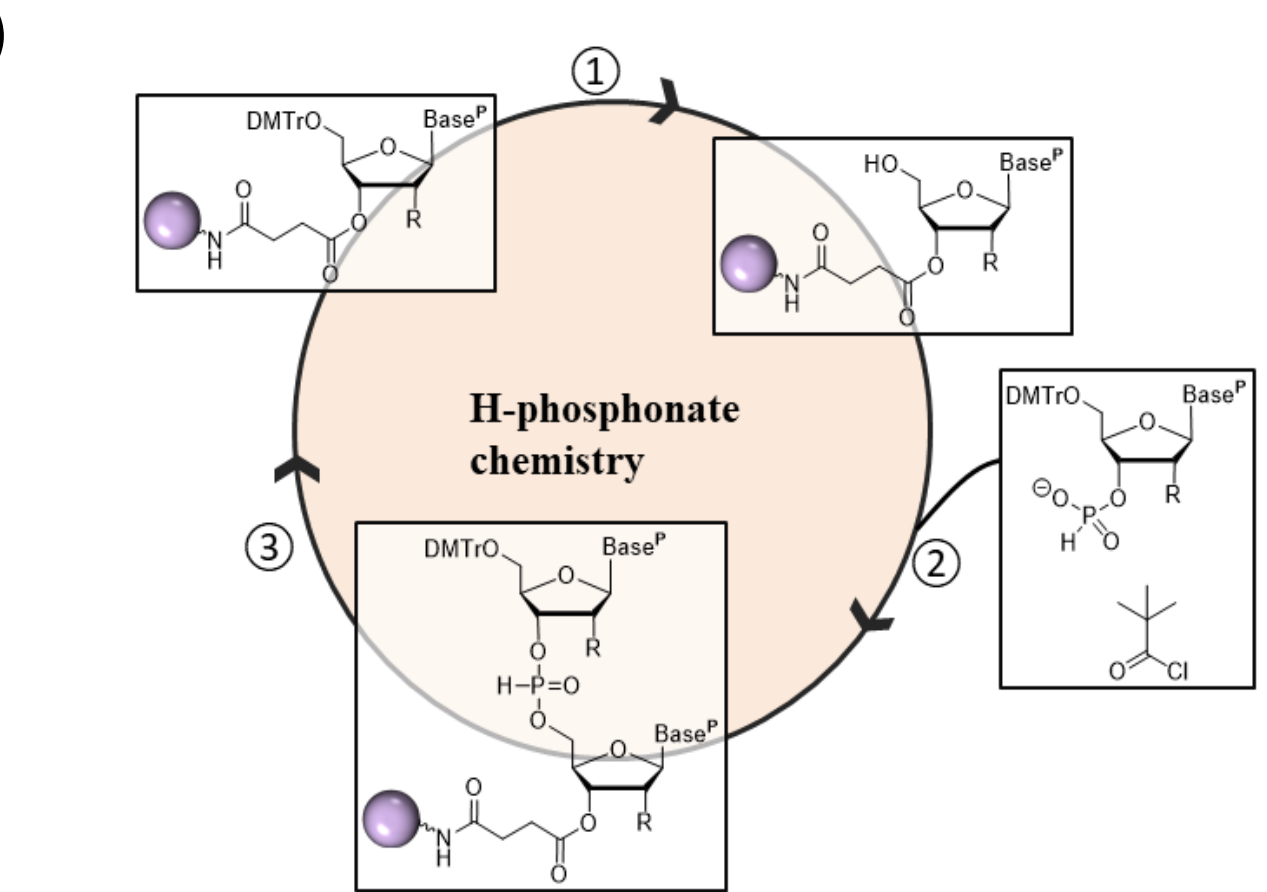

Figure 7. Schematic representation of the main solid-support driven syntheses of oligonucleotides. A) the synthetic cycle with phosphoramidite chemistry includes 1 ) deprotection of the DMTr groups; 2) condensation of the incoming phosphoramidite building block with a tetrazole activation step; 3) capping of the unreacted phosphonate chemistry includes 1) deprotection of the DMTr groups; 2) condensation of the incoming $\mathrm{H}$-phosphonate building block in the presence of an activating agent such as pivaloyl chloride; 3) either the cycle is repeated or the sequence is subjected to an oxidation to P(V) followe d by a global deprotection protocol. 
Related to PNAs are glycerol nucleic acid (GNA; Fig. 6b) (134 $^{134}$ and serinol nucleic acid (SNA; Fig. 6c) ${ }^{135}$ in which the entire sugarphosphate scaffold of DNA is similarly replaced by acyclic backbones based on propylene glycol and serinol (2-amino1,3-propanediol), respectively. However, both GNA and SNA are negatively charged due to the presence of phosphate units that connect monomers together and are chiral in nature unlike PNA. GNA monomers are easily obtained by a ring opening reaction of DMT-protected $(R)-(+)$ - or $(S)$-(-)-glycidol by unprotected nucleobases, ${ }^{134}$ while SNA monomers are synthesized by coupling of the nucleobases to the amine moiety of L-serine via amide bond formation. ${ }^{34,135}$ Basemodified analogues of PNA, ${ }^{136} \mathrm{GNA}^{137}$ and $\mathrm{SNA}^{34}$ have all been reported and represent non-native analogues of DNA and RNA where all the structural constituent parts have been chemically altered compared to the parent nucleosides.

By combining sugar and nucleobase modifications, non-native nucleic acids can be obtained which display enhanced resistance against nuclease-mediated degradation and bear additional functionality which permits an expansion of the scope of applications. Representative examples are basemodified xenonucleic acids (XNAs), where the artificial sugar moiety confers orthogonality to canonical nucleic acids as well as serum stability. On the other hand, the altered nucleobase permits enhanced binding to complementary nucleic acid sequences $^{138}$ and proteins, ${ }^{139}$ fluorescent labelling via the introduction of pyrene moieties, ${ }^{140,141}$ or the introduction of additional functional groups via the $\mathrm{Cu}(\mathrm{I})$-catalyzed click reaction. ${ }^{142-144}$ In terms of synthetic approaches, basemodified XNA building blocks are mainly obtained by appending suitably protected modified nucleobases via Vorbrüggen or nucleobase anion glycosylation reactions. Similar synthetic approaches have also been applied for the synthesis of RNA analogues bearing functional alterations at the level of the nucleobase and sugar units. ${ }^{145,146}$

\section{Solid-phase synthesis}

The current access to a vast array of oligonucleotide chemical modifications is largely due to pioneering work in DNA and RNA chemistry and improved manufacturing and quality control methodologies. Automated solid-phase synthesis is probably the most common method for the construction of oligonucleotides and has revolutionized many scientific disciplines. This technology is based on the stepwise addition of activated nucleoside building blocks by $\mathrm{P}-\mathrm{O}$ bond formation relying on a $\mathrm{P}(\mathrm{III})$ center. ${ }^{147}$ The most common building blocks used in solid-phase synthesis of oligonucleotides are nucleoside $3^{\prime}$-phosphoramidites ${ }^{148}$ and $3^{\prime}$-H-phosphonates. ${ }^{149}$
${ }^{150}$ A schematic representation of the use of these monomers in solid-phase synthesis are highlighted in Fig. 7. A number of recent reviews have been dedicated to explaining the working principle of these methods so we will refer the interested reader to these articles. ${ }^{10,151,152}$

The success of solid-phase approaches is reflected by the access to modified oligonucleotides in up to gram and even kilogram scales at affordable costs. ${ }^{153}$ However, this method still suffers from high reagent and solvent consumption, necessity for activated building blocks, size and functional group limitations due to exposure to rather harsh conditions (vide infra), low degrees of multiplexing, and intrinsic scalability limitations. In addition, efficient synthesis of long RNA sequences by solid-phase approaches still remains more challenging than for their DNA counterparts mainly because of the necessity of protection of the $2^{\prime}-\mathrm{OH}$ of the ribose. ${ }^{154}$ Hence, numerous studies are dedicated to improving solidphase synthesis of modified oligonucleotides through an increase of coupling yields and rates, for instance, by identifying alternative protecting group strategies ${ }^{155,156}$ or protocols such as solution-phase synthesis. ${ }^{153,157}$ In addition to these chemical methods, microarray synthesis of oligonucleotides has advanced as a strong alternative to column-based oligonucleotide synthesis. In microarrays, large populations (up to a million different sequences) of DNA or RNA oligonucleotides are deposited, immobilized or synthesized directly on surfaces. ${ }^{158,} 159$ Microarrays can be produced by a number of strategies amongst which photolithography and inkjet printing hold great promise and will be discussed in more details in Section 3.5 of this article. The phosphate backbone connecting nucleotides together in DNA and RNA oligonucleotides bears negative charges under physiological conditions ( $\mathrm{p} K_{\mathrm{a}} \sim 2$ ) which is a strong impediment for crossing biological membranes. In addition, endogenous exo and endonucleases efficiently hydrolyze inter-nucleotide phosphodiester linkages and degrade DNA, and especially RNA, oligonucleotides within minutes. The simple substitution of a non-bridging oxygen by sulfur (PS) ${ }^{160,161}$ or another chalcogen increases the hydrophobicity of the oligonucleotides while enhancing binding to serum and plasma proteins, ${ }^{162}$ and hence cellular internalization and circulation times. In terms of synthesis, PS oligonucleotides are obtained by solid-phase synthesis that differs only at the level of the oxidation step from that of canonical PO oligonucleotides. Initially, elemental sulfur $\left(\mathrm{S}_{8}\right)^{163}$ was used but was gradually replaced by more efficient sulfur transfer reagents (e.g., Beaucage reagent 22; Fig. 8). ${ }^{164}$ Unlike phosphodiester linkages, PSs are chiral and the oxidation step yields a mixture of two diastereomers. The chirality of the PS modification has a profound impact on the 
pharmacokinetic and pharmacodynamic properties of oligonucleotides since Sp-configured PS linkages are more resistant to nuclease degradation than their $R p$ counterparts $^{161}, 165,166$ but concurrently reduce the binding affinity to target RNA. ${ }^{167}$ Elegant synthetic protocols have been devised to synthesize PS-modified oligonucleotides with full stereocontrol. A first step towards this goal was achieved by careful selection of the phosphoramidite activators since these induce a stereochemical bias during solid-phase synthesis. ${ }^{168} \mathrm{~A}$ major improvement in the stereo-controlled synthesis of PS oligonucleotides was achieved by the introduction of chiral 3'$O$-oxazaphospholidine building blocks in place of phosphoramidites, combined with the use of $\mathrm{N}$-(cyanomethyl)pyrrolidinium trifluoromethanesulfonate coupling agents during solid-phase synthesis (23 in Fig. 8). ${ }^{165}$ This strategy allowed the synthesis of a stereopure analogue of mipomersen -a clinically approved antisense oligonucleotide. ${ }^{165}$ More recently, an elegant method was established for the stereocontrolled synthesis of PS-oligonucleotides that circumvents the need for $\mathrm{P}(\mathrm{III})$ reagents. In this strategy, a chiral $P(V)$ reagent based on a limonene scaffold and a $P(V)$ oxathiaphospholane sulfide core reacts with a free $3^{\prime}-\mathrm{OH}$ moiety and yields stereopure PS oligonucleotides (24 and $\mathbf{2 5}$ in Fig. 8). ${ }^{169}$ As an alternative to such synthetic protocols, the stereochemical issue of PS linkages can be overcome by using prochiral phosphorodithioate $\left(\mathrm{PS}_{2}\right)$ linkages. ${ }^{170}$ Synthesis of $\mathrm{PS}_{2}$-containing oligonucleotides is rather straightforward, mainly requiring thiophosphoramidite building blocks, followed by oxidation of the resulting thiophosphites with a sulfurizing reagent. ${ }^{171}$ The usefulness of the $\mathrm{PS}_{2}$ modification to improve the properties of both antisense agents and aptamers has clearly been established. ${ }^{172,173}$

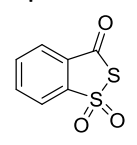

22

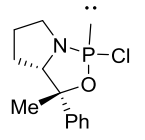

23

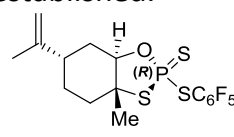

24

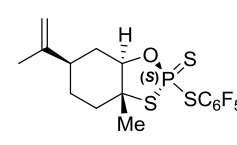

25
Figure 8. Structures of the Beaucage reagent (22) and of chiral precursors (23-25) used in the stereocontrolled synthesis of PS-oligonucleotides.

Besides the substitution of the non-bridging oxygens with sulfur or borane $\left(\mathrm{BH}_{3}{ }^{-}\right),{ }^{174}$ alternative internucleotide phosphodiester modifications have been reported recently. In this context, the laboratory of Tom Brown has introduced a biocompatible artificial backbone consisting of a triazole linkage (e.g. 8 in Fig. 1) obtained by splint or CuAAC-mediated chemical ligation of oligonucleotide precursors. ${ }^{95}$ The triazole substitution does not affect replication by polymerases both in vitro $^{175,176}$ and in vivo 27,177

Improvement of cellular uptake of oligonucleotides without the use of transfecting agent represents a major goal in the development of therapeutic nucleic acids. For instance, inspired by the efficiency of cell penetrating peptides, the phosphodiester linkage can be replaced by a permanently positively charged guanidinium group (see 6 in Fig. 1). ${ }^{178,} 179$ The Mirkin group recently reported a facile and high-yielding synthesis of guanidine linked oligodeoxynucleotides using iodine to couple protected thiourea monomers on a solid support. This robust protocol enabled the facile and highyielding synthesis of 20-nt long oligonucleotides that displayed robust unaided cellular uptake, as compared to unmodified oligonucleotides, without apparent cellular toxicity. ${ }^{25}$

\section{Post-synthetic approaches}

Solid-phase synthesis of modified oligonucleotides involves conditions that are not necessarily compatible with more fragile functional groups such as aldehydes, thiols, or tetrazines. ${ }^{180}$ In addition, each modified sequence needs to be prepared separately with custom made building blocks, each of which requires non-negligible synthetic efforts. Other applications such as visualization of nucleic acids within cells or even living organisms, require labelling and functionalization strategies that do not interfere with biological processes and that cannot be easily achieved via solid-phase synthesis. Therefore, various post-synthetic approaches have been devised to bypass these limitations. Robust and reliable postsynthetic methods for the incorporation of functional groups into nucleic acids need to be bioorthogonal, biocompatible, high-yielding, and capable of operating under mild conditions. ${ }^{116}$ In this context, cycloadditions, and particularly the CUAAC reaction, are enjoying wide popularity for the functionalization of nucleic acids. In the CuAAC reaction, azide and terminal alkyne moieties efficiently react in the presence of a $\mathrm{Cu}(\mathrm{I})$ catalyst to form a triazole heterocycle without interference from other nucleosidic functional groups. The CUAAC is compatible with modification protocols for in vitro and in vivo labelling of oligonucleotides and nucleotides. ${ }^{94,181-}$ ${ }^{183}$ Copper-free versions of the CuAAC such as the ring-strain promoted azide-alkyne cycloadditions (SPAAC) are attracting an increased attention, especially for in vivo labelling purposes, since they omit the use of cytotoxic $\mathrm{Cu}(\mathrm{I})$ in the functionalization reactions. ${ }^{123}$ In SPAAC, the need for the $\mathrm{Cu}(\mathrm{I})$ catalyst is compensated by the release of ring strain of cyclooctynes substituted with electron withdrawing units. ${ }^{184}$ Even though the second order rate constants for SPAAC reactions are typically 1 or 2 orders of magnitude below those observed with the corresponding CuAAC, ${ }^{185,}{ }^{186}$ copper-free click reactions are invaluable for the metabolic labelling of nucleic acids. ${ }^{94,181,187,188}$ Due to the intrinsic properties of the alkyne-azide cycloaddition, numerous DNA and RNA building blocks (triphosphates and phosphoramidites) have been reported for post-synthetic modification applications via CUAAC and SPAAC (see Fig. 5).

Another popular, copper-free cycloaddition reaction is the Diels-Alder reaction with inverse electron demand (iEDDA) ${ }^{125}$ where electron-rich dienophiles (e.g. strained alkenes or alkynes) react with electron-poor dienes (such as 1,2,4triazines or 1,2,4,5-tetrazines) to form six-membered heterocycles including dihydropyridazines (with alkenes as dienophiles), pyridazines (with alkynes as dienophiles), and pyridyl-containing structures (with triazines as dienes). ${ }^{189-191}$ Electron-poor dienes such as 1,2,4,5-tetrazines are often 
incompatible with both solid-phase and polymerase-mediated synthesis of oligonucleotides ${ }^{180,192}$ and therefore suitable building blocks containing electron rich dienophiles are usually preferred. The iEDDA method has mainly been used for the in vitro modification of nucleic acids ${ }^{193,194}$ and only few reports have been dedicated to in vivo labelling strategies. ${ }^{195,} 196$

Alternative copper-free click reactions are the "photoclick" and the "sulfo-click" reactions. ${ }^{197,198}$ In the photoclick reaction, the cycloaddition of a tetrazole with an alkene forms a pyrazoline cycloadduct which is triggered by photoirradiation. The advantages of the photoclick reaction over other postsynthetic labeling methods include high spatio-temporal control, lack of (toxic) catalyst, and biocompatibility and bioorthogonality. The photoclick approach has been used for the in vitro and in vivo labelling of DNA. ${ }^{96,198}$ In the sulfo-click reaction, thioacids react with sulfonyl azides in the presence of a base to yield $\mathrm{N}$-acyl sulfonamide conjugates with secondorder kinetic constants comparable to that of the SPAAC. ${ }^{197,} 199$ The sulfo-click reaction was recently applied to conjugate deoxyribonucleosides and ribonucleosides to peptides and biotin moieties displaying potential for the labelling of oligonucleotides. $^{197}$

Transient protection and caging of DNA and RNA oligonucleotides can be achieved by different post-synthetic approaches. The inclusion of light sensitive blocking group is certainly one of the most popular and developed strategies, since it allows for a spatio-temporal control of the activity of nucleic acids by simple, non-invasive, light irradiation. ${ }^{200}$ Blocking groups mainly based on nitrobenzyl ${ }^{201}$ or substituted phenol groups ${ }^{202}$ have been appended at virtually any position of the nucleosidic scaffold and the intended function of the photocaged DNA or RNA oligonucleotides can be restored by photoirradiation which removes the light sensitive groups. An alternative strategy involves a transient blockade of the function of RNA by the installation of an acetylation pattern on the $2^{\prime}-\mathrm{OH}$ groups of RNA. A simple treatment with an azidecontaining acylation reagent leads to a high yield of 2'-Oacetylated RNA that displays impaired enzyme recognition, folding, and hybridization properties. A treatment with a phosphine reduces the azide to the corresponding amine which undergoes an intramolecular cyclization and a concomitant elimination of a lactam which restores the bioactivity of the RNA oligonucleotide. ${ }^{203}$

\section{Mechanochemistry}

Mechanochemistry is a relatively new discipline within the field of chemistry that takes advantage of mechanical forces (such as grinding, shearing, or crushing) to provide the energy for chemical reactions, often in the complete absence of solvent. Particularly, mechanochemistry has emerged as an exciting tool for organic chemists that can often enable reactivity not observed in solution with short reaction times, high yields, and little or no solvent. ${ }^{204,205}$ However, the application of mechanochemistry to nucleosides and nucleic acids is relatively underdeveloped, but has recently been reviewed. ${ }^{206}$ Nonetheless, some interesting applications will be highlighted here.

Vyle and coworkers have demonstrated non-selective, silylations of 2', 3', and 5'-OH groups of ribonucleosides, followed by in situ benzoylation of the exocyclic amine of cytidine using vibration ball milling (VBM). ${ }^{207}$ Compared to traditional silylations, their approach is much faster and proceeds with near quantitative yield. In addition, the Vyle group has focused their efforts towards the mechanochemical synthesis of novel nucleotide pyrophosphate and pyrophosphorothiolate linkages. ${ }^{208-210}$ They have also demonstrated other interesting applications of mechanochemistry to nucleic acids which are covered in their review. $^{206}$

Interestingly, Migaud and co-workers have also combined mechanochemistry with ionic liquids for preparation of nucleic acid phosphoramidites. ${ }^{211,212}$ The use of ionic liquids stabilized moisture-sensitive phosphitylating reagents and allowed for rapid and high yielding preparation of phosphoramidites, ready for solid-phase synthesis.

Recently, VBM has been applied by Damha, Friščić and coworkers using both $\mathrm{H}$-phosphonate and phosphoramidite methods to synthesize DNA dimers and trimers under near solvent-free conditions. ${ }^{213}$ Their work is noteworthy in that it is the first to apply mechanochemistry to the synthesis of nucleotides linked by phosphodiester bonds, but also includes a method for preparation of phosphorothioates. Their $\mathrm{H}$ phosphonate approach converts the pentavalent $\mathrm{P}(\mathrm{III})$ center to a $P(V)$ center with a sulfur-transfer reagent. Careful selection of the sulfur transfer reagent allows conversion to the phosphodiester or phosphorothioate backbone. ${ }^{214}$ Additionally, through careful selection of the activator, they were able to achieve in situ detritylation based on the equivalents of pyridine (Fig. 9a). Their phosphoramidite approach uses elemental sulfur (Fig. 9b) to synthesize phosphorothioates, as they have interestingly found some of the more modern sulfurization reagents (Beaucage's reagent 22) to be incompatible with the mechanochemical conditions. 


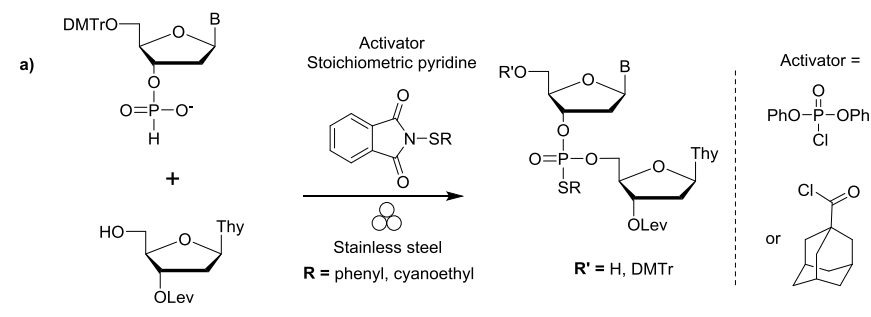

b)

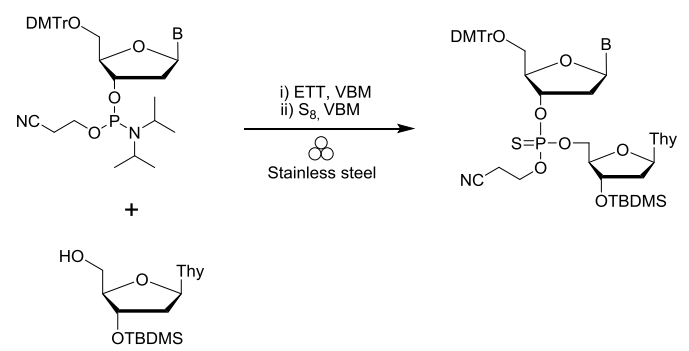

Figure 9. Mechanochemical synthesis of short DNA fragments by vibration bal milling. a) H-phosphonate approach using different activators and a sulfur transfer reagent. b) Phosphoramidite approach using elemental sulfur fo preparation of phosphorothioates.

\section{Polymerase-mediated synthesis}

Enzymatic oligonucleotide synthesis, using polymerases derived from nature, is a cornerstone technique in the biochemical laboratory utilizing the high efficiencies, fidelities and ease of application provided by eons of evolution. While automated solid-phase synthesis is widely used for large scale oligonucleotide syntheses, resulting oligonucleotide products are severely size constrained, with yields dramatically decreasing as sequence length increases up to a practical limit of around 100 nucleotides (often less for RNA). Using polymerases, these size constraints can be overcome, albeit requiring a template strand and a far lower scale (in the $\mu \mathrm{g}$ range). Enzymatic incorporation of modified nucleoside triphosphates ( $\mathrm{N}^{*}$ TPs and $\mathrm{N}^{*} \mathrm{TPs}$ ) improves the chemical space that can be explored during the SELEX process, discussed in detail in section 3.4, and as such prescreening of a modified nucleotide for enzymatic recognition, incorporation and reverse transcription is required. ${ }^{110,215-217}$

Since the advent of PCR, the number of commercially available natural polymerases has increased dramatically. Fortunately for life and unfortunately for modified oligonucleotide synthesis, these natural polymerases can be highly nucleotide specific for canonical nucleotides and unforgiving to nucleotide modifications. Engineering of new polymerases, based on those found in nature, can lead to more successful incorporation of chemically-modified triphosphates and ribonucleotide triphosphates. A number of engineering strategies exist including Darwinian mimicking directed evolution, rational design based on computer modelling, and random mutagenesis and screening. ${ }^{218}$ A clear example of the power of polymerase engineering with $\mathrm{dN} * \mathrm{TP}$ acceptance is 'Therminator DNA polymerase' an engineered, triply mutated, variant of $9^{\circ} \mathrm{N}$ DNA polymerase rationally designed following successful previous mutation of the Vent DNA Polymerase exo and related polymerases. ${ }^{219}$ Therminator is rendered compatible with a wide range of sugar, base and backbone modifications alongside ribonucleotide compatibility as outlined in a recent review. ${ }^{220}$ It has been reported that polymerases of the B family (such as Vent (exo'), KOD, and Pwo) are more efficiently able to incorporate multiple consecutive base modified nucleotides. ${ }^{110,221-224}$

Perhaps the most generally tolerated modification in enzymatic incorporation is pendant addition at the C5 pyrimidine position, with the $\mathrm{C7}$ position of adenine and guanine being other common modification targets. ${ }^{225}$ These positions are known to cause minimal disruption of WatsonCrick base pairing, as introduced bulky groups sit comfortably in the major groove. ${ }^{222,}{ }^{226}$ At these positions base modifications can often be incorporated using standard polymerases such as Vent (exO) or KOD, including multiple consecutive incorporations. ${ }^{227,} 228$ Other sites such as position N4 of pyrimidines have been shown to accommodate modifications rather well and efficiently serve as substrates for polymerases. ${ }^{229}$ Modifications can also be accommodated in the minor groove of DNA by altering dN*TPs at position 2 of purines without impairing contacts with polymerases necessary for enzymatic synthesis. ${ }^{31}$ Many types of pendant moieties have been successfully incorporated. ${ }^{230-232}$ The nature of the attached modification as well as that of the linker arm have an effect on the efficiency of incorporation in PCR. ${ }^{233} \mathrm{~A}$ recent report demonstrated the marked effect that the hydrophobicity of pendant groups have on PCR efficiency, with hydrophobic groups observed to drastically reduce the quantity of PCR product produced. ${ }^{221}$ Interestingly, polymerases also tolerate nucleotides devoid of nucleobases and predominantly incorporate these minimal nucleotides opposite templating adenine nucleotides following the wellestablished "A rule". ${ }^{234}$

Sugar modification can prove less compatible with polymerases. This reluctance at accepting sugar-modified $\mathrm{dN}^{*}$ TPs arises from various structural features of polymerases, including the presence of bulky amino acid residues which enable polymerases to dismiss nucleotides bearing 2'-
A)

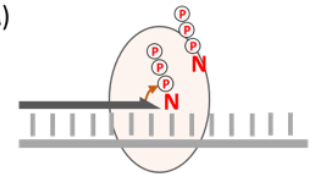

B)

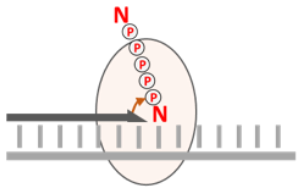

C)
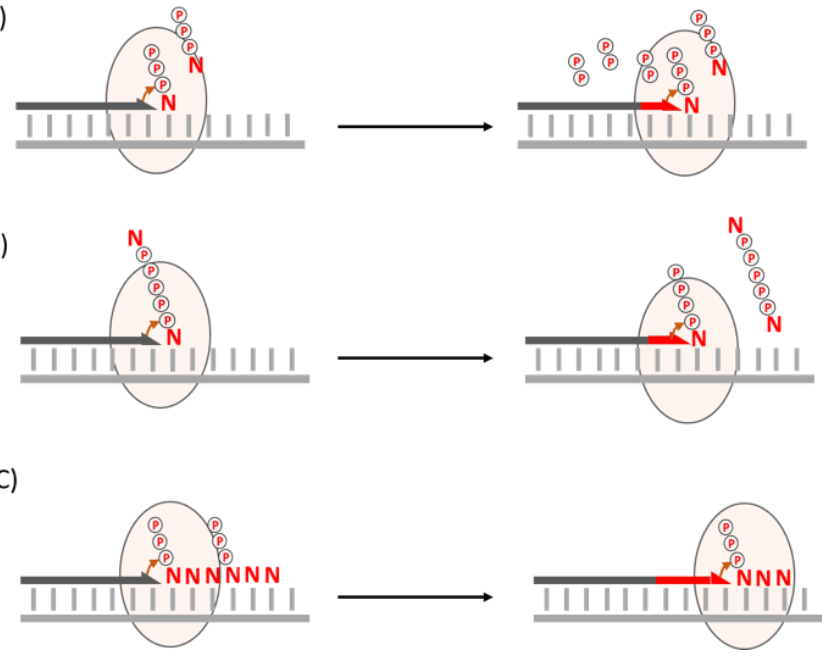

substituents

substituents 
Figure 10. Schematic representation of primer extension reaction with A) DNA polymerases using natural dN*TPs and formation of pyrophosphate as byproduct; B) DNA polymerases and pentaphosphate deoxynucleotide dimers primer elongated by one nucleotide on the right hand side), itself a substrate for polymerases and incorporated into DNA. A second, incoming pentaphosphat deoxynucleotide dimer then allows DNA synthesis to continue; C) a ribozyme and nucleotide triplet building blocks.

from unmodified counterparts. ${ }^{235}$ In addition to this steric gate discrimination, the action of polymerases generally requires interaction with the $3^{\prime}-\mathrm{OH}$ for efficient triphosphate orientation making modifications at this position less easy to incorporate by natural polymerases. Despite this, polymerases have been found to incorporate a wide range of sugar modifications such as $2^{\prime}$-fluoroarabinonucleic acids (FANA), ${ }^{224}$ LNA, ${ }^{236} 7,5$-bicylo-DNA, ${ }^{237}$ and $\left(3^{\prime}-2^{\prime}\right) \alpha$-L-threose nucleic acid (TNA), ${ }^{238,} 239$ among others. Backbone modifications of the phosphodiester linker involving replacement of the nonbinding negatively charged oxygen with a negatively charged species such as PS and borane $\left(\mathrm{BH}_{3}{ }^{-}\right)$have been successfully achieved enzymatically, albeit perhaps leading to some copy error issues with PS. ${ }^{240}$ Some examples of nucleotides bearing modifications at more than one specific location, typically at the level of the sugar and the

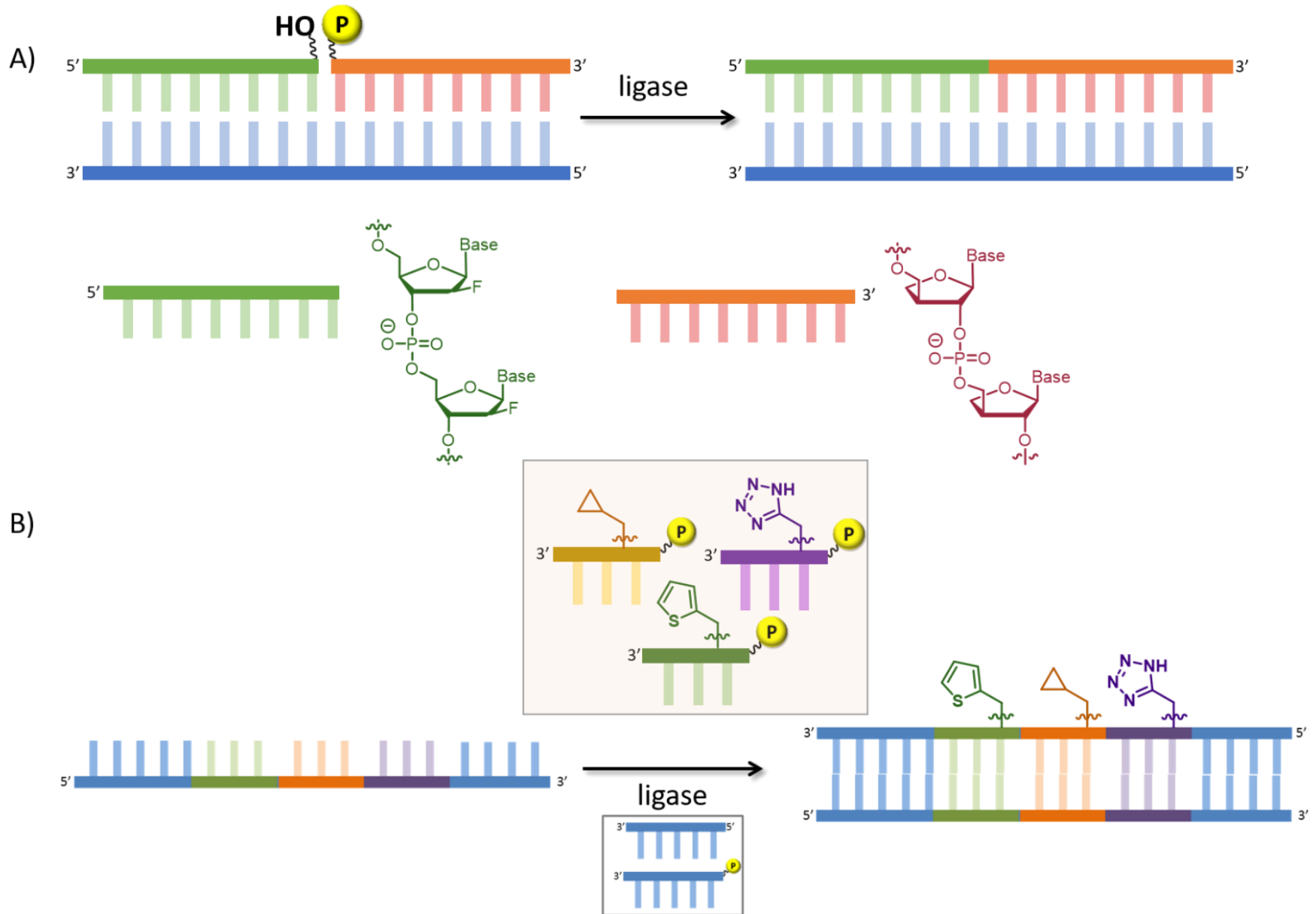

Figure 11. Ligase-mediated synthesis of modified oligonucleotides: A) two modified oligonucleotides (e.g. containing FANA or TNA units) can be ligated using a bridging DNA or XNA template; B) multiple nucleotide codons containing base-modified nucleotides can be ligated to generate modified oligonucleotides.

nucleobase, have been reported but are clearly underrepresented amongst all dN*TPs. ${ }^{143,144,241}$

As the appetite for investigation of longer oligonucleotide sequences increases, as does the necessity for more advanced enzyme mediated synthetic protocols. In this context, enzymatic synthesis of modified nucleic acids can also be achieved by means of template-independent polymerases such as Pol $\theta$ or the terminal deoxynucleotidyl transferase $(\mathrm{TdT})$. These polymerases are mainly active in repair mechanisms and extend ssDNA with (random) nucleotide insertions. The terminal transferase activity of such polymerases can be hijacked to append modified nucleotides at the $3^{\prime}$-termini of single-stranded DNA or RNA oligonucleotides. The substrate tolerance of both Pol $\theta$ and the
$\mathrm{TdT}$ is quite broad, especially when $\mathrm{Mn}^{2+}$ is used as a cofactor, and ranges from nucleobase modifications to ribonucleotide analogues ${ }^{194,242-245}$ and to a certain extent even to XNA-based nucleotides. ${ }^{246}$ These favorable properties have propelled polymerases with terminal transferase capacity into a number of practical applications including functional tagging, general enhancement of in vivo stability, or the formation of conjugates with other biomolecules such as peptides. More recently, TdT-controlled DNA synthesis has been suggested as a valid alternative to replace phosphoramidites in solid-phase synthesis $^{7}$ and oligonucleotides consisting of up to 300 nucleotides could be crafted by such an approach. ${ }^{247}$ Paralleling these efforts in DNA synthesis, RNA polymerases capable of terminal transferase activity such as the Terminal 
Uridylyl Transferase (TUTase) ${ }^{188}$ and poly(A) polymerase $(\mathrm{PAP})^{248}$ are currently evaluated for the synthesis of modified RNA oligonucleotides.

Interesting, alternative enzymatic synthesis strategies have recently been reported by the Kool and Holliger groups that circumvent the need for nucleoside triphosphates as activated building blocks. ${ }^{249,250}$ Indeed, dN*TPs are prone to hydrolysis, both upon storage and under elevated temperatures required for PCR for instance, ${ }^{251}$ while the accumulation of the pyrophosphate by-product generated during DNA synthesis inhibits polymerases and might even lead to primer degradation via catalysis of the reverse reaction (Fig. 10a). In order to circumvent these limitations, nucleotide dimers interconnected with a pentaphosphate bridge have been proposed as an alternative to $\mathrm{dN}^{*} \mathrm{TPs}$. These nucleotide analogues are more stable to hydrolytic degradation since they do not bear a terminal phosphate group and since the byproduct after incorporation into DNA is not pyrophosphate but a nucleoside tetraphosphate which are good substrates for polymerases (Fig. 10b). These dimeric pentaphosphate analogues are also readily tolerated by DNA polymerases such as the Klenow fragment of DNA Polymerase I (exo-) and therefore represent valid alternatives to $\mathrm{dN}^{*} \mathrm{TPs}^{249}$ Instead of increasing and modifying the polyphosphate moiety, multiple nucleosides can be integrated in triphosphate analogues. Such trinucleotide triphosphates (triplets) can readily be polymerised by a ribozyme obtained by in vitro evolution methods (Fig. 10c). ${ }^{250}$ Both strategies have been applied to canonical nucleic acids but are certainly amenable to modified counterparts.

\section{Ligation and enzymatic methods}

The polymerization of $\mathrm{dN}^{*}$ TPs is an efficient and versatile method for the introduction of additional chemical groups into nucleic acids, but it is limited by the number of modifications that can be incorporated (all four canonical nucleotides can be modified $^{252,253}$ and up to two additional unnatural base pairs might be included ${ }^{254}$ ) and by the fact that all nucleotides will bear the same modification. As an alternative, other enzymes such as ligases can be used to construct modified oligonucleotides. This can be achieved either by templated ligation of two fully modified oligonucleotide precursors or by the ligase-mediated polymerization of tri- or penta-nucleotide fragments (Fig. 11). The first approach involves phosphodiester bond formation between a 3'-hydroxyl group on the acceptor oligonucleotide and a $5^{\prime}$-phosphate unit of the donor sequence on a bridging DNA template complementary to both fragments (Fig. 11a). Prior to bond formation, the ligase -mainly the T4 DNA ligase - binds to the cofactor ATP which needs to be added to the reaction mixture to generate an enzyme-AMP $\varepsilon$ amino lysyl phosphoramidate intermediate. ${ }^{255}$ This intermediate then undergoes nucleophilic attack by the $5^{\prime}$ phosphate moiety resulting in AMP transfer to the donor sequence. The adenylated DNA then undergoes a second nucleophilic attack by the ligase-activated $3^{\prime}-\mathrm{OH}$ of the acceptor sequence to form the phosphodiester bond and release AMP. ${ }^{256}$ T4 DNA ligase is capable of efficiently joining short pieces of DNA or RNA containing $C$-nucleotides ${ }^{257}$ and nucleobase ${ }^{258}$ as well as XNA sugar modifications such as FANA or $2^{\prime}-\mathrm{OMe}^{259}$ especially when the modified building blocks are located in the acceptor sequence. The T4 DNA ligase, however, has a limited substrate tolerance, and other ligases such as the T3 or the T7 DNA ligase can be employed instead, as was reported in the case of TNA (threose nucleic acid) containing oligonucleotides. ${ }^{260}$ Alternatively, artificial ligases with an extended substrate repertoire can be engineered by directed evolution experiments or obtained by rational design which will undoubtedly facilitate the synthesis of longer modified oligonucleotides. ${ }^{261,262}$

In the second, related approach, multiple phosphodiester linkages are formed using smaller oligonucleotide precursors owing to the compatibility of the T4 DNA ligase with short oligonucleotides (Fig. 11b). ${ }^{263}$ Initially, highly efficient polymerization was achieved using codons consisting of trinucleotides bearing base modifications at the first (5'-end) position of the fragment, resulting in the synthesis of oligonucleotides containing up to 150 nucleotides. ${ }^{264}$ The polymerization efficiency can be increased when modified pentanucleotide codons are used albeit at the expense of a lower density of modification as compared to ligation with shorter codons. ${ }^{265,} 266$ Such an approach is particularly appealing for the construction of modified, randomized libraries of oligonucleotides for in vitro selection experiments and has permitted the identification of densely functionalized aptamers against thrombin ${ }^{267}$ and the PCSK9 and IL-6 proteins. ${ }^{268,269}$ While other ligases, such as the T3 DNA ligase, were shown to be capable of polymerizing base-modified pentanucleotide codons, ${ }^{270}$ this method has not been extended to sugar-modified oligonucleotides yet.

Recently, other enzymes were suggested as alternatives to polymerases and ligases for the chemical labelling of nucleic acids. For instance, adenosine deaminases acting on RNA (ADARs) are RNA editing enzymes that catalyze the deamination of $\mathrm{C} 6$ of adenosine to yield inosine nucleotides, which are. in turn, recognized as guanosines by ribosomes and RNA-dependent polymerases. The combination of the catalytic activity of ADARs and the propensity of inosine to react with Michael acceptors was harnessed to develop a new labeling method for adenosine nucleotides in A-C mismatches of dsRNA substrates. ${ }^{271}$

\section{Applications}

Several decades of research into nucleoside modifications have resulted in their use in a vast number of applications. In non-canonical DNA structures, they have been incorporated for structure elucidation, manipulation, and stabilization, in addition to various therapeutic and diagnostic applications. Additionally, the field of oligonucleotide therapeutics, particularly antisense, RNAi, and aptamer-based candidates, would not have gained momentum without the introduction of nucleoside modifications. Similarly, the use of photolabile protecting groups in nucleosides has made it possible to 
synthesize libraries of millions of unique oligonucleotides with microarray technology.

\section{Stabilization of non-canonical DNA structures}

Non-canonical DNA structures do not rely on the typical Watson-Crick base-pairing for formation, and several lines of evidence suggest that they are ubiquitous in biological systems. G-quadruplexes and i-motifs, for instance, have been suggested to regulate important cellular processes such as transcription and telomere extension and are currently considered as important therapeutic targets. ${ }^{272-274}$ Triple helix formation, on the other hand, has been explored as a therapeutic tool for transcription modulation and antigene therapy. ${ }^{275,276}$ There is also increasing evidence to suggest that RNA triple helices mediate biological mechanisms associated with telomere maintenance, RNA splicing, and protection of RNA against degradation. ${ }^{277}$ In addition to their biological and therapeutic relevance, the aforementioned structures have been used in nanotechnological and biotechnological applications including catalysis and sensing. ${ }^{278,279}$

Modified nucleosides have been incorporated into noncanonical nucleic acids to elucidate their structure and uncover a deeper understanding of their folding properties and biological significance. Here, we highlight the major contributions of nucleoside modifications to the study of $G$ quadruplexes, i-motifs, and triple helices.

\section{Stabilizing G-quadruplexes}

Nucleic acid modifications have been beneficial for the study, elucidation and manipulation of G-quadruplex structure. Here, we summarize the primary factors that enable modified nucleosides to stabilize G-quadruplexes and modulate their folding topology. Additionally, key examples showcasing some applications of chemically-modified G-quadruplexes are highlighted. For more comprehensive lists and summaries on modified nucleosides incorporated into G-quadruplexes, the reader may consult recent reviews. ${ }^{280,281}$

G-quadruplexes originate from guanine-rich sequences and consist of stacked guanine tetrads (Fig. 12a) which can be strung together via connecting loops. The tetrads are stabilized by Hoogsteen base pairs and further stabilized by central cations (such as $\mathrm{Na}^{+}$or $\mathrm{K}^{+}$). Based on the number of component strands, a G-quadruplex can be tetramolecular, bimolecular, or unimolecular. Additionally, a G-quadruplex can adopt a parallel, antiparallel, or hybrid $(3+1)$ topology (Fig. $12 \mathrm{~b})$, depending on several factors including loop length and composition, nature of the stabilizing cation, and orientation (syn/anti) of the $\mathrm{N}$-glycosidic bond of its constituent nucleotides. ${ }^{272,282}$

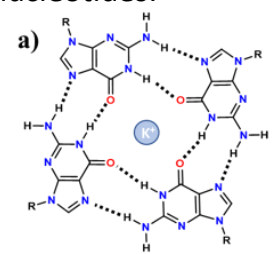

b)

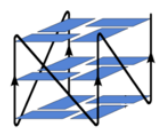

Parallel

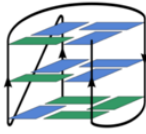

Hybrid (3+1)

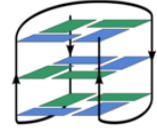

Antiparallel
Figure 12. a) G-tetrad with a central potassium ion; b) Different G-quadruplex topologies.

Certain modified nucleosides have been found to stabilize the G-quadruplexes they were studied in, irrespective of their glycosidic bond orientation. Prominent examples are illustrated in Fig. 13. Often, substituting the amino group at the guanine $\mathrm{C} 2$ position preserves the anti $\mathrm{N}$-glycosidic bond conformation without interfering with the hydrogen bonding network of a tetrad. ${ }^{283}$ For instance, N2-methyl dG ( $\underline{\mathrm{mG}}$ ) (26) can improve base stacking in the parallel tetramolecular antiHIV G-quadruplex formed from 5'-TmGGGAG-3', thereby exhibiting thermal stability $10{ }^{\circ} \mathrm{C}$ higher than its unmodified counterpart. $^{284}$ This G-quadruplex, among other N2-methyl substituted variants, also exhibited improved anti-HIV activity. ${ }^{284}$ 5-Fluorouridine substituting loop thymidines (28) has also been shown to stabilize G-quadruplexes, such as the antiparallel thrombin-binding aptamer (TBA). ${ }^{285}$ In fact, the two most stabilizing substitutions at positions 4 and 13 of TBA were found to increase anticoagulant activity. Given that the thymines at these positions are the only two that stack onto the tetrad bases, it was suggested that the fluorine atom of 5fluorouracil strengthens the stacking interactions, leading to increased stability. Modified nucleosides capable of stabilizing G-quadruplexes have also found applications as G-quadruplex probes, and a prominent example is 5-(benzofuran-2-yl)uracil (5bu) (29). ${ }^{286}$ Based on its fluorescence signal, 5bu was shown to distinguish parallel, antiparallel and hybrid $(3+1)$ DNA and RNA G-quadruplexes, as well as exhibit significant fluorescence enhancement when incorporated into G-quadruplexes as opposed to duplexes. In addition to probing G-quadruplex structure, probes like 5 bu can be used to develop fluorescence binding assays.
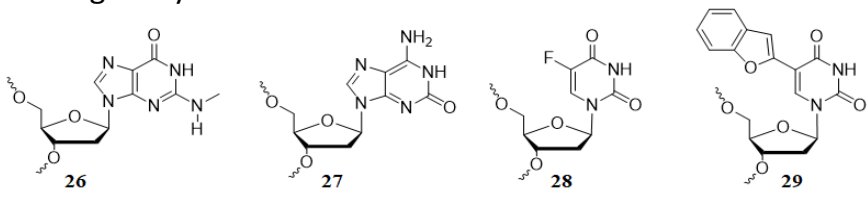

Figure 13. Selected modified nucleosides that stabilized the G-quadruplexes they were studied $i n ;(26) \mathrm{N}^{2}$-methylguanosine ${ }^{284}$, $287 ;(27)$ isoguanosine ${ }^{288} ;(\mathbf{2 8}) 5$
fluorouridine

Often, modified nucleosides stabilize G-quadruplexes when substituting those nucleosides with matching glycosidic orientation. Syn-favoring 8-substituted guanosines, such as 8bromo- and 8-methyl- guanosine are widely utilized, as the substitutions point towards the grooves and do not interfere with overall quadruplex topology. ${ }^{281}$ For instance, 8bromoguanosine $(8 \mathrm{bg})$ has proven useful in promoting the predominant formation of certain topologies of the polymorphic telomeric G-quadruplex. ${ }^{289,} 290$ In fact, substituting two different pairs of $d G$ in the 25 -mer human telomeric sequence leads to the exclusive formation of either the hybrid1 or hybrid-2 telomeric G-quadruplex topology in potassium buffer. ${ }^{289}$ With the ability to stabilize different hybrid forms, 8br-modified G-quadruplexes were conducive to the development of a $\alpha$-hemolysin ion channel-based, singlemolecule probe for G-quadruplex and triplex structure. ${ }^{289}$ In another example, fluorescent syn-favoring 8-heteroaryl-2'- 
deoxyguanosine derivatives can stabilize the antiparallel thrombin-binding aptamer (TBA) in potassium buffers without altering its activity. ${ }^{291}$ In particular, 8-thienyl-dG was shown to be most useful in probing duplex-to-G-quadruplex exchange, due to the significant topology-dependent changes in emissivity. On the other hand, 8-substituted guanosines can be made to adopt a preferential anti conformation when aromatic groups are placed far enough from the nucleobase by a connecting vinyl tether. Accordingly, 8-(2phenylethenyl)guanine and 8-[2-(pyrid-4-yl)-ethenyl]guanine were shown to enhance the stability of the predominant topology adopted by 24-mer telomeric G-quadruplex in either sodium or potassium buffers when substituting $d G$ at position $9^{292}$

Owing to their preferential syn/anti conformation, modified nucleosides, particularly guanosine analogues, can be strategically placed to modulate G-quadruplex folding topology. A detailed review on this topic by Haase et al. is available for readers. ${ }^{293}$ Here, we will only summarize selected studies to provide different examples on structural manipulations of G-quadruplexes. Syn-to-anti and anti-to-syn substitutions can have unpredictable outcomes, as they could stimulate the refolding of the G-quadruplex with a different topology or obliterate G-quadruplex folding. One way in which guanosine analogues can alter G-quadruplex structures is by triggering a polarity inversion in a G-tetrad - an effect which normally does not perturb overall folding topology (Fig. 14). Polarity inversion refers to changes in the directionality (clockwise/anti-clockwise) of Hoogsteen hydrogen bonding within a tetrad, resulting in differences in base stacking. For instance, substituting the anti-favoring $5^{\prime}$-tetrad guanosines with syn-favoring 8-methylguanosine in a tetramolecular parallel G-quadruplex results in polarity inversion while preserving parallel-type topology. ${ }^{294}$ Similar effects are observed in non-parallel quadruplexes when anti-favoring nucleosides, such as 2'-deoxy-2'-fluororiboguanosine, substitute syn-adopting guanosines. ${ }^{295}$ The extent of destabilization that results from the structural perturbations when the guanosine analogues are introduced depends on several factors including the nature and position of the modifications and the length of the connecting loops. ${ }^{293}$
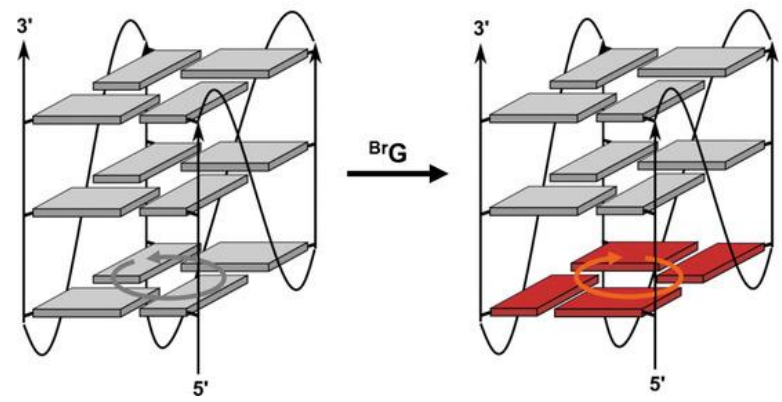

Figure 14. G-tetrad polarity inversion in the parallel MYC quadruplex after substituting anti guanosine (gray) in the $5^{\prime}$-tetrad with syn 8-bromoguanosin (red), reproduced from Ref. [306] ${ }^{293}$ with permission from John Wiley and Sons.

The second way a guanosine analogue can modulate Gquadruplex structure is by entirely changing the global topology. Typically, parallel G-quadruplexes have their guanosines in anti orientation, so parallel topology can be induced in non-parallel G-quadruplexes by replacing synpreferring guanosines with anti-conforming analogues. The most widely employed anti guanosine analogues are shown in Fig. 15, with 2'-deoxy-2'-fluoroarabinoguanosine (2'F-araG) (32) and locked riboguanosine (LNA-G) (3) promising superior stability of the induced parallel structures. ${ }^{296-301}$ The demonstrated ability of $2^{\prime} \mathrm{F}$-araG to induce an exclusive and stable parallel topology in the otherwise polymorphic telomeric G-quadruplex has been beneficial for the study of telomerase activity. ${ }^{302}$ Specifically, single-molecule FRET studies have recently revealed the mechanism by which telomerase can unwind and extend the parallel telomeric Gquadruplex. ${ }^{303}$ While $2^{\prime} \mathrm{F}$-araG substitutions have often been found to be stabilizing, the introduction of LNA-G is met with unpredictable outcomes, including stabilization/destabilization of quadruplex forms or obstruction of G-quadruplex formation. ${ }^{304}$ Strikingly, LNA-G substitution has also resulted in a novel G-quadruplex topology in $\mathrm{K}^{+}$buffer, termed as $\mathrm{V} 4$ fold, when it substitutes positions $2,4,6$ and 8 of $\mathrm{G}_{4} \mathrm{~T}_{4} \mathrm{G}_{4} \cdot{ }^{305,}{ }^{306}$ This unusual fold is dimeric in nature with $\mathrm{G}$-tracts that fold back into V-shaped loops, in such a way as to include features of both antiparallel and parallel topologies within a single structure.

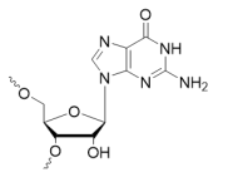

30

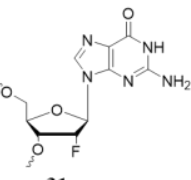

31

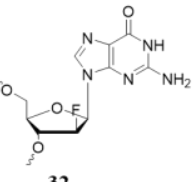

32

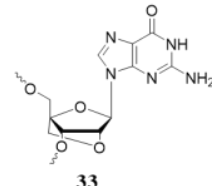

33
Figure 15. Common anti guanosine analogues employed to stabilize parallel Gquadryplex topologies; riboguanosine (30) ${ }^{307}$. ${ }^{2} 2^{\prime}-$ degegxy-2'-fluororiboguanosing

\section{Stabilizing i-motifs}

The quest to stabilize i-motif DNA structures originates from their poor stability beyond acidic $\mathrm{pH}$, which complicates their use in in-vitro applications under physiological conditions. Consequently, several nucleoside modifications have been employed to better understand the factors that lead to poor $\mathrm{i}$ motif stability at neutral $\mathrm{pH}$. Here, we summary the primary stabilizing modified nucleosides, as other recent reviews cover the topic more extensively. ${ }^{309,310}$
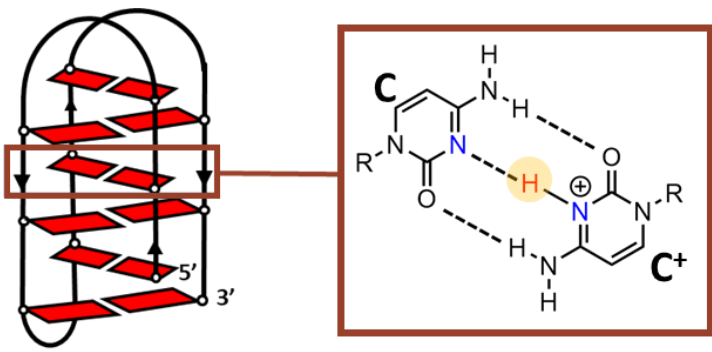

Figure 16. Schematic of i-motif and illustration of a hemi-protonated cytosinecytosine base pair.

The i-motif originates from C-rich sequences and consists of two parallel duplexes that are intercalated into one another in antiparallel orientation (Fig. 16). The intercalating hemiprotonated cytosine-cytosine base pairs are the prime 
contributors to i-motif structural stability, thereby explaining their tendency to form in acidic media. Other factors that contribute to i-motif stability are $\mathrm{C}$-tract length, ionic strength, the length of connecting loops, and capping base pairs in imotif loops. ${ }^{311,312}$

The primary stabilizing i-motif modifications are summarized in Fig. 17. Some base-modified cytidine analogues, such as 5 methylcytidine (34) and pseudoisocytidine (35), have been shown to slightly enhance the stability of the i-motif. ${ }^{313,314}$ For instance, introducing two methylcytidine substitutions into the human telomeric $\mathrm{i}$-motif results in up to $2{ }^{\circ} \mathrm{C}$ stabilization at $\mathrm{pH}$ $6 .^{313}$ The enhancement in stability is attributed, in part, to the electron-donating effect of the methyl substituent, which

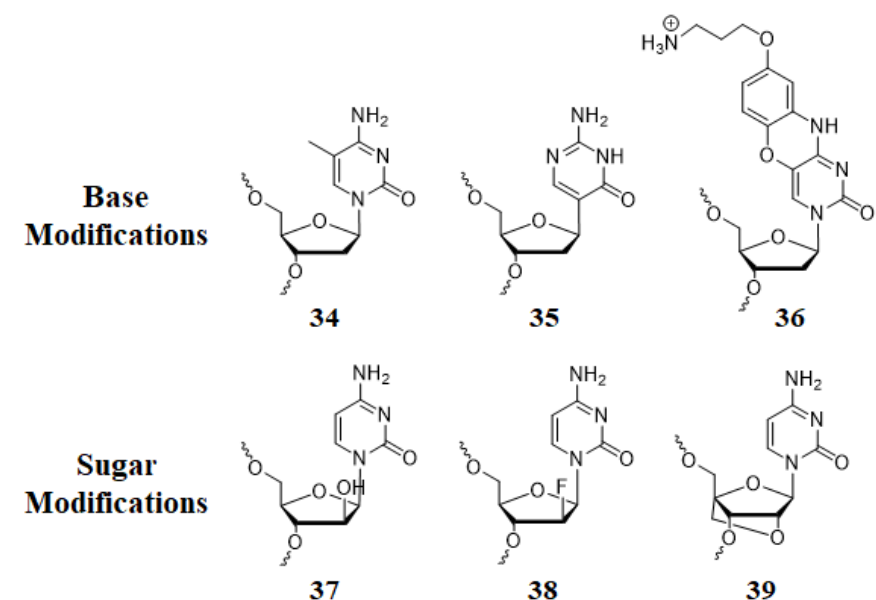

Figure 17. Selected modified nucleosides that reşulted in i-motif stabilization; (34) 5-methylcytidine
arabinocytidine ; arabinocytidine.

stabilizes the positive charge of the excess proton in the $\mathrm{C}-\mathrm{C}+$ base pair. ${ }^{319}$ Pseudoisocytidine was shown to be more promising, as a single substitution into a dimeric mini i-motif sequence results in detectable i-motif species at neutral $\mathrm{pH}$, compared to the otherwise unfolded unmodified sequence. ${ }^{314}$ Another important cytidine base analogue is the substituted phenoxazine nucleoside, known as i-clamp (36), which can stabilize i-motifs at neutral $\mathrm{pH}$ by up to $5{ }^{\circ} \mathrm{C}$ when dually substituted. ${ }^{315}$

Several sugar-modified cytidine analogues have also been incorporated into i-motifs, and the most stabilizing include $2^{\prime}$ arabinocytydine (araC) (37), 2'-deoxy-2'-fluoroarabinocytydine (2'F-araC) (38), and locked nucleic acid cytidines (LNA-C) (39). Typically, i-motif deoxynucleotides adopt a C3'-endo (North) sugar pucker, but ribonucleotides, which prefer a similar pucker, were shown to be destabilizing. $^{320}$ This destabilization has been primarily attributed to the solvation of the hydroxyl groups, which are oriented towards the minor groove. ${ }^{321}$ The effect of solvation is reduced for 2'-fluororibonucleotides incorporated into imotifs, thereby explaining their moderate stabilizing effects. ${ }^{321}$ While LNA-C strongly adopts a C3'-endo pucker, it may destabilize or stabilize the i-motif depending on the number and positions of the substitutions. ${ }^{318}$ Particularly, LNA-C can be stabilizing if it is placed in such a way as to promote $\mathrm{C}-\mathrm{H} \cdots \mathrm{O}$ contacts in the i-motif narrow groove. In contrast, $\mathrm{C2}^{\prime}$-endo (South) conforming araC and $2^{\prime} \mathrm{F}$-araC have been shown to stabilize i-motif structures, primarily because their 2'-hydroxy and 2'-fluoro groups, respectively, point toward the i-motif major groove and avoid any steric clashes. ${ }^{316,317} 2^{\prime} \mathrm{F}$-araC, in particular, has proven most effective at stabilizing $\mathrm{i}$-motifs at neutral $\mathrm{pH}^{317,}{ }^{322}$ Studies show that $2^{\prime} \mathrm{F}$-araC results in incremental stabilization of i-motifs with every additional substitution of deoxycytidine, and a fully substituted telomeric i-motif exhibits enhanced thermal stability by $17.2^{\circ} \mathrm{C}$ at $\mathrm{pH} 7$ and an enhanced transitional $\mathrm{pH}$ of $7.6 \pm 0.3$ (compared to 6.3 \pm 0.2 in the unmodified equivalent). ${ }^{317}$ The stability of the $2^{\prime} F$ araC modified telomeric i-motif was also shown to persist in the presence of a concomitant complementary telomeric Gquadruplex, thereby resisting hybridization. ${ }^{302}$

Lastly, phosphate backbone modifications have also been explored, with relevant examples including phosphorothioate (PS) linkages and the polyamide backbone of peptide nucleic acid (PNA). ${ }^{273},{ }^{323}, 324$ Studies have shown that phosphorothioate, but not methylphosphonate, is conducive to i-motif formation. Even at neutral $\mathrm{pH}$, only little or no decrease in thermal stability is observed for PS-modified imotifs.

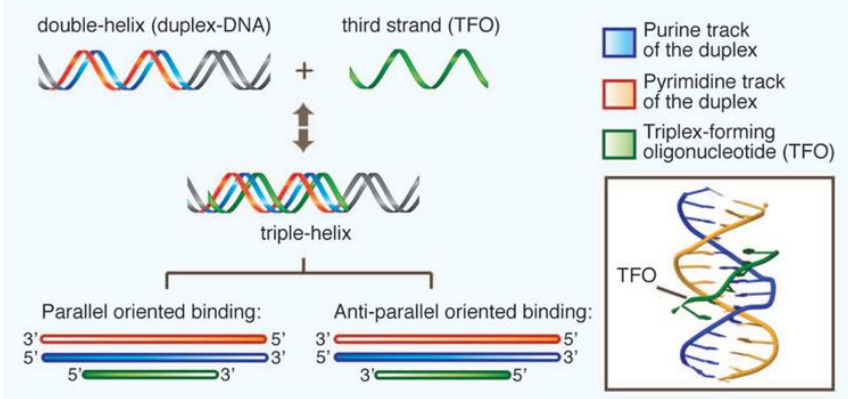

Figure 18. Orientation of component strands of parallel and antiparallel triplexes. The inset cartoon is a triple helix structure derived from a NMR structure (PDB-id:1BWG). Reproduced from Ref. ${ }^{25}$ with permission from Taylor \& Francis.

\section{Stabilizing triple helices}

Triple helices, or triplexes, consist of a triplex-forming oligonucleotide (TFO) that is hydrogen-bonded via Hoogsteen or reverse Hoogsteen base pairing to the purine bases of an oligopurine:oligopyrimidine duplex (Fig. 18). ${ }^{339-341}$ Depending on the base composition of the TFO (TC-rich, GT-rich, or ATrich), triple helices are classified as parallel or antiparallel, in reference to the orientation $\left(5^{\prime}\right.$ to $\left.3^{\prime}\right)$ of the TFO backbone relative to the oligopurine it binds to in the duplex. Chemical modifications have been employed in TFOs and triple helices for several reasons, such as overcoming the poor physiological stability of the structures, addressing charge repulsion between the strands, and equipping TFOs with nuclease resistance for use in therapeutics. Here, we provide several examples (Fig. 19) of nucleoside modifications that have been utilized to stabilize triplexes. More comprehensive reviews on triplexes and their respective chemical modifications have appeared. $^{276,280,342}$ 
Phosphate backbone modifications have been employed to stabilize triplexes, and prominent examples include phosphorothioate (40), $\mathrm{N3}^{\prime} \rightarrow \mathrm{P}^{\prime}$ phosphoramidate (41), and cationic $\quad \mathrm{N}, \mathrm{N}$-diethyl-ethylenediamine $\quad$ (DEED) phosphoramidate linkages (42). ${ }^{326-328} \quad \mathrm{N3}^{\prime} \rightarrow \mathrm{P}^{\prime}$ phosphoramidate-linked TG-rich and TC-rich TFOs were shown to bind more strongly to their duplex targets than their phosphate-linked counterparts, partly due to improved Hoogsteen base-pairing facilitated by the $\mathrm{C3}^{\prime}$-endo pucker of the sugar. ${ }^{327}$ While several unmodified TFOs failed to form stable triplexes at neutral $\mathrm{pH}$, the triplexes consisting of the modified TFO exhibited thermal stabilities of at least $40{ }^{\circ} \mathrm{C}$. The same study also demonstrated that the TFO inhibited transcription of a gene by halting RNA polymerase II at the site

\section{Backbone Modifications}

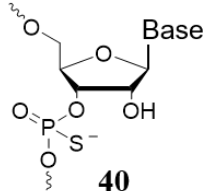

Base Modifications

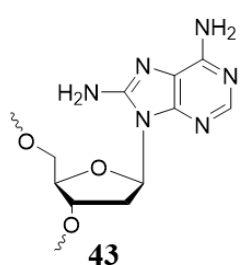

43
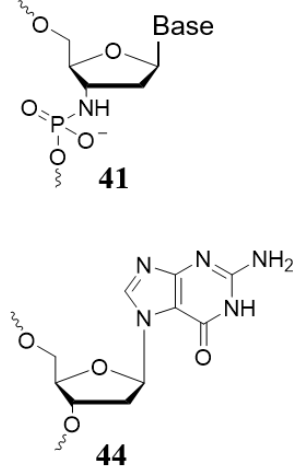

44

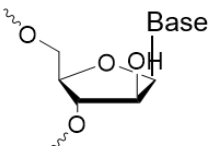

49
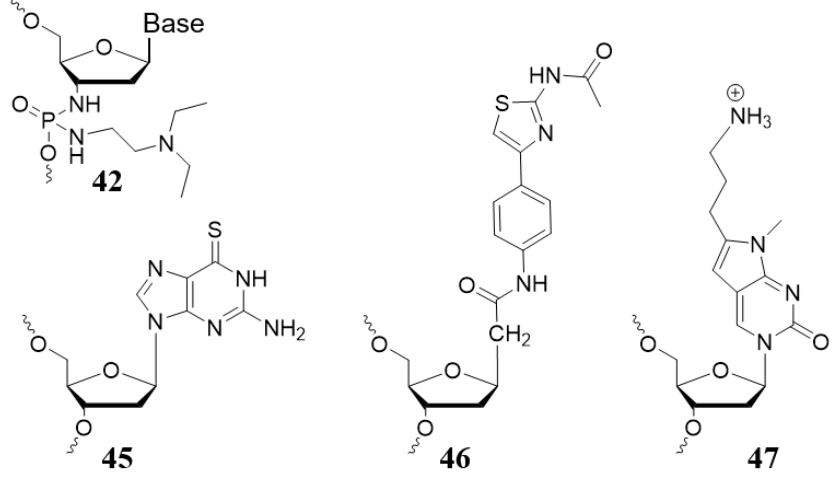

46

47

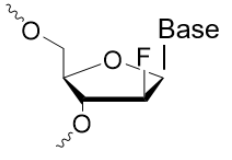

48

\section{Sugar \\ Sugar
Modifications}

of triplex formation. Cationic TFOs utilizing DEED

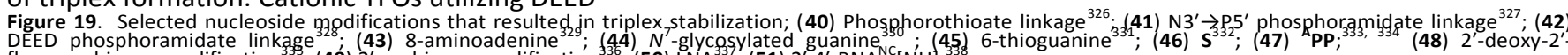

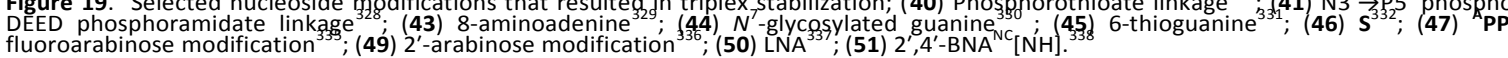

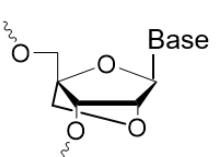

50

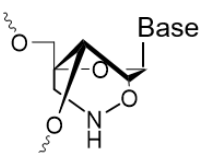

51 
Figure 20 Selected examples of prominent nucleoside modifications used in ASO and si RNA; (40) Phosphorothioate (PS) linkage; (41) N3'-P5' thiophosphoroamidate linkage; (52) morpholino phosphorodiamidate (PMO) backbone; (53) peptide nucleic acid (PNA) backbone; (54) methoxypropylphosphonate (MOP) linkage; (55) phosphotriester linkages;
deoxy-2'-fluoro (2'F); (59) S-constrained ethyl bridged nucleic acid (cEt); (60) 5-methylcytosine; (61) 5-methyluracil (thymine); (62) abasic nucleoside; (63) 2deoxy-2'-fluo
thiothymine.

a)

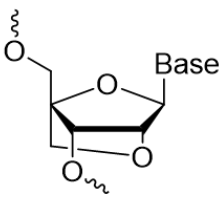

LNA, 50

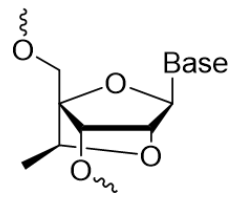

cEt, 59

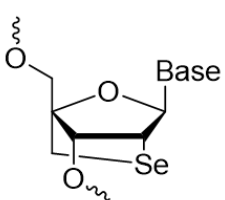

64

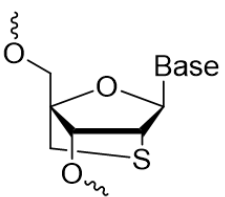

65

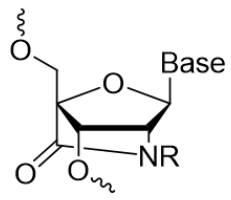

$66 \quad \mathbf{R}=\mathrm{H}, \mathrm{Me}$

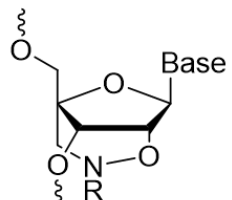

67 b)<smiles>[R16]CO[C@]12CC([R])[C@H](OC)[C@H]1O[C@H]([R16])C2</smiles><smiles>[B]C1CC2(COC(=O)O)CCCC(OC)C2O1</smiles>

4,3-bicyclo DNA, 69

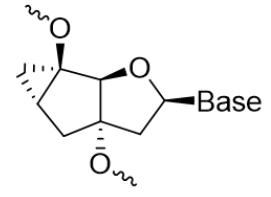

tcDNA, 70<smiles>COCC12CC(C([18O]C)C1F)C2[18OH]</smiles>

2'F-NMC 4

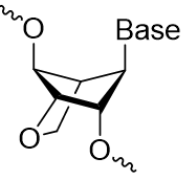

Oxanorbornane DNA, 71

$\mathbf{R}=\mathrm{H}, \mathrm{NH}_{2}$

Figure 21 Selected conformationally constrained nucleoside analogues. a) LNA analogues b) Other bi- and tricyclic nucleoside analogues

phosphoramidate linkages were also shown to mediate gene expression. $^{343}$

Triplexes with cationic TFOs could form in the absence of divalent $\mathrm{Mg}^{2+}$ cation and demonstrated improved stability. ${ }^{328}$ Interestingly, they also formed under physiological $\mathrm{K}^{+}$ concentrations which often hinder triplex formation and promote TFO self-aggregation and G-quartet formation.

The effect of several nucleobase modifications on triplex stability has also been explored. 8-Aminopurines have been utilized in several purine-rich TFOs and the resulting enhancement in triplex stability at neutral $\mathrm{pH}$ has been studied. ${ }^{329,} 344,345$ For instance, it is suggested that the added stability of triplexes containing 8-aminoadenine (43) originates from the extra Hoogsteen hydrogen bond between the amino group and thymidine in A-TT triads, in addition to the fact that the amino group is well-accommodated in the minor-Major groove of the triplexes. ${ }^{329,}{ }^{344}$ Similarly, another base modification that is capable of stabilizing $\mathrm{pH}$-dependent triplexes at neutral $\mathrm{pH}$ is $N^{7}$-glycosylated guanine (44). ${ }^{330,346}$ This modification has been shown to display the same hydrogen bonding functionality as protonated cytidine, which explains its role in stabilizing $\mathrm{C}+\mathrm{GC}$ triads. Other base modifications, such as 6 -thioguanine (45), have been shown to favor triplex formation by preventing the self-aggregation of TFOs into G-quadruplexes in physiological conditions. ${ }^{331}$ Another more challenging aspect of triplex studies has been to stabilize triplex sequences containing pyrimidine-purine interruption sites (also known as pyrimidine inversions), which would be found in duplexes that are not entirely composed of homopurine:homopyrimidine strands. ${ }^{332,}{ }^{334}$ For this purpose, sequence-nonspecific nucleosides, such as $\mathbf{S}(\mathbf{4 6})$, were designed and shown to be successful. ${ }^{332,347} \mathbf{S}$ consists of two unfused aromatic rings linked to 2 '-deoxyribose and studies showed that it could stabilize triplexes with interruption sites, with some discrimination toward TA base pairs. Similarly, substituted $3 \mathrm{H}$-pyrrolo[2,3-d]pyrimidin-2(7H)-one analogues, such as ${ }^{A}$ PP (47), were found to recognize CG base pairs with enhanced selectivity and affinity. ${ }^{333,334}$

Lastly, sugar modifications have also been employed to stabilize triplexes. 2'-deoxy-2'-fluoroarabinonucleoside ( $2^{\prime} F$ araN) (48) and $2^{\prime}$-arabinonucleoside ( $2^{\prime}$-araN) (49) TFOs have been demonstrated to stabilize antiparallel triplexes upon hybridization to DNA duplexes and DNA(purine):RNA(pyrimidine) duplexes, similar to DNA and RNA TFOs. ${ }^{335,}{ }^{336}$ However, unlike RNA TFOs, 2'F-araN and 2'araN TFOs could not form stable triplexes with RNA(purine):DNA(pyrimidine) and RNA:RNA duplexes, thereby highlighting the importance intermolecular $\mathrm{C2}^{\prime} \mathrm{OH}$-phosphate contacts in stabilizing antiparallel triplexes. ${ }^{348}$ LNA (50) has also proven useful in stabilizing triplexes, whether it substitutes deoxynucleosides in the TFO or in the pyrimidine strand of the target duplex. ${ }^{337}$ In the TFO, it can preorganize strand conformation owing to its locked $\mathrm{C3}^{\prime}$-endo pucker, thereby reducing the entropic cost of binding to the major groove. Similarly, LNA introduced into the pyrimidine strand of the target duplex (alternating with DNA monomers) folds the duplex into a conformation that is amenable to TFO binding. The improved affinity to the target duplex that LNA can confer to TFOs has been manipulated in a DNA photocleavage study, where the LNA modified TFO demonstrated consequent improved photoreactivity. ${ }^{349}$ Another bridged nucleic acid analogue known as $2^{\prime}, 4^{\prime}-\mathrm{BNA}^{\mathrm{NC}}[\mathrm{NH}](\mathbf{5 1})$ was also explored and studies showed that it could, in some instances, provide higher triplex stabilization and nuclease resistance than LNA. In particular, TFOs with consecutive or extensive $2^{\prime}, 4^{\prime}-\mathrm{BNA}^{\mathrm{NC}}[\mathrm{NH}]$ modifications are characterized with improved duplex affinity compared to LNA. ${ }^{338}$ 


\section{Antisense oligonucleotides (ASO) and siRNA}

Following the success of phosphorothioate-modified (PS) antisense oligonucleotides, the field of nucleic acid therapeutics took off and experienced worldwide efforts to produce druggable oligonucleotides using numerous nucleoside modifications. Importantly, research focused on those modifications that conferred oligonucleotides with improved therapeutic activity, bioavailability, nuclease stability, and reduced off-target effects. Here, we summarize common and recently developed nucleoside modifications for antisense and RNAi, in addition to those which have been useful in improving the CRISPR-Cas delivery system. Some examples of common and recent nucleoside modifications are highlighted in Fig. 20. For more comprehensive recent reviews on the topic, including those that detail strategies for designing ASOs and siRNA, readers may consult cited works. ${ }^{350}$ 354

\section{Phosphate backbone modifications}

Internucleotide linkage modifications have been successfully used to improve the therapeutic properties of ASOs and siRNA. The phosphorothioate (PS) linkage (40) was the first modification introduced and among the most successful. It has been incorporated into 5 of 10 FDA-approved oligonucleotide drugs, as it confers them with improved nuclease resistance, trafficking and uptake. ${ }^{352}$ Although PS-modified ASOs bind with reduced affinity to their complementary target, they can still elicit RNase H-mediated mRNA cleavage, so PS linkages are typically used in conjunction with other modifications that increase binding affinity to a target. ${ }^{355,356}$ On the other hand, PS backbones in siRNA result in reduced activity, so they are only occasionally utilized in oligonucleotide termini to confer nuclease resistance. ${ }^{357}$ Morpholino phosphorodiamidate (PMO, 52) and peptide nucleic acid (PNA, 53) linkages are both neutral backbones that have been extensively studied in therapeutic oligonucleotides, with the former being successfully incorporated into two FDA-approved ASOs. ASOs with these modifications cannot elicit RNase $\mathrm{H}$ activity and instead operate as excellent steric blockers or splice modulators. ${ }^{358-360}$ Although they have a similar or greater affinity to their target strand compared to unmodified ASOs, they do not readily traverse cell membranes alone. ${ }^{361}$ Typically, conjugation to short peptides improves tissue distribution and in vivo activity. ${ }^{362-364}$ In siRNA, the use of PNA in the oligonucleotide overhangs demonstrated enhanced silencing activity and serum stability. ${ }^{365}$ In recent years, several other backbone modifications have been explored. In ASOs, for instance, N3'-P5' thiophosphoroamidate linkages (41) have demonstrated therapeutic utility when incorporated into ASOs designed for telomerase inhibition. ${ }^{366,}{ }^{367}$ More recently, neutral methoxypropylphosphonate (MOP, 54) linkages were used in PS-ASOs. ${ }^{368}$ The study showed that even a single MOP substitution near the $5^{\prime}$ terminus of gapmer PS-ASOs preserves RNase $\mathrm{H}$ activity while reducing or eliminating their hepatotoxicity. Neutral linkages have also been explored in siRNA, and a recent example is the phosphotriester backbone linked to thioester groups (55). ${ }^{369}$ siRNA with mixed phosphotriester and phosphodiester backbones can cross cell membranes more easily and bind serum albumin, thereby achieving improved pharmacokinetic properties. They also serve as prodrugs that are converted into native, functional siRNA by thioesterases. A final phosphate modification to consider in siRNA is that of the terminal $5^{\prime}$-phosphate, which is required for RISC loading but can be removed by cellular dephosphorylation. ${ }^{354}$ Various phosphate analogueues have been explored to overcome this challenge, ${ }^{370}$ and $5^{\prime}$-(E)-vinyl phosphonate has been shown to equip siRNA with improved gene silencing activity. ${ }^{371,372}$

\section{Ribose sugar modifications}

Sugar modifications serve many purposes in the therapeutic utility of nucleic acids. ${ }^{351}$ Modifications of the furanose ring of ribose can bias the sugar puckering through stereoelectronic effects $^{373,374}$ which can stabilize secondary structures as well as increase binding affinity for target sequences. ${ }^{350}$ Additionally, modifications of the sugar ring can increase nuclease resistance, increase bioavailability, and reduce toxicity. ${ }^{353}$ Ribose modifications at the $2^{\prime}$ position are undoubtedly the most commonly used to alter the sugar conformation. ${ }^{350}$ Examples of modifications in ASOs include $2^{\prime}$ O-methyl (2'-OMe; 56), 2'-O-methoxyethyl (2'-MOE, 57), 2'deoxy-2'-fluoro $\left(2^{\prime} F, 58\right)$, and $2^{\prime}$-deoxy-2'-fluoroarabino ( $2^{\prime} F$ ara or FANA, 48) in Fig.20, among many others that are wellreviewed. ${ }^{350,375}$ Other notable sugar modified oligonucleotides include a large family of conformationally constrained nucleic acids (Fig. 21). Examples are the well-known, LNA (50), 376, 377 tricyclo-DNA (70), ${ }^{378-381}$ S-constrained ethyl LNA (cEt, 59), and a series LNAs with different bridging heteroatoms including nitrogen $(66,67),{ }^{382,383}$ selenium $(64),{ }^{384,385}$ sulfur $(65),{ }^{386}$ and mixes of those ${ }^{338,387,388}$ (reviewed in ${ }^{350,}{ }^{389}$ ). Bicyclo DNA analogues have also been investigated, and these include bcDNA (68), ${ }^{379}$ 4,3-bicyclo DNA (69), ${ }^{388} 2^{\prime}$ F Northern methanocarbacyclic oligonucleotide (2'F-NMC; 4), ${ }^{23}$ and oxanobornane modified oligonucleotides (71). ${ }^{390}$ All these modifications improve oligonucleotide nuclease stability and binding affinity to complementary RNA. ${ }^{350,352,375}$

2'-Modified riboses are the most commonly employed modified nucleosides in ASOs, yet they adopt a preferential C3'-endo pucker, deterring their extensive substitution into ASOs designed to elicit RNase $\mathrm{H}$ activity. ASOs require DNA-like character (C2'-endo preferring nucleosides) to prompt RNase $\mathrm{H}$-mediated cleavage. ${ }^{375}$ Pucker preferences are important in dictating the helical form (A or B) adopted by the duplexes. The intermediate helicity between $A$ and $B$ form of DNA:RNA hybrids enables important minor groove interactions between RNase $\mathrm{H}$ and the DNA strand, partly conducive to cleavage activity. ${ }^{391,} 392$ Substituting deoxynucleosides of DNA:RNA hybrids with $\mathrm{C3}^{\prime}$-endo preferring nucleosides pushes the duplex to adopt the A form more strongly, consequently reducing RNase $\mathrm{H}$ activity. To address this challenge, the gapmer strategy was adopted, whereby the central block of the ASO (RNase $\mathrm{H}$ binding site) is composed of 
deoxynucleosides for induction of RNase $\mathrm{H}$ cleavage and flanking blocks are composed of modified ribonucleotides. ${ }^{393}$ 394 On the other hand, ASOs that operate as steric blockers (where RNase $\mathrm{H}$ mediated cleavage is not required) can utilize 2 '-modified riboses more readily, while RNAi mechanisms have been shown to be relatively tolerant to extensively modified SiRNA (with some exceptions). ${ }^{351}$

2'-OMe (56) was among the first modifications introduced into ASOs. Further exploration of chemistries similar to $2^{\prime}$-OMe resulted in the discovery of $2^{\prime}-\mathrm{MOE}$ (57). Oligonucleotides modified with $2^{\prime}-\mathrm{MOE}$ were shown to be even more stable to nucleases than those with $2^{\prime}-\mathrm{OMe}$ and have a higher binding affinity to RNA complements. ${ }^{395,396}$ The success of $2^{\prime}-M O E$ is exemplified by its use in three of six FDA-approved ASOs. It has been used to substitute flanking nucleosides of RNase $\mathrm{H}$ active gapmer ASOs, as well as throughout steric blocker ASO sequences. ${ }^{397-399}$

$2^{\prime} F$ (58) modifications have been used in similar ASO strategies, ${ }^{400,} 401$ and, unlike $2^{\prime}-\mathrm{MOE}$, they are very well tolerated in both strands of siRNA. ${ }^{402,403}$ In fact, one of the two FDA-approved siRNA drugs relies on extensive 2'F modifications, in addition to $2^{\prime}$-OMe, incorporations for improved oligonucleotide nuclease stability and binding affinity to complementary RNA. ${ }^{350,352,375348,369,391}$ As for the 2 '-OMe modification in particular, it has been shown to reduce the immunostimulatory effects of siRNA and is successfully used in both FDA-approved siRNA drugs. ${ }^{352}$ Several strategies have emerged to strategically employ $2^{\prime}$-OMe in siRNA, and one example is its incorporation at the two $5^{\prime}$ terminal nucleosides of the passenger strand to block it from entering into RISC and facilitate the loading of the guide strand. ${ }^{404}$ Over the years, ways to optimize siRNA activity, using these two modifications have been investigated and developed. ${ }^{351,354}$ For instance, 2'F modifications, being closer ribose mimics, can be substituted more frequently into a guide strand, as it requires compatibility with RNAi mechanisms. ${ }^{403,}{ }^{405}$ Other considerations include weakening siRNA duplex stability to promote guide strand loading into RNAi machinery, or ensuring that the guide strand binds with optimal helical geometry to the target mRNA to elicit cleavage by RISC. ${ }^{402,406,}$ 407

The epimer of 2'F, i.e., 2'-deoxy-2'-fluoroarabinose (2'F-ara or FANA, 48), has also been explored in therapeutic oligonucleotides for its ability to confer oligonucleotides with improved nuclease stability and improved hybridization to RNA. Contrary to aforementioned modified nucleosides, 2'Fara nucleosides adopt a preferential $\mathrm{O}^{\prime}$ '-endo conformation when hybridized to an RNA target and effectively mimic the deoxynucleosides in DNA/RNA hybrids, thereby eliciting RNase $\mathrm{H}$ activity. ${ }^{408}$ Consequently, FANA ASO design does not require a gapmer strategy, but mixing and alternating 2'F-ara nucleosides with deoxynucleosides is important for maintaining adequate rates of RNase $\mathrm{H}$ cleavage. ${ }^{409-411}$ Delivery of PS-FANA antisense oligonucleotides (ASOs) to the lung achieved appreciable local lung concentrations at the site of action, at low administered doses. In a 14-day inhalation study in monkeys, PDE-targeting PS-FANA ASOs were found to be safe and well tolerated at all dose levels tested (from 0.05 to $2.5 \mathrm{mg} / \mathrm{kg} /$ day). Moreover, pharmacokinetic studies indicated very low levels of PS-FANA ASOs in plasma $(<1 \%)$, and no plasma accumulation was obtained after repeated doses. ${ }^{412}$ More recently, Rossi and co-workers evaluated the in vitro potency of PS-FANA ASOs targeting highly conserved regions in the HIV-1 genome. ${ }^{413}$ Carrier-free cellular internalization of these oligomers resulted in strong suppression of HIV-1 replication in HIV-1-infected human primary cells, attributing these effects to both RNase $\mathrm{H} 1$ activation and steric hindrance of dimerization. In siRNA, FANA has been shown to be well-tolerated in the passenger strand, and the simultaneous incorporation of ribose $2^{\prime}$ modifications, such as $2^{\prime} F$, demonstrated improved gene silencing activity. ${ }^{414,}$ 415
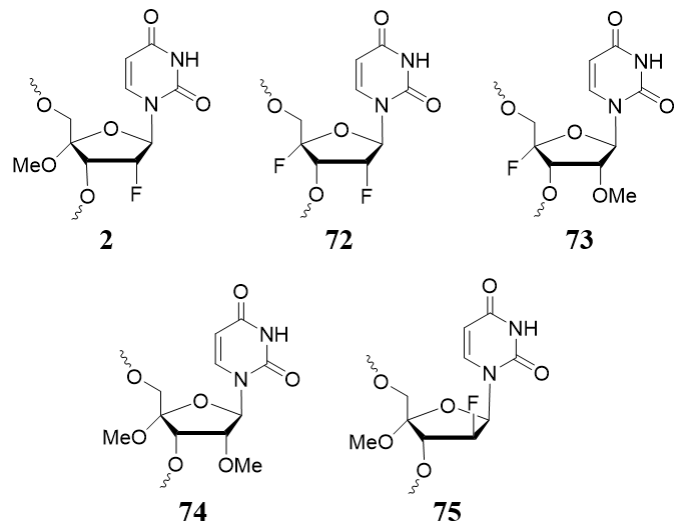
Figure 22. Examples of $2^{\prime}, 4^{\prime}$-modified nucleosides explored for potent siRNA
activity. (2) 2 $2^{\prime}$-deoxy-2'-fluoro- $4^{\prime}$-methoxyribouridine; (71) $2^{\prime}$-deoxy-2 $2^{\prime}, 4^{\prime}$ difluororibouridine; (72)
dimethoxyribouridine; (74) 2 '-deoxy-2'-fluoro-4'-methoxyarabinouridine

In addition to $2^{\prime}$ modifications, several nucleosides with simultaneous ribose $2^{\prime}$ and $4^{\prime}$ modifications have been synthesized and explored for their siRNA activity. In 2015, 2'deoxy-2', 4'-difluororibouridine (Fig. 22, 72) was incorporated into the guide strand of siRNA and was shown to be as potent as the $2^{\prime} \mathrm{F}$ modification. ${ }^{416,417}$ The $4^{\prime}$ fluorine modification is attractive because it reinforces the $C 3^{\prime}$-endo sugar pucker, ${ }^{418}$ thereby conformationally restricting the sugar without the need to introduce $2^{\prime}-4^{\prime}$ carbon bridges. This work has inspired subsequent studies utilizing $2^{\prime}, 4^{\prime}$ modifications, and those with most notable effects on siRNA potency include: $2^{\prime}$-deoxy-2'fluoro-4'-methoxyribouridine (2); 2'-methoxy-4'fluororibouridine (73); 2', $4^{\prime}$-dimethoxyribouridine (74); and 2'deoxy-2'-fluoro-4'-methoxyarabinouridine $(75) .^{21,419,420}$ These

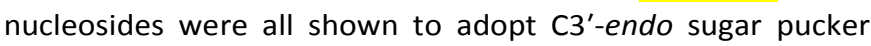
and confer oligonucleotides with enhanced nuclease resistance without altering the stability of RNA duplexes. These studies also showed that the $2^{\prime}, 4^{\prime}$ nucleosides were compatible with siRNA, and among siRNA duplexes tested, those with modifications at the $3^{\prime}$ overhangs were among the most potent.

Lastly, other sugar-modified nucleosides that have found applications in oligonucleotide therapeutics include bridged 
a)<smiles></smiles>

b)<smiles>[Y8]CCN1CCOCC1</smiles>

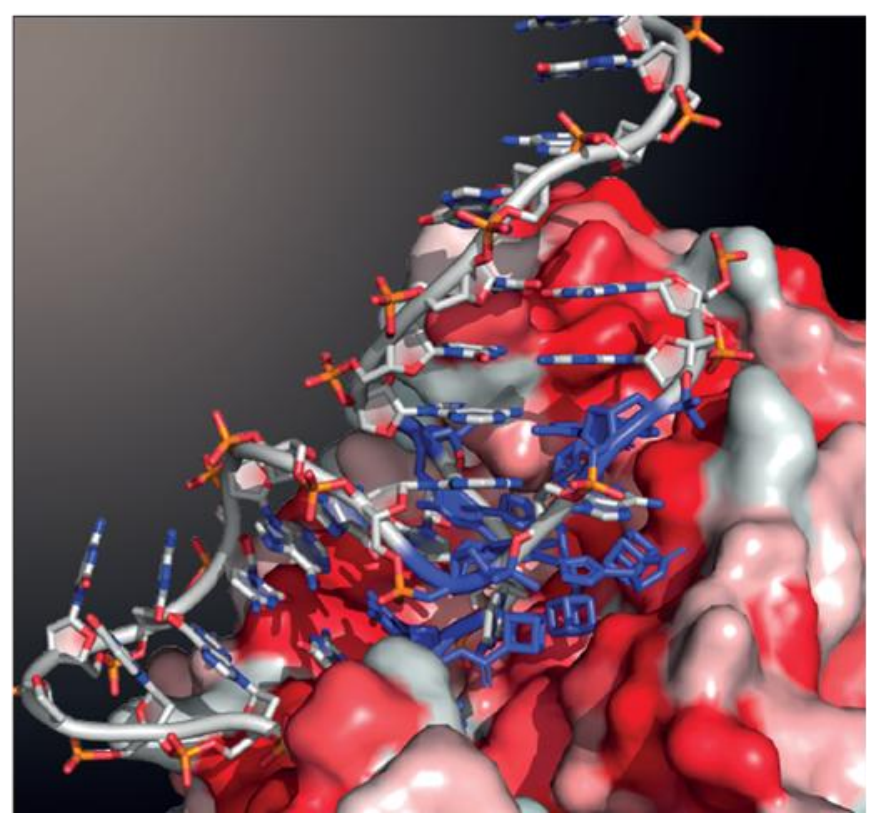

nucleic acids (BNA). Two most commonly used BNA are locked nucleic acid (LNA, 50) and 2'-4'-constrained ethyl BNA (cEt, 59). Owing to their locked $\mathrm{C3}^{\prime}$-endo pucker, LNA and cEt can conformationally preorganize ASOs, thereby remarkably enhancing their hybridization to complementary RNA. ${ }^{421-423}$

Fig. 23. a) Chemical structures of base-modified nucleoside triphosphates used in aptamer selections; b) X-ray structure of a cubane-modified aptamer in complex with the protein PVLDH (PDB ID code: 6TXR; courtesy from Dr. Pascal Röthlisberger).

\section{Nucleobase modifications}

Nucleobase modifications are less thoroughly explored in nucleic acid therapeutics, compared to backbone and sugar modifications, as they typically result in reduced oligonucleotide binding affinity or base-pairing specificity. 5Methylcytosine (60) and 5-methyluracil (61) have been among the most successful, and they are used in three of six FDAapproved ASO drugs. Owing to the stacking of the methyl group between planar nucleobases in the major groove, these 5-methylpyrimidines increase the thermal stability of oligonucleotide duplexes. ${ }^{350}$ In the context of RNAi, abasic nucleosides (62) have been employed to eliminate miRNA-like off-target repression, which represents a major challenge of SiRNA. ${ }^{428}$ Even though abasic nucleosides reduced oligonucleotide specificity, siRNA activity was maintained. In another application, abasic nucleosides in siRNA and 2thiothymidine (63) in ASO have been independently employed
Both BNAs have demonstrated therapeutic potential when used in combination with other modifications in gapmer ASOs, steric block ASOs, and siRNA. ${ }^{424-427}$ in allele-selective suppression of gene expression in Huntington's disease. ${ }^{429,430}$

\section{CRISPR}

Cluster regularly interspaced short palindromic repeats, or CRISPR as they are more often referred to, in conjunction with the CRISPR-associated (Cas) proteins, have garnered wide attention for their gene editing capabilities, most recently being the subject of the 2020 Nobel Prize in Chemistry. ${ }^{431}$ The most common system relies on the Cas9 endonuclease which can target DNA sites as directed by the CRISPR RNA (crRNA). ${ }^{432}$ Additionally, there is another RNA strand, the trans-activating CRISPR RNA (tracrRNA), which is required, but researchers have conveniently joined both strands together to form a single guide RNA (sgRNA) system. ${ }^{433}$ Two different mechanisms of gene editing can take place, non-homologous end joining (NHEJ) which can lead to insertions or deletions (indels), or 
homologous recombination (HR) which can introduce new sequences. However, like ASOs and siRNA, CRISPR faces similar challenges for delivery and stability in vitro as well as the increased risk of off-target effects. ${ }^{434}$ For these reasons, modifications to the sgRNA of CRISPR/Cas systems are required for effective use in cells.

The most common chemical modifications of ASOs and siRNA have also been incorporated into CRISPR RNA strands extensively and some key studies will be summarized, but they are well-reviewed. ${ }^{433,435,436}$ Incorporation of 2'-OMe, phosphorothioate backbones, or thiophosphonoacetate backbones, as well as combinations of them in the sgRNA showed increased indel efficiency in NHEJ. ${ }^{437}$ Use of these modifications resulted in similar effects when a fluorescent gene was inserted with HR. Additional studies with systematic introduction of 2'-OMe, 2'-fluoro, phosphorothioate, and cEt into the crRNA near the ends increased activity as internal positions were required for contact with Cas proteins. ${ }^{438}$ The 2'-OMe, 2'-fluoro, and phosphorothioate backbones were examined in further detail and incorporated into the crRNA and tracrRNA strands. ${ }^{439}$ Phosphorothioate incorporation near the end of the crRNA strand slightly improved efficacy while the 2 '-OMe and 2'-fluoro modifications were only tolerated at specific positions. Modification of the tracrRNA strand with $2^{\prime}$ OMe, but only at positions that were not interacting with the Cas9 protein were well-tolerated. Interestingly, Yin et al. found that incorporation of DNA nucleotides in place of RNA was not only well-tolerated, but significantly reduced off-target effects when incorporated at the $3^{\prime}$-end of crRNA. ${ }^{440}$ As long RNA oligonucleotides are difficult to synthesize by solid-phase synthesis and are often required for sgRNA approaches, this represents an important discovery in making CRISPR more available. However, extensive substitution with DNA was also found to reduce activity. ${ }^{441,442}$

Additionally, LNA and some of its derivatives (including the aforementioned cEt LNA) have been introduced to CRISPR sequences. In 2018, Cromwell et al. introduced LNA and $\mathrm{N}$ methyl substituted analogues into crRNA which greatly reduced off-target effects by destabilizing crRNA-DNA duplexes for incorrect sequences. ${ }^{443}$ O'Reilly et al. systematically investigated the double helix structure of crRNA and tracrRNA by introducing diverse chemical modifications with variable conformations (LNA, 2'-F, FANA, 2'-F-4'-OMe RNA, 2'-4'-diOMe RNA and others) and examining their effect on CRISPR/Cas9 activity. ${ }^{442}$ They found that A-form helices were tolerated best in the seed region of crRNA while other diverse modifications were better tolerated in other regions.

While there have been many similarities between the approaches of chemists to ASOs and siRNA as with CRISPR, there have been some unique applications towards the latter that are worth mentioning. To fully implement CRISPR-based therapeutics, it may be necessary to develop kill-switch inhibitors that can halt Cas enzyme activity on demand. Inspired by the discovery of anti-CRISPR proteins, the Gagnon and Damha groups explored small nucleic acids as potential inhibitors of Cas9 (termed CRISPR-SNuBs). ${ }^{444}$ Potent inhibition of Cas9 was achieved with a DNA hairpin tethered to a $2^{\prime}$ -
F/LNA ASO with perfect complementarity to $15 \mathrm{nts}$ of the tracrRNA that would normally bind the crRNA. The presence of this inhibitor slowed Cas9 activity in vitro and in HEK293T cells in a dose-dependent manner, having a calculated $\mathrm{EC}_{50}$ in vitro very near the concentration of the crRNA, with which it is designed to compete for binding. Palumbo et al. recently designed sgRNA bearing a variety of succinyl esters at the $3^{\prime}$ end including an iodoacetamide functional handle, strained cyclooctyne, Cy5 fluorophore, and biotin which had negligible effects on cleavage efficiency. ${ }^{445}$ Using the iodoacetamide functional handle they were able to achieve crosslinking with a mutant Cas9 protein and the biotinylated handle allowed for identification of three human proteins that bind to sgRNA. Wang et al. recently blocked important $2^{\prime} \mathrm{OH}$ contact points between sgRNA and the Cas9 protein with photolabile groups, thereby preventing formation of the active complex. ${ }^{446}$ Irradiation of living cells containing the modified SgRNA and Cas9 protein cleaved the photolabile groups allowing formation of the active complex and nuclease cleavage. Nahar et al. showed in 2018 that addition of a G-quadruplex forming sequence at the 3 '-end of sgRNA improved both efficiency, stability, and specificity in zebrafish embryos. ${ }^{447}$

\section{Aptamers}

In SELEX (systematic evolution of ligands by exponential enrichment) and related combinatorial methods of in vitro evolution, large populations ( $10^{13}$ molecules) are processed through iterative rounds of screening (for binding or catalysis), separation, and amplification steps to identify aptamers or nucleic acid catalysts. ${ }^{448-450}$ One important advantage of the polymerase-mediated synthesis of modified nucleic acids over all other methods is its compatibility with the SELEX protocol. Indeed, substitution of canonical nucleotides by modified counterparts in PCR or PEX reactions permits the generation of modified randomized libraries which can then be implemented in selection protocols. ${ }^{451-454}$ This direct inclusion in the SELEX protocol circumvents work-intensive and uncertain structureactivity relationship studies that can be applied in post-SELEX modification protocols of resulting functional nucleic acids. Another strength of enzymatic synthesis of modified DNA and RNA is the compatibility with in vivo settings and unrestricted size which is not the case with solid-phase synthesis. These features have been harnessed for the functional tagging and crosslinking of nucleic acids with biological targets in vitro and in vivo. ${ }^{455}$

Shortly after the advent of the SELEX method, early examples of aptamers obtained via selection experiments that included non-canonical nucleotides were reported. ${ }^{456-458}$ These early experiments demonstrated that 1) $\mathrm{dN}^{*} \mathrm{TPs}$ could replace canonical nucleotides for the construction of randomized libraries provided they were tolerated as substrates by RNA and/or DNA polymerases and that the resulting libraries could be converted to unmodified nucleic acids without loss of sequence and/or genetic information; 2) that the resulting aptamers displayed enhanced properties and did not necessarily require post-SELEX modifications; 3) an expanded 
physicochemical space could partially compensate screening for poorly represented sequences capable of activities that are difficult to be achieved by canonical nucleic acid polymers. These findings spurred numerous selection experiments with $\mathrm{dN} *$ TPs leading to the identification of aptamers containing XNAs, base-, sugar-, and/or phosphate-modifications.

\section{Base-modified aptamers}

Numerous selection campaigns aimed at improving the binding affinity of aptamers are based on the grafting of hydrophobic moieties on nucleobases in order to favor contact interactions with hydrophobic pockets and residues located on the intended protein targets. Notable examples include pyrimidine nucleoside triphosphates bearing functional groups reminiscent of the residues of the side-chains of amino acids (76 - 78 in Fig. 23a) that are used to identify SOMAmers (Slow Off-rate Modified Aptamers). ${ }^{459}$ The inclusion of these $\mathrm{dN}^{*}$ TPs in SELEX not only led to aptamers with high binding affinity (usually in the low $\mathrm{nM}$ range) but also markedly improved the success rate of selection experiments against more challenging protein targets. ${ }^{460} \mathrm{X}$-ray structural investigations of SOMAmerprotein complexes clearly demonstrated the implication of the side-chains of the modified nucleotides in important binding and recognition events with the target proteins, underscoring the validity of this approach. ${ }^{460}$ These inherent properties have led to the selection of SOMAmers against over 5000 different human proteins which have been used for the development of a proteomics assay (SOMAscan) ${ }^{461}$ for the simultaneous detection of multiple biomarkers in biological fluids as well as for a better understanding of the human plasma proteome. ${ }^{462}$

Another interesting, related example is nucleotide 79 (Fig. 23a) which is decorated with a tyrosine-like residue and that allowed the identification of high affinity binding aptamers $\left(K_{\mathrm{D}}\right.$ $=27 \mathrm{nM}$ ) targeted against live $E$. coli DH5 alpha cells. ${ }^{463}$ This base-modified aptamer compared favorably to an existing RNA aptamer identified against the same target. In addition to amino acid-like side chains, nucleotides have also been equipped with additional nucleic acid bases in the so-called base-appended base (BAB) modification (80 in Fig. 23a). The $B A B$ modification offers the possibility of forming new hydrogen and stacking interactions and several potent aptamers containing this modification have been selected. ${ }^{464}$ 465

Functional groups that differ from chemical patterns found in nature are scarcer, especially in the context of aptamer selection experiments. A prime example is $\mathrm{dU}^{\mathrm{C}} \mathrm{TP}$ (81 in Fig. 23a) which is equipped with the benzene isostere cubane. Cubane is entirely alien to biology and displays similar physicochemical properties to benzene. However, cubane is notoriously aplanar and non-aromatic and the cubyl hydrogen atoms are rather acidic due to the ring strain imposed by the cubic structure and these $\mathrm{C}-\mathrm{H}$ bonds can thus engage in hydrogen bonding interactions. An aptamer was raised against the malaria biomarker Plasmodium vivax lactate dehydrogenase $(P V L D H)$ using $\mathrm{dU}^{\mathrm{C}} \mathrm{TP}$ in a SELEX experiment. The resulting, so-called cubamer was capable of discriminating
PVLDH from the highly homologous $P f L D H$ in a mimetic clinical situation. An X-ray structural investigation revealed the formation of a cubane hydrophobic cluster which interacts with a hydrophobic pocket of $P v L D H$; this interaction is reminiscent of structures of SOMAmer-protein complexes. Interestingly, the presence of an unique hydrogen bond was observed between a cubyl hydrogen atom $(\mathrm{C}-\mathrm{H}(2))$ and a carbonyl of Leu232 which is believed to be important for protein binding and discrimination from PfLDH (Fig. 23b). ${ }^{230}$ The cubamer selection is related to the versatile click-SELEX method which has allowed the isolation of various basemodified aptamers. ${ }^{119,466}$ Another example of exotic functional groups are boronic acids since they are not known to occur naturally in proteins or nucleic acids. A boronic acid moiety was included on a dUTP analogue (82 in Fig. 23a) and used to identify an aptamer capable of binding to the glycosylation site of fibrinogen. ${ }^{467}$

Instead of equipping natural triphosphates with basemodifications, randomized libraries can also be supplemented with additional chemical diversity using genetic alphabet expansion strategies. Indeed, the natural genetic code consisting of the two Watson-Crick base pairs can be enlarged by adding artificial nucleotides that pair together to form unnatural base pairs (UBPs). ${ }^{78,254,468}$ This strictly requires the UBPs to be orthogonal to the canonical nucleotides which can be ensured either by reprogramming the hydrogen bonding pattern of nucleobases, ${ }^{79,254}$ by fine tuning the association of nucleotides via shape complementarity, ${ }^{469}$ or by replacing nucleobases with aromatic moieties that display large hydrophobic surfaces capable of interacting via stacking and packing forces. ${ }^{470,471}$ In addition to strict orthogonality, UBPs need to be replicated with high fidelity and efficiency and potentially in a totally sequence-independent manner. ${ }^{472,} 473$ UBPs that meet all these criteria have been employed for the selection of potent aptamers against a variety of targets. ${ }^{78,79,}$ ${ }^{474}$ Recently, efforts to identify additional UBPs have centered on the quest of novel artificial metal base pairs. In artificial metal base pairs, nucleotides act as ligands to coordinate a bridging metal cation and thus doing maintain orthogonality with the canonical base pairs. ${ }^{475}$ Enzymatic synthesis of artificial metal base pairs lags behind UBPs in terms of efficiency, replication and by-pass capacity. ${ }^{476}$ However, some successful examples have been reported ${ }^{477-479}$ which have led to the possibility of constructing modified functional nucleic acids. ${ }^{480-482}$ In addition, multiple studies have been dedicated at refining the structural and chemical requirements for the enzymatic synthesis of artificial metal base pairs ${ }^{476,483-485}$ and a recent report shows the possibility of forming up to ten consecutive $\mathrm{T}-\mathrm{Hg}^{\prime \prime}-\mathrm{T}$ metal base pairs by polymerase-mediated synthesis ${ }^{486}$ which bodes well for the construction of libraries containing metal UBPs for future use in SELEX experiments.

\section{Sugar-modified and XNA containing aptamers}

Initially, sugar-modified nucleoside triphosphates were used in selection experiments to identify more stable aptamers, especially with regards to nuclease-mediated degradation. Early experiments concentrated on rather minute alterations 
of the (deoxy)ribose scaffold such as the $2^{\prime}$-OMe, $2^{\prime}-\mathrm{F}$, and $2^{\prime}$ $\mathrm{NH}_{2}$ modifications (Fig. 24) which were in part driven by the poor acceptance of sugar modified nucleotides by DNA and RNA polymerases. These modifications are also interesting because they impart a high degree of nuclease-resistance to the ensuing aptamers and are rather cost-affordable (both as phosphoramidites and as triphosphates). However, recent progress in polymerase engineering and methods of directed evolution has permitted the discovery of polymerases and reverse transcriptases capable of synthesizing XNA oligonucleotides from DNA templates and complementary DNA from XNAs. ${ }^{216,487}$ Engineered polymerases opened up the possibility of increasing the chemical diversity of sugar modifications in randomized libraries. Engineered polymerases have been instrumental in the identification of aptamers with XNA modifications such as FANA, HNA, LNA, or TNA (Fig. 24) against both protein ${ }^{139,487-489}$ and small molecule targets. ${ }^{490,491}$ Evolved polymerases also facilitate the selection of aptamers with other sugar modifications such as $2^{\prime}$-OMe groups ${ }^{492}$ or bulkier functionalities appended at the $2^{\prime}$-position of the ribose. $^{493}$ In the latter approach, an engineered polymerase capable of efficient polymerization of $2^{\prime}$-modified nucleotides was used to construct libraries containing $2^{\prime}-\mathrm{N}_{3}$-modified cytosine nucleotides. The azide functionalities were then used as synthetic handles for the incorporation of additional functional groups via the CUAAC; an approach reminiscent of the click-SELEX method developed for the identification of base-modified aptamers. ${ }^{466}$ The resulting libraries were then used in SELEX to identify anti-HNE and anti-factor IXa aptamers with high binding affinities ( $K_{\mathrm{D}}$ values in the $20-100 \mathrm{nM}$ range). ${ }^{493}$

Instead of altering the 2 '-position or introducing orthogonal XNA scaffolds, resistance against nuclease-mediated degradation can be improved by substituting the 4'-oxygen atom of the furanose ring with a different heteroatom. Particularly, a 4 '-thio substitution pattern allows a 600-fold improvement of nuclease resistance compared to unmodified oligonucleotides and maintains the possibility of enzymatically constructing libraries for aptamer selections. ${ }^{494}$

A seemingly rather simple modification of the structure of nucleic acids involves changing their homochiral nature. This change in handedness can be obtained by using nucleotides containing L-2' deoxyribose sugar units to construct oligonucleotides instead of the corresponding, naturally occurring D-building blocks (Fig. 24f). While this appears as a rather straightforward substitution pattern and that various chemical methods for solid-phase synthesis of Loligonucleotides have been devised, enzymatic synthesis and evolution of ligands based on mirror-image polynucleotides is an arduous undertaking since natural enzymes, particularly polymerases do not recognize L-nucleotide building blocks and L-oligonucleotides. Hence, strategies for evolving mirror-image aptamers, the so-called Spiegelmers, rely on detours to evade the inability of natural enzymes to produce and process Loligonucleotides. Essentially, mirror-images of the target are produced by chemical synthesis and conventional SELEX with natural DNA/RNA is then applied to identify D-aptamers. After the selection protocol, the resulting aptamers are converted by solid-phase synthesis to the corresponding Lenantiomers. ${ }^{495}$ Application of this strategy has led to the identification of highly potent, nuclease stable aptamers against a variety of protein, nucleic acids, and small molecule targets. ${ }^{496-498}$ While natural polymerases are capable of binding to enantiomeric DNA, they cannot extend L-primers with any type of nucleoside triphosphate. ${ }^{499}$ In order to circumvent this shortcoming, there are three possible alternatives for the enzymatic synthesis of mirror-image DNA/RNA: 1. Chemical synthesis of existing polymerases with $D$ - rather than L-amino acids which then accept L-nucleoside triphosphates; $^{500,} 5012$ 2. Construction of related ligases consisting of enantiomeric D-amino acids capable of assembling L-DNA fragments together; ${ }^{502}$ 3. Cross-chiral ribozyme polymerases capable of assembling long RNA oligonucleotides with the opposite handedness. ${ }^{503}$ Hence, the emergence of possible enzymatic routes for the synthesis of Lnucleic acids combined with adapted sequencing protocols ${ }^{202}$ open up the possibility of direct selection of Spiegelmers in the near future.

$$
\text { a) }
$$

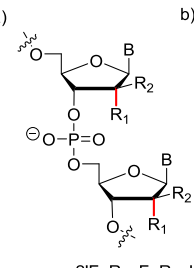

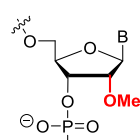

c)

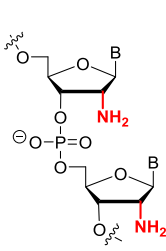

e)

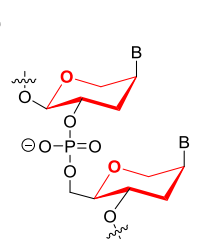

f)

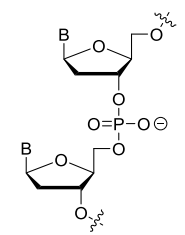

HNA

L-DNA
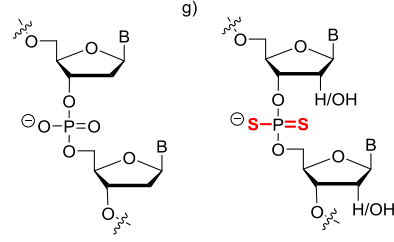

DNA

Figure 24. Chemical structure of sugar and backbone modifications used in aptamer selections; a) 2'-Fluoro-modification; b) 2'-methoxy-modification; c) 2' (

\section{Backbone-modified aptamers}

Numerous chemistries that deviate from the native backbone have been proposed for the development of therapeutic oligonucleotides but only a few are compatible with enzymatic DNA or RNA synthesis. ${ }^{24,33,504,505}$ Most backbone-modified aptamers obtained by direct selection contain phosphorothioate linkages and are obtained by replacing one or multiple nucleotides with $\alpha$-thio-(d)N*TPs during SELEX. These sulfur-containing analogues of canonical nucleotides are rather good substrates for DNA and RNA polymerases and are readily amenable to the construction of modified libraries. ${ }^{506}$ The simple substitution of a non-bridging oxygen atom by a sulfur has important repercussions since thioaptamers are markedly more resistant to nuclease degradation than unmodified aptamers and also display higher affinities for protein targets due to the reduction of cation binding and 
disruption of the hydration pattern. ${ }^{162,507,508}$ However, the number of oxygen to sulfur substitutions in the backbone of aptamers must be carefully assessed since the inclusion of too many PS units might cause non-specific binding and destabilize secondary structures of aptamers. As an alternative, single replacements of phosphate groups by phosphorodithioates $\left(\mathrm{PS}_{2}\right)$ has been recently shown to dramatically improve the binding affinity of an existing anti-thrombin aptamer, ${ }^{172,} 509$ presumably due to a localized induced-fit rearrangement of the nucleotide equipped with the $\mathrm{PS}_{2}$ linkage (Fig. 24g). ${ }^{172}$ Despite synthetic accessibility to $\mathrm{PS}_{2}$-containing nucleoside triphosphates ${ }^{510,511}$ this modification was only introduced in post- and not pre-SELEX approaches.

Instead of an atomistic substitution pattern based on sulfur, non-bridging oxygen atoms can also be replaced by borane $\left(\mathrm{BH}_{3}{ }^{-}\right)$units. The resulting $\alpha$-P-boranophosphate linkages are metabolically stable, ${ }^{512}$ are more lipophilic than native phosphate moieties, ${ }^{513}$ display low cytotoxicity, ${ }^{514}$ and have the potential to be employed in boron neutron capture therapy (BNCT). ${ }^{515}$ In view of these interesting features, $\mathrm{BH}_{3-}$ containing RNA aptamers against ATP have been identified by direct selection using single $\alpha$-P-borano-modified triphosphates ( $\alpha$-B-UTP and $\alpha-B-G T P$ ) in the SELEX protocol. ${ }^{505}$ However, no other aptamers have been selected with this particular backbone modification.

Alkylphosphonate linkages are isostructural but not isoelectrostatic analogues of canonical phosphate groups. Backbones containing alkylphosphonates are less prone to nuclease degradation than unmodified counterparts and have been proposed for the development of antisense therapeutic oligonucleotides despite their sensitivity to basic conditions. ${ }^{350}$ Polymerases, including the Klenow fragment of DNA polymerase $1^{516}$ and $\mathrm{TdT}^{517}$ readily accept $\alpha-P$ methylphosphonate nucleoside triphosphates as substrates and enable the synthesis of DNA containing these chargeneutral analogues. More recently, an engineered polymerase was obtained by a combination of molecular dynamics simulations and in vitro evolution and shown to be capable of synthesis and reverse transcription of $\alpha$-P-methyl and $\alpha$-Pethyl DNA. More importantly, mixed $\alpha$-P-methyl-/ $\alpha$-P-methylcontaining libraries could be generated and used in SELEX to identify fully modified, uncharged aptamers specific for streptavidin (with $K_{\mathrm{D}}$ values in the lower $\mathrm{nM}$ range). ${ }^{24}$

\section{Modified catalytic nucleic acid enzymes}

The discovery of naturally occurring catalytic RNA molecules (ribozymes) predates the advent of SELEX but these combinatorial methods of in vitro selection have allowed the identification of DNA enzymes (DNAzymes) along with nucleic acid molecules capable of catalyzing a broad variety of chemical transformations. ${ }^{451,471,518}$ The realisation that nucleic acid scaffolds required substantial concentrations of $\mathrm{M}^{2+}$ cofactors for activity to compensate the dearth of functional groups present on the nucleobases and backbone, combined with the notorious fragility to nucleases, rapidly called for the introduction of modified nucleotides in SELEX experiments. ${ }^{519}$ 521
As for aptamer selections, most unnatural modifications used in SELEX of nucleobase-modified ribozymes and DNAzymes centered on side-chains reminiscent of the amino acids found in the active sites of naturally occurring enzymes such as RNase A. Indeed, supplementing randomized oligonucleotide libraries with cationic amines and imidazoles (intended to mimic lysine and histidine side-chains used by RNase $A$ in the $\mathrm{M}^{2+}$-independent catalysis of RNA hydrolysis) permitted the identification of highly active catalysts that are capable of hydrolyzing RNA substrates under in vivo-like regimes. ${ }^{519,} 522$, 523 When the chemosphere of these libraries is further expanded by adding a third nucleotide bearing a permanently positively charged side-chain, DNAzymes can access all-RNA cleavage capacity under multiple turnover conditions through an electrostatic stabilization of their overall three-dimensional structures. ${ }^{524-526}$ Modified nucleoside triphosphates have also been used to address other challenges in nucleic acid catalysis. For instance, even though various selection campaigns have been devised to identify unmodified proteolytic DNAs and RNAs, ${ }^{527,} 528$ amide-bond cleavage can only be achieved by base-modified scaffolds. ${ }^{109,529}$ This stringent need is rather surprising given that the half-lives for the uncatalyzed hydrolysis of the phosphodiester bond in RNA and the amide bond in proteins differ only by a factor of $\sim 20 .{ }^{528}$ The addition of extra functional groups can also increase the network of hydrogen bonding accessible to nucleic acids and hence promote catalysis of organic reactions such as the Diels-Alder reaction. $^{520}$

An increase in chemical diversity of the scaffold of nucleic acid catalysts can also be provided by sugar modifications which grant access to nuclease resistant XNAzymes. A first example of an XNA catalyst was obtained by the construction of modified libraries with a mutant of the Tgo DNA polymerase that tolerates a number of sugar-modified dN*TPs followed by application of SELEX. Amongst the identified catalysts, a FANAzyme exhibited the most favorable kinetic properties $\left(k_{\text {obs }}=0.026 \mathrm{~min}^{-1}\right.$ in the presence of $20 \mathrm{mM} \mathrm{Mg}^{2+}$ ) including multiple turnover catalysis for the cleavage of all-RNA substrates. ${ }^{530}$ Other XNAzymes capable of RNA or FANA ligation were also identified by application of the same strategy. More recently, a highly potent FANAzyme was identified by Chaput and co-workers.$^{531}$ without requiring any specifically engineered polymerase since efficient FANAsynthesis was achieved with wild-type Tgo DNA polymerase and reverse transcription to natural DNA was supported by the Bst polymerase. ${ }^{224}$ The most efficient FANA-based catalyst hydrolyzes all-RNA substrates with a catalytic efficiency $\left(k_{\text {cat }} / K_{\mathrm{M}}=3.3 \cdot 10^{5} \mathrm{~min}^{-1} \mathrm{M}^{-1}\right)$ comparable to that of unmodified RNA-cleaving DNAzymes assayed under high $\mathrm{M}^{2+}$ concentrations. ${ }^{531}$ Interestingly, this FANAzyme hydrolyzes substrates containing a single embedded riboguanosine nucleotide with higher pseudo-first-order rate constant than DNAzyme 10-23 which is based on canonical DNA and has already been used in clinical trials. ${ }^{532}$

Clearly, non-native modifications play a major role in catalytic nucleic acids since they are suspected to have enhanced RNAbased catalysis in an RNA World hypothesis by compensating 
the short length of sequences by enhanced catalytic activity and promiscuity ${ }^{53}$ and have permitted (and will certainly continue) expansion of the catalytic repertoire of DNAzymes and ribozymes.

\section{Incorporation of reactive and functional groups}

The inclusion of additional chemical groups in nucleic acids via enzymatic synthesis is obviously not restricted to merely promoting binding and catalytic activities. ${ }^{534}$ Popular examples involve the appendage of fluorescent and radioactive tags for the in vitro and in vivo detection of nucleic acids. ${ }^{185,535-537}$ This can be achieved by using nucleotides bearing simple basemodifications where fluorescein, BODIPY, or other organic dyes are attached to the nucleobase via rigid linker arms. ${ }^{223}$ Alternatively, more complex structures can be integrated on the nucleobases of nucleotide analogues such as antibodies. Even though antibody-modified nucleotides are larger in size than DNA polymerases they are readily incorporated into DNA. The presence of these antibodies can then be detected via an interaction with a secondary antibody used in combination with classical fluorescent read-out systems such as the horse radish peroxidase. ${ }^{538}$

Lastly, naturally occurring nucleobases can be substituted with non-native, fluorescent counterparts. The resulting constructs bear highly emissive surrogates that can be used for monitoring molecular and dynamic events at specific positions since they display isolated absorption bands and thus permit selective excitation in the presence of canonical nucleobases. ${ }^{539}$ The nucleobase surrogates can be designed as isomorphs of the natural heterocyclic bases on furanoses to minimally perturb the overall structure of double helices or functional nucleic acids. ${ }^{540,}{ }^{541}$ Alternatively, larger fluorophores can be integrated on natural furanoses or sugars with altered chemistry. ${ }^{542,543}$ Such fluorescent analogues are continuously employed for the in vitro and in vivo detection of specific DNAs or RNAs.

The incorporation of cross-linking moieties into nucleic acids via the polymerization of modified nucleotides is advantageous since these reactive functional groups are often sensitive to the rather harsh conditions imposed by solidphase synthesis or might require intricate synthetic pathways. ${ }^{229}$ Hence, cross-linking agents ranging from small modification patterns ${ }^{544,545}$ such as 4-thio-thymidine ${ }^{546}$ or chloroacetamide-modified nucleobases ${ }^{547}$ to more complex functional groups such as diazirine ${ }^{548}$ or squaramate ${ }^{98}$ have been introduced into RNA and DNA using polymerases and modified nucleotides. This strategy is particularly suitable for the investigation of interactions and contacts between nucleic acids and proteins for instance in the context of investigating DNA repair mechanisms. ${ }^{549}$

\section{Photolithographic nucleic acid synthesis}

Photolithographic nucleic acid synthesis refers to the lightdriven, in situ synthesis of repertoires of oligonucleotide sequences on microarray chip technology. ${ }^{550,} 551$ Maskless photolithography is a modern, automated, and robust technique that utilizes digital micromirrors to achieve automated synthesis of thousands to millions of unique, spatially-defined nucleic acid sequences. ${ }^{552}$ The advent of this technology has allowed for the generation and manipulation of large amounts of nucleic acid data and has therefore been beneficial for several applications, including gene profiling, ${ }^{553}$ genotyping, ${ }^{554}$ gene synthesis, ${ }^{555}$ and re-sequencing. ${ }^{556}$ Several reviews on photolithographic synthesis and its applications are cited. ${ }^{557,558}$ Additionally, photolithographic DNA synthesis has been vital for the development of DNA as a medium for data storage. $^{559,560}$ To continuously improve available DNA-based storage technologies, several research groups have been investigating portable storage ${ }^{561}$ digital data encryption, ${ }^{562}$, and storage architectures, ${ }^{563}$ among other innovations.

As suggested by the name, photolithography relies on light for the in situ synthesis of nucleic acid strands. Synthesis of oligonucleotides primarily proceeds via the phosphoramidite cycle of solid-phase synthesis described in Section 2.2 (Fig. 7a), with one key difference: a photolabile $5^{\prime}-\mathrm{OH}$ protecting group is used instead of the acid-cleavable DMT group. In addition to reducing reaction times and avoiding harsh deprotection conditions, photolabile protecting groups enable spatial control, such that coupling reactions can proceed at defined positions on the microarray surface.

The earliest photolabile protecting groups utilized in photolithographic nucleic acid synthesis included [( $\alpha$-methyl-2nitropiperonyl)-oxy]-carbonyl (MeNPOC) and dimethoxybenzoincarbonate (DMBOC) groups. ${ }^{564,565}$ Later, 2(2-nitrophenyl)-propyloxycarbonyl (NPPOC) group was used to protect the $5^{\prime}-\mathrm{OH}$ of phosphoramidites, as it led to more efficient photocleavage and higher yielding syntheses. ${ }^{566}$ Only recently were groups introduced with even higher photolytic activity, and these are benzoyl-NPPOC and thiophenylNPPOC. ${ }^{567-569}$ Use of thiophenyl-NPPOC, in particular, led to twelve-fold increase in photolytic efficiency and a reduction in synthesis errors relative to NPPOC.

In addition to synthesis of DNA, photolithography has been employed to construct libraries of nucleic acids composed of alternative nucleosides, thereby highlighting the versatility of the technique. A study has shown that PNA libraries can be synthesized using NPPOC-protected monomers, ${ }^{570}$ and a more recent study has successfully optimized conditions for the challenging synthesis of RNA on microarrays. ${ }^{155,} 571,572$ 2'Deoxy-2'-fluoroarabinonucleic acids (FANA) have also been used in microarrays to map the affinity landscape of the thrombin-binding aptamer. ${ }^{573}$ In the study, several combinations of 2' $\mathrm{F}$-araN resulted in considerable increases in aptamer stability and affinity, with significant contributions deriving from substituted thymidines at positions 3 and 12 . The versatility of microarray synthesis has also allowed for the higher-level engineering of nucleic acid constructs to equip them with additional functionality and complexity. For instance, a recent study has shown that a synthesized DNA library is responsive to post-synthetic chemical modifications such as cross-linking DNA strands and post-synthetic enzymatic modifications using DNA or RNA ligases and polymerases. ${ }^{3}$ 


\section{Conclusions and perspectives}

DNA and RNA oligonucleotides clearly provide a versatile blueprint upon which a rich variety of functionality can be achieved through thoughtful chemical modification. The use of oligonucleotides in a broad range of fields and disciplines is a testament to the creativity employed in designing novel functional oligonucleotides. With the discovery of additional, natural modification patterns on DNA and RNA, warrants the development of innovative synthetic and chemoenzymatic methods, which can, in turn, be applied to introduce other, non-native modifications. Chemoenzymatic methods, including polymerization of $\mathrm{dN}^{*} \mathrm{TPs}$ and ligation of oligonucleotides containing modified fragments, along with chemical methods such as mechanochemistry and photolithographic synthesis will facilitate the ever-growing demand for DNA and RNA sequences equipped with non-native modifications.

Since the first modification of oligonucleotides in the form of the PS backbone, a modification still widely employed today, the repertoire of possible chemical modification has continued to grow rapidly. Fundamental studies on chemically-modified nucleic acids have provided significant structural insights on the stability of various forms of DNA and RNA, as well as a deeper understanding of structure-function relationships in biologically and therapeutically relevant contexts. Chemical modifications of the nucleobases permit practically limitless inclusion of functional moieties that lead to properties including increased binding affinity and catalytic activities, and reduced immunostimulatory effects. Owing to nucleobase modifications, fluorescent or redox labels may be introduced as well. In addition, modifications to the sugar-phosphate backbone have been extensively targeted to overcome issues with nuclease degradation and membrane crossing in therapeutic oligonucleotides, with much success. Through sugar-phosphate modifications, stabilization of secondary structures and increased binding affinity has been achieved while nuclease resistance, increased bioavailability and reduced toxicity have also been imparted.

Oligonucleotide therapeutics are now recognized as the third major drug discovery platform, in addition to small molecules and antibodies. With an ability to engage targets that are otherwise undruggable by conventional therapeutics, nucleic acid-based drugs have opened new avenues for treating intractable diseases, such as Huntington disease and spinal muscular atrophy. Nucleic acid therapeutics have also emerged as promising alternatives to conventional vaccine approaches. Already, mRNA vaccines against SARS-CoV- 2 are available, and others are being tested for other infectious agents, or employed in numerous cancer clinical trials. ${ }^{574}$ Recent progress has been rapid, broad and exciting, with several oligonucleotide-based drugs on the market and over a hundred candidates in early to late-stage clinical trials. Such advances have been possible, largely due to the ability to rationally design and readily prepare nucleic acid analogues, allowing specific alterations to many of the inherent properties that affect their biological activity and potency. Oligonucleotide therapeutics is now focused on developing effective delivery strategies and the cornerstones that determine productive pharmacokinetic and pharmacodynamic relationships for chemically modified nucleic acids. These include delivery strategies for promising clinical candidates targeting the liver, tumor, muscle, and the central nervous system. Also, conjugation to other nucleic acid sequences such as aptamers or to other chemical modifications such as photosensitizers will open new therapeutic avenues. Perseverance, combined with innovative and strategic nucleic acid designs and delivery systems, will continue to provide significant and exciting advancements in this field.

\section{Conflicts of interest}

There are no conflicts to declare.

\section{Acknowledgements}

M.H. acknowledges funding from Institut Pasteur (starting funds and DARRI grant number INNOV 17-19). L. K. M. thanks the ARC Foundation for cancer research for a postdoctoral Research Fellowship (grant number: S-FB18006). M.J.D acknowledges funding from the National Science and Engineering Council of Canada (Discovery Grant). R.E-K. is the recipient of a scholarship from the Fonds de recherche du Québec - Nature et technologies (FRQNT). We acknowledge Dr. Hala Abou Assi for providing illustrations in selected figures.

\section{References}

1. A. Lacroix, E. Vengut-Climent, D. de Rochambeau and H. F. Sleiman, ACS Central Sci., 2019, 5, 882-891.

2. P. S. Kwon, S. Ren, S. J. Kwon, M. E. Kizer, L. Kuo, M. Xie, D. Zhu, F. Zhou, F. M. Zhang, D. Kim, K. Fraser, L. D. Kramer, N. C. Seeman, J. S. Dordick, R. J. Linhardt, J. Chao and X. Wang, Nat. Chem., 2020, 12, 26-35.

3. K. Holz, E. Schaudy, J. Lietard and M. M. Somoza, Nat. Commun., 2019, 10, 8.

4. R. R. Breaker and G. F. Joyce, Chem. Biol., 1994, 1, 223229.

5. C. E. Weinberg, Z. Weinberg and C. Hammann, Nucleic Acids Res., 2019, 47, 9480-9494.

6. T. J. Wilson, Y. J. Liu, N. S. Li, Q. Dai, J. A. Piccirilli and D. M. J. Lilley, J. Am. Chem. Soc., 2019, 141, 7865-7875.

7. H. H. Lee, R. Kalhor, N. Goela, J. Bolot and G. M. Church, Nat. Commun., 2019, 10.

8. K. Yang, C. M. McCloskey and J. C. Chaput, ACS Synth. Biol., 2020, DOI: 10.1021/acssynbio.0c00361, 10.1021/acssynbio.1020c00361.

9. E. M. Harcourt, A. M. Kietrys and E. T. Kool, Nature, 2017, 541, 339-346

10. M. Flamme, L. K. McKenzie, I. Sarac and M. Hollenstein Methods, 2019, 161, 64-82.

11. T. Pan, Cell Res., 2018, 28, 395-404.

12. T. Wang and R. M. Kohli, Cell Chem. Biol., 2020, DOI: 10.1016/j.chembiol.2020.09.006.

13. M. Helm, R. Giege and C. Florentz, Biochemistry, 1999, 38, 13338-13346. 
A. Hienzsch, C. Deiml, V. Reiter and T. Carell, Chem.-Eur J., 2013, 19, 4244-4248.

15. M. Nainyte, T. Amatov and T. Carell, Chem. Commun., 2019, 55, 12216-12218.

16.

D. Adams, A. Gonzalez-Duarte, W. D. O'Riordan, C. C. Yang, M. Ueda, A. V. Kristen, I. Tournev, H. H. Schmidt, T. Coelho, J. L. Berk, K. P. Lin, G. Vita, S. Attarian, V. PlanteBordeneuve, M. M. Mezei, J. M. Campistol, J. Buades, T. H. Brannagan, B. J. Kim, J. Oh, Y. Parman, Y. Sekijima, P. N. Hawkins, S. D. Solomon, M. Polydefkis, P. J. Dyck, P. J. Gandhi, S. Goyal, J. Chen, A. L. Strahs, S. V. Nochur, M. T. Sweetser, P. P. Garg, A. K. Vaishnaw, J. A. Gollob and O. B. Suhr, N. Engl. J. Med., 2018, 379, 11-21.

P. C. Zamecnik and M. L. Stephenson, Proc. Natl. Acad. Sci. U.S.A., 1978, 75, 280-284.

18. M. L. Stephenson and P. C. Zamecnik, Proc. Natl. Acad. Sci. U.S.A., 1978, 75, 285-288.

19. C. F. Bennett, B. F. Baker, N. Pham, E. Swayze and R. S. Geary, Annu. Rev. Pharmacol. Toxicol., 2017, 57, 81-105.

20. M. Hornum, J. Stendevad, P. K. Sharma, P. Kumar, R. B. Nielsen, M. Petersen and P. Nielsen, Chem.-Eur. J., 2019, 25, 7387-7395.

E. Malek-Adamian, D. C. Guenther, S. Matsuda, S. Martínez-Montero, I. Zlatev, J. Harp, M. Burai Patrascu, D. J. Foster, J. Fakhoury, L. Perkins, N. Moitessier, R. M Manoharan, N. Taneja, A. Bisbe, K. Charisse, M. Maier, K. G. Rajeev, M. Egli, M. Manoharan and M. J. Damha, J. Am. Chem. Soc., 2017, 139, 14542-14555. Y. Kitamura, S. Moribe and Y. Kitade, Bioorg. Med. Chem. Lett., 2018, 28, 3174-3176.

23. M. Akabane-Nakata, P. Kumar, R. S. Das, N. D. Erande, S. Matsuda, M. Egli and M. Manoharan, Org. Lett., 2019, 21, 1963-1967.

24. S. Arangundy-Franklin, A. I. Taylor, B. T. Porebski, V. Genna, S. Peak-Chew, A. Vaisman, R. Woodgate, M. Orozco and P. Holliger, Nat. Chem., 2019, 11, 533-542.

25. K. Skakuj, K. E. Bujold and C. A. Mirkin, J. Am. Chem. Soc., 2019, 141, 20171-20176.

26. P. F. Conlon, O. Eguaogie, J. J. Wilson, J. S. T. Sweet, J. Steinhoegl, K. Englert, O. G. A. Hancox, C. J. Law, S. A Allman, J. H. R. Tucker, J. P. Hall and J. S. Vyle, Chem. Sci., 2019, 10, 10948-10957.

27. L. Taemaitree, A. Shivalingam, A. H. El-Sagheer and T. Brown, Nat. Commun., 2019, 10.

28. S. Manna, D. Sarkar and S. G. Srivatsan, J. Am. Chem. Soc., 2018, 140, 12622-12633.

29.

A. Aro-Heinila, T. Lonnberg and P. Virta, Bioconjugate Chem., 2019, .30, 2183-2190

30. Z. Y. Yang, H. J. Kim, J. T. Le, C. McLendon, K. M. Bradley, M. S. Kim, D. Hutter, S. Hoshika, O. Yaren and S. A. Benner, Nucleic Acids Res., 2018, 46, 5902-5910.

31. J. Matyasovsky and M. Hocek, Org. Biomol. Chem., 2020, 18, 255-262.

32. A. Johnson, A. Karimi and N. W. Luedtke, Angew. Chem. Int. Ed., 2019, 131, 16995-16999.

33.

M. Luo, E. Groaz, M. Froeyen, V. Pezo, F. Jaziri, P. Leonczak, G. Schepers, J. Rozenski, P. Marliere and P. Herdewijn, J. Am. Chem. Soc., 2019, 141, 10844-10851.

34 K. Murayama, Y. Yamano and H. Asanuma, J. Am. Chem. Soc., 2019, 141, 9485-9489.

35. R. L. Setten, J. J. Rossi and S. P. Han, Nat. Rev. Drug Discov., 2019, 18, 421-446.
36.

\section{A. Huffman, A. Fryszkowska, O. Alvizo, M. Borra-} Garske, K. R. Campos, P. N. Devine, D. Duan, J. H. Forstater, S. T. Grosser and H. M. Halsey, Science, 2019, 366, 1255-1259.

46. S. Kang, S. H. Jang, J. Lee, D. G. Kim, M. Kim, W. Jeong and Y. H. Rhee, Org. Lett., 2017, 19, 4684-4687.

47. R. Declercq, A. V. Aerschot, R. J. Read, P. Herdewijn and L. V. Meervelt, J. Am. Chem. Soc., 2002, 124, 928-933.

48. A. Eschenmoser, Pure Appl. Chem., 1993, 65, 1179-1188.

49. A. Eschenmoser, Nachr. Chem. Tech. Lab., 1991, 39, 795807.

50. P. Herdewijn, Chemistry Biodivers., 2010, 7, 1-59.

51. D. Sabatino and M. J. Damha, J. Am. Chem. Soc., 2007, 129, 8259-8270.

52. M. Habibian, S. I. Martínez-Montero, G. Portella, Z. Chua, D. S. Bohle, M. Orozco and M. J. Damha, Org. Lett., 2015 , 17, 5416-5419.

53. S. Tripathi, B. G. Roy, M. G. Drew, B. Achari and S. B. Mandal, J. Org. Chem., 2007, 72, 7427-7430.

54. K. Augustyns, F. Vandendriessche, A. Van Aerschot, R Busson, C. Urbanke and P. Herdewijn, Nucleic Acids Res., 1992, 20, 4711-4716.

55. M. Egli, P. S. Pallan, C. R. Allerson, T. P. Prakash, A. Berdeja, J. Yu, S. Lee, A. Watt, H. Gaus and B. Bhat, J. Am. Chem. Soc., 2011, 133, 16642-16649.

56. P. P. Seth, J. Yu, A. Jazayeri, P. S. Pallan, C. R. Allerson, M. E. Østergaard, F. Liu, P. Herdewijn, M. Egli and E. E. Swayze, J. Org. Chem., 2012, 77, 5074-5085.

57. M. E. Østergaard, T. Dwight, A. Berdeja, E. E. Swayze, M. E. Jung and P. P. Seth, J. Org. Chem., 2014, 79, 8877-8881. S. Karkare and D. Bhatnagar, Appl. Microbiol. Biotechnol., 2006, 71, 575-586.

J. Summerton, Advances in Applied Biotechnology Series, 1989, 2, 71-80.

60.

61.

J. O. Hoberg, J. Org. Chem., 1997, 62, 6615-6618.

C. S. Madsen, S. Witzke, P. Kumar, K. Negi, P. K. Sharma, M. Petersen and P. Nielsen, Chem.-Eur. J., 2012, 18, 74347442.

62. M. Hornum, P. K. Sharma, C. Reslow-Jacobsen, P. Kumar, M. Petersen and P. Nielsen, Chem. Commun., 2017, 53, 9717-9720. 
63.

K. Beck, C. Reslow-Jacobsen, M. Hornum, C. Henriksen and P. Nielsen, Bioorg. Med. Chem. Lett., 2019, 29, 740743.

64. K. M. Beck, M. B. Krogh, M. Hornum, P. T. Ludford, Y. Tor and P. Nielsen, Org. Biomol. Chem., 2020, 18, 7213-7223.

65. T. Carell, C. Brandmayr, A. Hienzsch, M. Muller, D. Pearson, V. Reiter, I. Thoma, P. Thumbs and M. Wagner, Angew. Chem. Int. Ed., 2012, 51, 7110-7131.

66. M. Hocek, Accounts Chem. Res., 2019, 52, 1730-1737.

67. B. T. Le, M. Hornum, P. K. Sharma, P. Nielsen and R. N. Veedu, RSC Adv., 2017, 7, 54542-54545.

68. H. Peacock, A. Kannan, P. A. Beal and C. J. Burrows, J. Org. Chem., 2011, 76, 7295-7300.

69. M. Kimoto and I. Hirao, ACS Synth. Biol., 2017, 6, 19441951.

70.

W. Xu, K. M. Chan and E. T. Kool, Nat. Chem., 2017, 9, 1043-1055.

71. A. R. Rovira, A. Fin and Y. Tor, J. Am. Chem. Soc., 2015, 137, 14602-14605.

72. A. F. Fuchtbauer, M. S. Wranne, M. Bood, E. Weis, P. Pfeiffer, J. R. Nilsson, A. Dahlen, M. Grotli and L. M. Wilhelmsson, Nucleic Acids Res., 2019, 47, 9990-9997.

73. M. Hocek and M. Fojta, Chem. Soc. Rev., 2011, 40, 58025814.

74. A. Simonova, I. Magriñá, V. Sýkorová, R. Pohl, M. Ortiz, L. Havran, M. Fojta, C. K. O'Sullivan and M. Hocek, Chem.Eur. J., 2020, 26, 1286-1291.

75. Z. H. Qiu, L. H. Lu, X. Jian and C. He, J. Am. Chem. Soc., 2008, 130, 14398-14399.

76. Z. Vanikova, M. Janouskova, M. Kambova, L. Krasny and M. Hocek, Chem. Sci., 2019, 10, 3937-3942.

77. D. A. Malyshev and F. E. Romesberg, Angew. Chem. Int. Ed., 2015, 54, 11930-11944.

78. M. Kimoto, R. Yamashige, K. Matsunaga, S. Yokoyama and I. Hirao, Nat. Biotechnol., 2013, 31, 453-457.

79. L. Q. Zhang, Z. Y. Yang, K. Sefah, K. M. Bradley, S. Hoshika, M. J. Kim, H. J. Kim, G. Z. Zhu, E. Jimenez, S. Cansiz, I. T. Teng, C. Champanhac, C. McLendon, C. Liu, W. Zhang, D. L. Gerloff, Z. Huang, W. H. Tan and S. A. Benner, J. Am. Chem. Soc., 2015, 137, 6734-6737.

80. K. L. Seley-Radtke and M. K. Yates, Antiviral Res., 2018, 154, 66-86.

81. L. P. Jordheim, D. Durantel, F. Zoulim and C. Dumontet, Nat. Rev. Drug Discov., 2013, 12, 447-464.

82. P. Herdewijn, Antisense Nucleic Acid Drug Dev., 2000, 10, 297-310.

83. E. De Clercq, J. Descamps, P. De Somer, P. J. Barr, A. S. Jones and R. T. Walker, Proc. Natl. Acad. Sci. U.S.A., 1979, 76, 2947-2951.

84. H. Vorbruggen, K. Krolikiewicz and B. Bennua, Chem. Ber.Recl., 1981, 114, 1234-1255.

85. G. D. Daves, Accounts Chem. Res., 1990, 23, 201-206.

86. K. W. Wellington and S. A. Benner, Nucleosides Nucleotides Nucleic Acids, 2006, 25, 1309-1333.

87. L. A. Agrofoglio, I. Gillaizeau and Y. Saito, Chem. Rev., 2003, 103, 1875-1916.

88. B. Roy, A. Depaix, C. Perigaud and S. Peyrottes, Chem. Rev., 2016, 116, 7854-7897.

89. M. Hoffer, R. Duschinsky, J. J. Fox and N. Yung, J. Am. Chem. Soc., 1959, 81, 4112-4113.

90. J. Lietard and C. J. Leumann, J. Org. Chem., 2012, 77, 4566-4577.
91. A. Sniady, M. W. Bedore and T. F. Jamison, Angew. Chem. Int. Ed., 2011, 50, 2155-2158.

92. C. Y. Liang, W. H. Ju, S. J. Ding, H. Sun and G. N. Mao, Molecules, 2017, 22.

93. P. H. Li, H. Q. He, Y. Q. Zhang, R. Yang, L. L. Xu, Z. X. Chen, Y. Y. Huang, L. M. Bao and G. Z. Xiao, Nat. Commun., 2020, 11, 10.

94. A. B. Neef and N. W. Luedtke, ChemBioChem, 2014, 15, 789-793.

95. M. Shelbourne, T. Brown, A. H. El-Sagheer and T. Brown, Chem. Commun., 2012, 48, 11184-11186.

96. S. Arndt and H. A. Wagenknecht, Angew. Chem. Int. Ed., 2014, 53, 14580-14582.

A. M. Pyka, C. Domnick, F. Braun and S. Kath-Schorr, Bioconjugate Chem., 2014, 25, 1438-1443.

I. Ivancová, R. Pohl, M. Hubálek and M. Hocek, Angew. Chem. Int. Ed., 2019, 58, 13345-13348.

J. C. Chaput, P. Herdewijn and M. Hollenstein, ChemBioChem, 2020, DOI: 10.1002/cbic.201900725, 5.

J. C. Chaput and P. Herdewijn, Angew. Chem. Int. Ed., 2019, 58, 11570-11572.

101. Q. J. Zhang, J. S. Sun, Y. G. Zhu, F. Y. Zhang and B. Yu, Angew. Chem. Int. Ed., 2011, 50, 4933-4936.

102. H. P. Mattelaer, A. S. Van Hool, F. de Jong, M. Van der Auweraer, L. Van Meervelt, W. Dehaen and P. Herdewijn, Eur. J. Org. Chem., 2020, DOI: 10.1002/ejoc.202000563, doi: 10.1002/ejoc.202000563.

103. E. Perez, P. A. Sanchez-Murcia, J. Jordaan, M. D. Blanco, J. M. Mancheno, F. Gago and J. Fernandez-Lucas, ChemCatChem, 2018, 10, 4406-4416.

104. S. Vichier-Guerre, T. R. C. Ku, S. Pochet and K. L. SeleyRadtke, ChemBioChem, 2020, 21, 1412-1417.

105. J. Del Arco, A. Mills, F. Gago and J. Fernandez-Lucas, ChemBioChem, 2019, 20, 2996-3000.

106. F. Seela, V. R. Sirivolu and P. Chittepu, Bioconjugate Chem., 2008, 19, 211-224.

107. J. A. Brazier, T. Shibata, J. Townsley, B. F. Taylor, E. Frary, N. H. Williams and D. M. Williams, Nucleic Acids Res., 2005, 33, 1362-1371.

108. J. Dadova, P. Vidlakova, R. Pohl, L. Havran, M. Fojta and M. Hocek, J. Org. Chem., 2013, 78, 9627-9637.

109. M. Hollenstein, Org. Biomol. Chem., 2013, 11, 5162-5172.

110. S. Jäger, G. Rasched, H. Kornreich-Leshem, M. Engeser, O. Thum and M. Famulok, J. Am. Chem. Soc., 2005, 127, 15071-15082.

111. M. B. Walunj, A. A. Tanpure and S. G. Srivatsan, Nucleic Acids Res., 2018, 46.

112. K. H. Shaughnessy, Molecules, 2015, 20, 9419-9454.

113. D. Ukale, V. S. Shinde and T. Lonnberg, Chem.-Eur. J., 2016, 22, 7917-7923.

114. F. Seela and X. H. Peng, J. Org. Chem., 2006, 71, 81-90.

115. P. Leonard, D. Kondhare, X. Jentgens, C. Daniliuc and F. Seela, J. Org. Chem., 2019, 84, 13313-13328.

116. D. Ganz, D. Harijan and H.-A. Wagenknecht, RSC Chem. Biol., 2020, DOI: 10.1039/DOCB00047G, doi: 10.1039/D1030CB00047G.

P. Röthlisberger, F. Levi-Acobas and M. Hollenstein, Bioorg. Med. Chem. Lett., 2017, 27, 897-900.

N. Raddaoui, S. Stazzoni, L. Mockl, B. Viverge, F. Geiger, H. Engelke, C. Brauchle and T. Carell, ChemBioChem, 2017, 18, 1716-1720. 
119. F. Pfeiffer, F. Tolle, M. Rosenthal, G. M. Brandle, J. Ewers and G. Mayer, Nat. Protoc., 2018, 13, 1153-1180.

120. S. Croce, S. Serdjukow, T. Carell and T. Frischmuth, ChemBioChem, 2020, 21, 1641-1646.

121. T. Triemer, A. Messikommer, S. M. K. Glasauer, J. Alzeer M. H. Paulisch and N. W. Luedtke, Proc. Natl. Acad. Sci. U.S.A., 2018, 115, E1366-E1373.

122. J. M. Baskin, J. A. Prescher, S. T. Laughlin, N. J. Agard, P. V. Chang, I. A. Miller, A. Lo, J. A. Codelli and C. R. Bertozzi, Proc. Natl. Acad. Sci. U.S.A., 2007, 104, 16793-16797.

123. N. J. Agard, J. A. Prescher and C. R. Bertozzi, J. Am. Chem. Soc., 2004, 126, 15046-15047.

124. M. A. Tasdelen and Y. Yagci, Angew. Chem. Int. Ed., 2013, 52, 5930-5938.

125. B. L. Oliveira, Z. Guo and G. J. L. Bernardes, Chem. Soc. Rev., 2017, 46, 4895-4950.

126. P. E. Nielsen, M. Egholm, R. H. Berg and O. Buchardt, Science, 1991, 254, 1497-1500.

127. E. Cadoni, A. Manicardi and A. Madder, Molecules, 2020, 25, 1296.

128. M. Frenkel-Pinter, M. Samanta, G. Ashkenasy and L. J. Leman, Chem. Rev., 2020, 120, 4707-4765.

129. W. H. Zhou, L. Hu, L. M. Ying, Z. Zhao, P. K. Chu and X. F. Yu, Nat. Commun., 2018, 9.

130. J. P. Salvi, N. Walchshofer and J. Paris, Tetrahedron Lett., 1994, 35, 1181-1184.

131. K. L. Dueholm, M. Egholm, C. Behrens, L. Christensen, H. F. Hansen, T. Vulpius, K. H. Petersen, R. H. Berg, P. E. Nielsen and O. Buchardt, J. Org. Chem., 1994, 59, 57675773.

132. J. Saarbach, D. Masi, C. Zambaldo and N. Winssinger, Bioorg. Med. Chem., 2017, 25, 5171-5177.

133. C. Baldoli, S. Maiorana, E. Licandro, G. Zinzalla and D. Perdicchia, Org. Lett., 2002, 4, 4341-4344.

134. L. L. Zhang, A. Peritz and E. Meggers, J. Am. Chem. Soc., 2005, 127, 4174-4175.

135. H. Kashida, K. Murayama, T. Toda and H. Asanuma, Angew. Chem. Int. Ed., 2011, 50, 1285-1288.

136. M. Suchy and R. H. E. Hudson, J. Org. Chem., 2014, 79, 3336-3347.

137. B. Jash and J. Müller, Angew. Chem. Int. Ed., 2018, 57, 9524-9527.

138. O. Bande, R. Abu El Asrar, D. Braddick, S. Dumbre, V. Pezo, G. Schepers, V. B. Pinheiro, E. Lescrinier, P. Holliger, P. Marliere and P. Herdewijn, Chem.-Eur. J., 2015, 21, 50095022.

139. M. R. Dunn, C. M. McCloskey, P. Buckley, K. Rhea and J. C. Chaput, J. Am. Chem. Soc., 2020, 142, 7721-7724.

140. B. R. Babu and J. Wengel, Chem. Commun., 2001, DOI: 10.1039/b106065c, 2114-2115.

141. M. E. Ostergaard, P. Kumar, B. Baral, D. J. Raible, T. S. Kumar, B. A. Anderson, D. C. Guenther, L. Deobald, A. J. Paszczynski, P. K. Sharma and P. J. Hrdlicka, ChemBioChem, 2009, 10, 2740-2743.

142. A. B. Neef and N. W. Luedtke, Proc. Natl. Acad. Sci. U.S.A., 2011, 108, 20404-20409.

143. H. Mei and J. C. Chaput, Chem. Commun., 2018, 54, 12371240.

144. F. Levi-Acobas, A. Katolik, P. Rothlisberger, T. Cokelaer, I. Sarac, M. J. Damha, C. J. Leumann and M. Hollenstein, Org. Biomol. Chem., 2019, 17, 8083-8087.
145.

146.

147.

148.

149.

150.

151.

152.

153.

154.

155.

156.

157.

158.

159.

160.

161.

162.

163.

164.

165.

165.

166.

167.

168.

169.

D. B. Gophane, B. Endeward, T. F. Prisner and S. T. Sigurdsson, Org. Biomol. Chem., 2018, 16, 816-824.

M. Menzi, B. Wild, U. Pradere, A. L. Malinowska, A. Brunschweiger, H. L. Lightfoot and J. Hall, Chem.-Eur. J., 2017, 23, 14221-14230.

R. L. Letsinger and W. B. Lunsford, J. Am. Chem. Soc., 1976, 98, 3655-3661.

S. L. Beaucage and M. H. Caruthers, Tetrahedron Lett., 1981, 22, 1859-1862.

D. Vlaho and M. J. Damha, Curr. Protoc. Nucleic Acid Chem., 2018, d73, e53.

B. L. Gaffney and R. A. Jones, Tetrahedron Lett., 1988, 29 , 2619-2622.

S. Roy and M. Caruthers, Molecules, 2013, 18, 1426814284.

R. A. Hughes and A. D. Ellington, Cold Spring Harbor Perspect. Biol., 2017, 9, 17.

H. Lönnberg, Beilstein J. Org. Chem., 2017, 13, 1368-1387.

A. H. El-Sagheer and T. Brown, Proc. Natl. Acad. Sci. U.S.A., 2010, 107, 15329-15334.

J. G. Lackey, D. Mitra, M. M. Somoza, F. Cerrina and M. J. Damha, J. Am. Chem. Soc., 2009, 131, 8496-8502.

A. Biscans, M. Bos, A. R. Martin, N. Ader, G. Sczakiel, J. J. Vasseur, C. Dupouy and F. Debart, ChemBioChem, 2014, 15, 2674-2679.

G. Creusen, C. O. Akintayo, K. Schumann and A. Walther, J. Am. Chem. Soc., 2020, DOI: 10.1021/jacs.0c05488, 10.1021/jacs.1020c05488.

M. S. Algahtani, D. J. Scurr, A. L. Hook, D. G. Anderson, R. S. Langer, J. C. Burley, M. R. Alexander and M. C. Davies, J. Control. Release, 2014, 190, 115-126.

S. Kosuri, N. Eroshenko, E. M. LeProust, M. Super, J. Way, J. B. Li and G. M. Church, Nat. Biotechnol., 2010, 28, 1295U1108.

X. L. Shen and D. R. Corey, Nucleic Acids Res., 2018, 46, 1584-1600.

F. Eckstein, Nucl. Acid Ther., 2014, 24, 374-387.

M. Hyjek-Skladanowska, T. A. Vickers, A. Napiorkowska, B. A. Anderson, M. Tanowitz, S. T. Crooke, X. H. Liang, P. P. Seth and M. Nowotny, J. Am. Chem. Soc., 2020, 142, 74567468.

P. M. J. Burgers and F. Eckstein, Tetrahedron Lett., 1978 , 3835-3838.

R. P. Iyer, W. Egan, J. B. Regan and S. L. Beaucage, J. Am. Chem. Soc., 1990, 112, 1253-1254.

N. Iwamoto, D. C. D. Butler, N. Svrzikapa, S. Mohapatra, I. Zlatev, D. W. Y. Sah, Meena, S. M. Standley, G. L. Lu, L. H. Apponi, M. Frank-Kamenetsky, J. J. Zhang, C. Vargeese and G. L. Verdine, Nat. Biotechnol., 2017, 35, 845-851l.

M. A. Islam, A. Fujisaka, J. Kawakami, T. Yamaguchi and S. Obika, Bioorg. Med. Chem. Lett., 2020, 30, 4.

M. Li, H. L. Lightfoot, F. Halloy, A. L. Malinowska, C. Berk, A. Behera, D. Schumperli and J. Hall, Chem. Commun., 2017, 53, 541-544.

H. Jahns, M. Roos, J. Imig, F. Baumann, Y. L. Wang, R. Gilmour and J. Hall, Nat. Commun., 2015, 6.

K. W. Knouse, J. N. deGruyter, M. A. Schmidt, B. Zheng, J. C. Vantourout, C. Kingston, S. E. Mercer, I. M. McDonald, R. E. Olson, Y. Zhu, C. Hang, J. Zhu, C. X. Yuan, Q. G. Wang, P. Park, M. D. Eastgate and P. S. Baran, Science, 2018, 361, 1234-1238. 
170. J. Nielsen, W. K. D. Brill and M. H. Caruthers, Tetrahedron Lett., 1988, 29, 2911-2914.

171. W. S. Marshall and M. H. Caruthers, Science, 1993, 259, 1564-1569.

172. N. D. Abeydeera, M. Egli, N. Cox, K. Mercier, J. N. Conde, P. S. Pallan, D. M. Mizurini, M. Sierant, F. E. Hibti, T. Hassell, T. Z. Wang, F. W. Liu, H. M. Liu, C. Martinez, A. K. Sood, T. P. Lybrand, C. Frydman, R. Q. Monteiro, R. H. Gomer, B. Nawrot and X. B. Yang, Nucleic Acids Res., 2016, 44, 8052-8064.

173. S. Y. Wu, X. B. Yang, K. M. Gharpure, H. Hatakeyama, M. Egli, M. H. McGuire, A. S. Nagaraja, T. M. Miyake, R. Rupaimoole, C. V. Pecot, M. Taylor, S. Pradeep, M. Sierant, C. Rodriguez-Aguayo, H. J. Choi, R. A. Previs, G. N. Armaiz-Pena, L. Huang, C. Martinez, T. Hassell, C. Ivan, V. Sehgal, R. Singhania, H. D. Han, C. Su, J. H. Kim, H. J. Dalton, C. Kovvali, K. Keyomarsi, N. A. J. McMillan, W. W. Overwijk, J. S. Liu, J. S. Lee, K. A. Baggerly, G. LopezBerestein, P. T. Ram, B. Nawrot and A. K. Sood, Nat. Commun., 2014, 5, 12.

174. D. S. Sergueev and B. R. Shaw, J. Am. Chem. Soc., 1998, 120, 9417-9427.

175. J. F. Chen, Y. R. Baker, A. Brown, A. H. El-Sagheer and T. Brown, Chem. Sci., 2018, 9, 8110-8120.

176. A. H. El-Sagheer and T. Brown, Chem. Commun., 2011, 47, 12057-12058.

177. A. H. El-Sagheer, A. P. Sanzone, R. Gao, A. Tavassoli and T. Brown, Proc. Natl. Acad. Sci. U.S.A., 2011, 108, 1133811343.

178. F. Vandendriessche, M. Voortmans, J. Hoogmartens, A. Vanaerschot and P. Herdewijn, Bioorg. Med. Chem. Lett., 1993, 3, 193-198.

179. K. Skakuj, K. E. Bujold and C. A. Mirkin, Curr. Protoc. Nucleic Acid Chem., 2020, 81, e110.

180. G. B. Cserep, O. Demeter, E. Batzner, M. Kallay, H. A. Wagenknecht and P. Kele, Synthesis, 2015, 47, 2738-2744.

181. K. J. Westerich, K. S. Chandrasekaran, T. Gross-Thebing, N. Kueck, E. Raz and A. Rentmeister, Chem. Sci., 2020, 11, 3089-3095.

182. A. H. El-Sagheer and T. Brown, Chem. Soc. Rev., 2010, 39, 1388-1405.

183. C. Y. Huang, M. Yague-Capilla, D. Gonzalez-Pacanowska and Z. F. Chang, Sci Rep, 2020, 10, 10.

184. J. C. Jewett and C. R. Bertozzi, Chem. Soc. Rev., 2010, 39, 1272-1279.

185. K. Krell, D. Harijan, D. Ganz, L. Doll and H. A. Wagenknecht, Bioconjugate Chem., 2020, 31, 990-1011.

186. E. Kim and H. Koo, Chem. Sci., 2019, 10, 7835-7851.

187. L. Anhauser, S. Huwel, T. Zobel and A. Rentmeister, Nucleic Acids Res., 2019, 47, 12.

188. J. T. George, M. Azhar, M. Aich, D. Sinha, U. B. Ambi, S. Maiti, D. Chakraborty and S. G. Srivatsan, J. Am. Chem. Soc., 2020, 142, 13954-13965.

189. D. N. Kamber, Y. Liang, R. J. Blizzard, F. Liu, R. A. Mehl, K. N. Houk and J. A. Prescher, J. Am. Chem. Soc., 2015, 137, 8388-8391.

190. J. Seckute, J. Yang and N. K. Devaraj, Nucleic Acids Res., 2013, 41.

191. U. Rieder and N. W. Luedtke, Angew. Chem. Int. Ed., 2014, 53, 9168-9172.
192.

193.

194.

195.

196.

197.

198.

199.

200.

201.

202.

203.

204.

205.

206.

207.

208.

209.

210.

\section{1.}

212.

213.

214.

215.

216.

217.

218.

219.
M. Merkel, S. Arndt, D. Ploschik, G. B. Cserep, U. Wenge, P. Kele and H. A. Wagenknecht, J. Org. Chem., 2016, 81, 7527-7538.

F. Eggert and S. Kath-Schorr, Chem. Commun., 2016, 52, 7284-7287.

M. L. Winz, E. C. Linder, T. Andre, J. Becker and A. Jäschke, Nucleic Acids Res., 2015, 43.

U. Reisacher, D. Ploschik, F. Ronicke, G. B. Cserep, P. Kele and H. A. Wagenknecht, Chem. Sci., 2019, 10, 4032-4037.

I. Nikic, G. E. Girona, J. H. Kang, G. Paci, S. Mikhaleva, C. Koehler, N. V. Shymanska, C. V. Santos, D. Spitz and E. A. Lemke, Angew. Chem. Int. Ed., 2016, 55, 16172-16176.

G. Clavé, E. Dursun, J. J. Vasseur and M. Smietana, Org. Lett., 2020, 22, 1914-1918.

Y. X. Wu, G. L. Guo, J. D. Zheng, D. Xing and T. Zhang, ACS Sens., 2019, 4, 44-51.

D. T. S. Rijkers, R. Merkx, C. B. Yim, A. J. Brouwer and R. M. J. Liskamp, J. Pept. Sci., 2010, 16, 1-5.

A. Deiters, Curr. Opin. Chem. Biol., 2009, 13, 678-686.

L. Wu, F. Pei, J. H. Zhang, J. Z. Wu, M. K. Feng, Y. Wang, H. W. Jin, L. R. Zhang and X. J. Tang, Chem.-Eur. J., 2014, 20, 12114-12122.

X. Y. Liu and T. F. Zhu, Cell Chem. Biol., 2018, 25, 11511156.e1153.

A. Kadina, A. M. Kietrys and E. T. Kool, Angew. Chem. Int. Ed., 2018, 57, 3059-3063.

D. Tan and T. Friščić, Eur. J. Org. Chem., 2018, 2018, 1833.

T. Friščić, C. Mottillo and H. M. Titi, Angew. Chem. Int. Ed., 2020, 59, 1018-1029.

O. Eguaogie, J. S. Vyle, P. F. Conlon, M. A. Gîlea and Y. Liang, Beilstein J. Org. Chem., 2018, 14, 955-970.

N. Giri, C. Bowen, J. S. Vyle and S. L. James, Green Chem., 2008, 10, 627-628.

M. VictoriaáBerberian, Org. Biomol. Chem., 2011, 9, 64966497.

O. Eguaogie, L. A. Cooke, P. M. Martin, F. Ravalico, L. P. Conway, D. R. Hodgson, C. J. Law and J. S. Vyle, Org. Biomol. Chem., 2016, 14, 1201-1205.

O. Eguaogie, P. F. Conlon, F. Ravalico, J. S. Sweet, T. B. Elder, L. P. Conway, M. E. Lennon, D. R. Hodgson and J. S. Vyle, Beilstein J. Org. Chem., 2017, 13, 87-92.

K. Crossey, C. Hardacre and M. E. Migaud, Chem. Commun., 2012, 48, 11969-11971.

C. Hardacre, H. Huang, S. L. James, M. E. Migaud, S. E. Norman and W. R. Pitner, Chem. Commun., 2011, 47, 5846-5848.

J. D. Thorpe, D. O'Reilly, T. Friscic and M. J. Damha, Chem.-Eur. J., 2020, 26, 8857-8861.

C. B. Reese and H. Yan, J. Chem. Soc.-Perkin Trans. 1, 2002, 2619-2633.

V. Borsenberger, M. Kukwikila and S. Howorka, Org. Biomol. Chem., 2009, 7, 3826-3835.

G. Houlihan, S. Arangundy-Franklin, B. T. Porebski, N. Subramanian, A. I. Taylor and P. Holliger, Nat. Chem., 2020, 12, 14.

K. Sakthivel and C. F. Barbas, Angew. Chem. Int. Ed., 1998, 37, 2872-2875.

T. A. Coulther, H. R. Stern and P. J. Beuning, Trends Biotechnol., 2019, 37, 1091-1103.

B. Bauwens, J. Rozenski, P. Herdewijn and J. Robben, ChemBioChem, 2018, 19, 2410-2420. 
220. A. F. Gardner, K. M. Jackson, M. M. Boyle, J. A. Buss, V. Potapov, A. M. Gehring, K. M. Zatopek, I. R. Correa, J. L. Ong and W. E. Jack, Front. Mol. Biosci., 2019, 6, 9.

221. O. A. Zasedateleva, S. A. Surzhikov, V. E. Shershov, R. A. Miftakhov, D. A. Yurasov, V. E. Kuznetsova and A. V. Chudinov, Bioorganic Chem., 2020, 99, 8.

222. H. M. Kropp, K. Diederichs and A. Marx, Angew. Chem. Int. Ed., 2019, 58, 5457-5461.

223. M. Kuba, T. Kraus, R. Pohl and M. Hocek, Chem.-Eur. J., 2020, 26, 11950-11954.

224. C. G. Peng and M. J. Damha, J. Am. Chem. Soc., 2007, 129, 5310-5311.

225. H. Cahová, A. Panattoni, P. Kielkowski, J. Fanfrlík and M. Hocek, ACS Chem. Biol., 2016, 11, 3165-3171.

226. S. Obeid, A. Baccaro, W. Welte, K. Diederichs and A. Marx, Proc. Natl. Acad. Sci. U.S.A., 2010, 107, 21327-21331.

227. M. Ondruš, V. Sýkorová, L. Bednárová, R. Pohl and M. Hocek, Nucleic Acids Res., 2020, 48, 11982-11993.

228. P. Capek, H. Cahova, R. Pohl, M. Hocek, C. Gloeckner and A. Marx, Chem.-Eur. J., 2007, 13, 6196-6203.

229. J. Jakubovska, D. Tauraite, L. Birstonas and R. Meskys, Nucleic Acids Res., 2018, 46, 5911-5923.

230. Y. W. Cheung, P. Röthlisberger, A. E. Mechaly, P. Weber, F. Levi-Acobas, Y. Lo, A. W. C. Wong, A. B. Kinghorn, A. Haouz, G. P. Savage, M. Hollenstein and J. A. Tanner, Proc. Natl. Acad. Sci. U.S.A., 2020, 117, 16790-16798.

231. A. Baccaro, A. L. Steck and A. Marx, Angew. Chem. Int. Ed., 2012, 51, 254-257.

232. H. Hoshino, Y. Kasahara, H. Fujita, M. Kuwahara, K. Morihiro, S. Tsunoda and S. Obika, Bioorg. Med. Chem. Lett., 2016, 26, 530-533.

233. S. E. Lee, A. Sidorov, T. Gourlain, N. Mignet, S. J. Thorpe, J. A. Brazier, M. J. Dickman, D. P. Hornby, J. A. Grasby and D. M. Williams, Nucleic Acids Res., 2001, 29, 1565-1573.

234. P. Röthlisberger, F. Levi-Acobas, I. Sarac, R. Ricoux, J.-P. Mahy, P. Herdewijn, P. Marlière and M. Hollenstein, Tetrahedron Lett., 2018, 59, 4241-4244.

235. A. I. Taylor, G. Houlihan and P. Holliger, Cold Spring Harbor Perspect. Biol., 2019, 11, 15.

236. R. N. Veedu, B. Vester and J. Wengel, ChemBioChem, 2007, 8, 490-492.

237. S. Diafa, D. Evequoz, C. J. Leumann and M. Hollenstein, Chem.-Asian J., 2017, 12, 1347-1352.

238. J. K. Ichida, A. Horhota, K. Y. Zou, L. W. McLaughlin and J. W. Szostak, Nucleic Acids Res., 2005, 33, 5219-5225.

239. M. R. Dunn and J. C. Chaput, ChemBioChem, 2016, 17, 1804-1808.

240. A. Shivalingam, A. E. S. Tyburn, A. H. El-Sagheer and T. Brown, J. Am. Chem. Soc., 2017, 139, 1575-1583.

241. M. Renders, S. Dumbre, M. Abramov, D. Kestemont, L. Margamuljana, E. Largy, C. Cozens, J. Vandenameele, V. B. Pinheiro, D. Toye, J. M. Frere and P. Herdewijn, Nucleic Acids Res., 2019, 47, 2160-2168.

242. T. Kent, P. A. Mateos-Gomez, A. Sfeir and R. T. Pomerantz, Elife, 2016, 5, e13740.

243. I. Sarac and M. Hollenstein, ChemBioChem, 2019, 20, 860871.

244. P. Röthlisberger, F. Levi-Acobas, I. Sarac, B. Baron, P. England, P. Marliere, P. Herdewijn and M. Hollenstein, Chem. Commun., 2017, 53, 13031-13034.

245. E. K. Jang, R. G. Son and S. P. Pack, Nucleic Acids Res., 2019, 47
246.

247.

248.

249.

250.

251.

252.

253.

K. Vastmans, J. Rozenski, A. Van Aerschot and P. Herdewijn, Biochim. Biophys. Acta-Protein Struct. Molec. Enzym., 2002, 1597, 115-122.

M. Eisenstein, Nat. Biotechnol., 2020, 38, 1113-1115.

M.-L. Winz, E. C. Linder, J. Becker and A. Jäschke, Chem. Commun., 2018, 54, 11781-11784.

M. G. Mohsen, D. B. Ji and E. T. Kool, Nucleic Acids Res., 2019, 47, 9495-9501.

J. Attwater, A. Raguram, A. S. Morgunov, E. Gianni and P. Holliger, Elife, 2018, 7, e35255.

S. P. Sau and J. C. Chaput, Bioorg. Med. Chem. Lett., 2016, 26, 3271-3273.

E. Eremeeva, M. Abramov, L. Margamuljana, J. Rozenski, V. Pezo, P. Marliere and P. Herdewijn, Angew. Chem. Int. Ed., 2016, 55, 7515-7519.

S. Jäger and M. Famulok, Angew. Chem. Int. Ed., 2004, 43 3337-3340.

254. S. Hoshika, N. A. Leal, M. J. Kim, M. S. Kim, N. B. Karalkar, H. J. Kim, A. M. Bates, N. E. Watkins, H. A. SantaLucia, A. J. Meyer, S. DasGupta, J. A. Piccirilli, A. D. Ellington, J. SantaLucia, M. M. Georgiadis and S. A. Benner, Science, 2019, 363, 884-887.

255. A. V. Cherepanov, E. V. Doroshenko, J. Matysik, S. de Vries and H. J. M. de Groot, Proc. Natl. Acad. Sci. U.S.A., 2008, 105, 8563-8568.

256. S. Shuman, J. Biol. Chem., 2009, 284, 17365-17369.

257. Y. Oda, J. Chiba, F. Kurosaki, Y. Yamade and M. Inouye, ChemBioChem, 2019, 20, 1945-1952.

258. D. Loakes, A. VanAerschot, D. M. Brown and F. Hill, Nucleosides Nucleotides, 1996, 15, 1891-1904.

259. D. Kestemont, M. Renders, P. Leonczak, M. Abramov, G. Schepers, V. B. Pinheiro, J. Rozenski and P. Herdewijn, Chem. Commun., 2018, 54, 6408-6411.

260. C. M. McCloskey, J. Y. Liao, S. Bala and J. C. Chaput, ACS Synth. Biol., 2019, 8, 282-286.

261. E. Csibra, M. Renders and V. B. Pinheiro, ChemBioChem, 2020, DOI: 10.1002/cbic.202000203, 10.1002/cbic.202000203.

262. M. Vanmeert, J. Razzokov, M. U. Mirza, S. D. Weeks, G. Schepers, A. Bogaerts, J. Rozenski, M. Froeyen, P. Herdewijn, V. B. Pinheiro and E. Lescrinier, Nucleic Acids Res., 2019, 47, 7130-7142.

263. L. E. Kotler, D. Zevinsonkin, I. A. Sobolev, A. D. Beskin and L. E. Ulanovsky, Proc. Natl. Acad. Sci. U.S.A., 1993, 90, 4241-4245.

264. R. Hili, J. Niu and D. R. Liu, J. Am. Chem. Soc., 2013, 135, 98-101.

C. Guo, D. H. Kong, Y. Lei and R. Hili, Synlett, 2018, 29, 1405-1414.

266. D. H. Kong, Y. Lei, W. Yeung and R. Hili, Angew. Chem. Int. Ed., 2016, 55, 13164-13168.

267. D. H. Kong, W. Yeung and R. Hili, J. Am. Chem. Soc., 2017, 139, 13977-13980.

P. A. Lichtor, Z. Chen, N. H. Elowe, J. C. Chen and D. R. Liu, Nat. Chem. Biol., 2019, 15, 419-426.

Z. Chen, P. A. Lichtor, A. P. Berliner, J. C. Chen and D. R. Liu, Nat. Chem., 2018, 10, 420-427.

Y. Lei, J. Washington and R. Hili, Org. Biomol. Chem., 2019, 17, 1962-1965.

271. S. D. Knutson, M. M. Korn, R. P. Johnson, L. R. Monteleone, D. M. Dailey, C. S. Swenson, P. A. Beal and J. M. Heemstra, Chem.-Eur. J., 2020, 26, 9874-9878. 
272. J. Spiegel, S. Adhikari and S. Balasubramanian, Trends Chem., 2020, 2, 123-136.

273. S. Modi, A. H. Wani and Y. Krishnan, Nucleic Acids Res., 2006, 34, 4354-4363.

274. C. E. Kaiser, N. A. Van Ert, P. Agrawal, R. Chawla, D. Yang and L. H. Hurley, J. Am. Chem. Soc., 2017, 139, 8522-8536.

275. S. Buchini and C. J. Leumann, Curr. Opin. Chem. Biol., 2003, 7, 717-726.

276. M. Duca, P. Vekhoff, K. Oussedik, L. Halby and P. B. Arimondo, Nucleic Acids Res., 2008, 36, 5123-5138.

277. J. A. Brown, Wiley Interdiscip. Rev. RNA, 2020, 11, e1598.

278. F. Wang, X. Liu and I. Willner, Angew. Chem. Int. Ed. 2015, 54, 1098-1129.

279. L.-X. Wang, J.-F. Xiang and Y.-L. Tang, Adv. Synth. Catal., 2015, 357, 13-20.

280. O. Doluca, J. M. Withers and V. V. Filichev, Chem. Rev., 2013, 113, 3044-3083.

281. J. Sagi, J. Nucleic Acids, 2017, 2017, 1-45.

282. M. L. Bochman, K. Paeschke and V. A. Zakian, Nat. Rev. Genet., 2012, 13, 770-780.

283. X. Liu, I. C. M. Kwan, S. Wang and G. Wu, Org. Lett., 2006, 8, 3685-3688.

284. M. Koizumi, K. Akahori, T. Ohmine, S. Tsutsumi, J. Sone, T. Kosaka, M. Kaneko, S. Kimura and K. Shimada, Bioorg. Med. Chem. Lett., 2000, 10, 2213-2216.

285. A. Virgilio, L. Petraccone, V. Vellecco, M. Bucci, M. Varra, C. Irace, R. Santamaria, A. Pepe, L. Mayol, V. Esposito and A. Galeone, Nucleic Acids Res., 2015, 43, 10602-10611.

286. A. A. Tanpure and S. G. Srivatsan, Nucleic Acids Res., 2015, 43, e149-e149.

287. C. J. Lech and A. T. Phan, Nucleic Acids Res., 2017, 45, 6265-6274.

288. F. Seela, C. Wei and A. Melenewski, Nucleic Acids Res., 1996, 24, 4940-4945.

289. N. An, A. M. Fleming and C. J. Burrows, J. Am. Chem. Soc., 2013, 135, 8562-8570.

290. A. T. Phan, V. Kuryavyi, K. N. Luu and D. J. Patel, Nucleic Acids Res., 2007, 35, 6517-6525.

291. K. L. Fadock, R. A. Manderville, P. Sharma and S. D. Wetmore, Org. Biomol. Chem., 2016, 14, 4409-4419.

292. A. Dumas and N. W. Luedtke, Nucleic Acids Res., 2011, 39, 6825-6834.

293. L. Haase, B. Karg and K. Weisz, ChemBioChem, 2019, 20, 985-993.

294. A. Virgilio, V. Esposito, A. Randazzo, L. Mayol and A. Galeone, Nucleic Acids Res., 2005, 33, 6188-6195.

295. J. Dickerhoff and K. Weisz, Angew. Chem. Int. Ed., 2015, 54, 5588-5591.

296. C. G. Peng and M. J. Damha, Nucleic Acids Res., 2007, 35, 4977-4988.

297. C. J. Lech, Z. Li, B. Heddi and A. T. Phan, Chem. Commun., 2012, 48, 11425-11427.

298. A. T. Phan, K. N. Luu and D. J. Patel, Nucleic Acids Res., 2006, 34, 5715-5719.

299. A. Randazzo, V. Esposito, O. Ohlenschläger, R. Ramachandran and L. Mayol, Nucleic Acids Res., 2004, 32, 3083-3092.

300. D. Pradhan, L. H. Hansen, B. Vester and M. Petersen, Chem.-Eur. J., 2011, 17, 2405-2413.

301. M. Marušič, R. N. Veedu, J. Wengel and J. Plavec, Nucleic Acids Res., 2013, 41, 9524-9536.
302.

303.

Nucleic Acids Res., 2017, 45, 11535-11546.

B. P. Paudel, A. L. Moye, H. Abou Assi, R. El-Khoury, S. B. Cohen, J. K. Holien, M. L. Birrento, S. Samosorn, K. Intharapichai, C. G. Tomlinson, M.-P. Teulade-Fichou, C. González, J. L. Beck, M. J. Damha, A. M. Van Oijen and T. M. Bryan, elife, 2020, 9, e56428.

304. Z. Li, C. J. Lech and A. T. Phan, Nucleic Acids Res., 2013, 42, 4068-4079.

305. N. Zhang, A. Gorin, A. Majumdar, A. Kettani, N. Chernichenko, E. Skripkin and D. J. Patel, J. Mol. Biol., 2001, 311, 1063-1079.

306. L. Haase and K. Weisz, Nucleic Acids Res., 2020, DOI: 10.1093/nar/gkaa720.

307. C.-F. Tang and R. H. Shafer, J. Am. Chem. Soc., 2006, 128, 5966-5973.

308. N. Martín-Pintado, M. Yahyaee-Anzahaee, G. F. Deleavey, G. Portella, M. Orozco, M. J. Damha and C. González, J. Am. Chem. Soc., 2013, 135, 5344-5347.

309. H. Abou Assi, M. Garavís, C. González and M. J. Damha, Nucleic Acids Res., 2018, 46, 8038-8056.

310. H. A. Day, P. Pavlou and Z. A. E. Waller, Bioorg. Med. Chem., 2014, 22, 4407-4418.

311. K. Gehring, J.-L. Leroy and M. Guéron, Nature, 1993, 363, 561-565.

312. M. Guéron and J.-L. Leroy, Curr. Opin. Struct. Biol., 2000, 10, 326-331.

313. B. Xu, G. Devi and F. Shao, Org. Biomol. Chem., 2015, 13, 5646-5651.

314. B. Mir, X. Solés, C. González and N. Escaja, Sci Rep, 2017, 7, 2772.

315. V. B. Tsvetkov, T. S. Zatsepin, E. S. Belyaev, Y. I. Kostyukevich, G. V. Shpakovski, V. V. Podgorsky, G. E. Pozmogova, A. M. Varizhuk and A. V. Aralov, Nucleic Acids Res., 2018, 46, 2751-2764.

316. S. Robidoux and M. J. Damha, J. Biomol. Struct. Dyn., 1997, 15, 529-535.

317. H. A. Assi, R. W. Harkness, V, N. Martin-Pintado, C. J. Wilds, R. Campos-Olivas, A. K. Mittermaier, C. González and M. J. Damha, Nucleic Acids Res., 2016, 44, 4998-5009. N. Kumar, J. T. Nielsen, S. Maiti and M. Petersen, Angew. Chem. Int. Ed., 2007, 46, 9220-9222.

B. Yang and M. T. Rodgers, J. Am. Chem. Soc., 2014, 136, 282-290.

L. Lacroix, J.-L. Mergny, J.-L. Leroy and C. Hélène, Biochemistry, 1996, 35, 8715-8722.

C. P. Fenna, V. J. Wilkinson, J. R. P. Arnold, R. Cosstick and J. Fisher, Chem. Commun., 2008, DOI: 10.1039/B804833A, 3567-3569.

322. H. Abou Assi, Y. C. Lin, I. Serrano, C. González and M. J. Damha, Chem.-Eur. J., 2018, 24, 471-477.

323. J. Mergny, Nucleic Acids Res., 1998, 26, 4797-4803.

324. Y. Krishnan-Ghosh, E. Stephens and S. Balasubramanian, Chem. Commun., 2005, DOI: 10.1039/b510405j, 5278.

F. A. Buske, J. S. Mattick and T. L. Bailey, RNA Biol., 2011, 8, 427-439.

326. J. G. Hacia, B. J. Wold and P. B. Dervan, Biochemistry, 1994, 33, 5367-5369.

327. C. Escudé, C. Giovannangeli, J. S. Sun, D. H. Lloyd, J. K. Chen, S. M. Gryaznov, T. Garestier and C. Hélène, Proc. Natl. Acad. Sci. U.S.A., 1996, 93, 4365-4369. 
328. J. M. Dagle and D. L. Weeks, Nucleic Acids Res., 1996, 24, 356. 2143-2149.

329. R. G. García, E. Ferrer, M. J. Macías, R. Eritja and M. 357. Orozco, Nucleic Acids Res., 1999, 27, 1991-1998.

330. J. Hunziker, E. S. Priestley, H. Brunar and P. B. Dervan, J. Am. Chem. Soc., 1995, 117, 2661-2662.

331. W. M. Olivas and L. J. Maher, III, Nucleic Acids Res., 1995, 23, 1936-1941.

332. D. Guianvarc'h, R. Benhida, J.-L. Fourrey, R. Maurisse and J.-S. Sun, Chem. Commun., 2001, 1814-1815.

333. R. T. Ranasinghe, D. A. Rusling, V. E. C. Powers, K. R. Fox and T. Brown, Chem. Commun., 2005, DOI: 10.1039/B502325D, 2555-2557.

334. D. A. Rusling, V. E. C. Powers, R. T. Ranasinghe, Y. Wang, S. D. Osborne, T. Brown and K. R. Fox, Nucleic Acids Res., 2005, 33, 3025-3032.

335. C. J. Wilds and M. J. Damha, Bioconjugate Chem., 1999, 10, 299-305.

336. A. Noronha and M. J. Damha, Nucleic Acids Res., 1998, 26 , 2665-2671.

337. Y. V. Pabon-Martinez, Y. Xu, A. Villa, K. E. Lundin, S. Geny, C.-H. Nguyen, E. B. Pedersen, P. T. Jørgensen, J. Wengel, L. Nilsson, C. I. E. Smith and R. Zain, Sci Rep, 2017, 7, 11043.

338. S. M. Abdur Rahman, S. Seki, S. Obika, H. Yoshikawa, K. Miyashita and T. Imanishi, J. Am. Chem. Soc., 2008, 130, 4886-4896.

339. H. Moser and P. Dervan, Science, 1987, 238, 645-650.

340. T. Le Doan, L. Perrouault, D. Praseuth, N. Habhoub, J.-L. Decout, N. T. Thuong, J. Lhomme and C. Héène, Nucleic Acids Res., 1987, 15, 7749-7760.

341. P. Beal and P. Dervan, Science, 1991, 251, 1360-1363.

342. G. Devi, Y. Zhou, Z. Zhong, D.-F. K. Toh and G. Chen, Wiley Interdiscip. Rev. RNA, 2015, 6, 111-128.

343. C. P. Bailey, D. L. Weeks and J. M. Dagle, Nucleic Acids Res., 1998, 26, 4860-4867.

344. A. Aviñó, E. Cubero, C. González, R. Eritja and M. Orozco, J. Am. Chem. Soc., 2003, 125, 16127-16138.

345. R. Soliva, R. Güimil García, J. R. Blas, R. Eritja, J. L. Asensio, C. González, F. J. Luque and M. Orozco, Nucleic Acids Res. 2000, 28, 4531-4539.

346. H. Brunar and P. B. Dervan, Nucleic Acids Res., 1996, 24, 1987-1991.

347. Y. Wang, D. A. Rusling, V. E. C. Powers, O. Lack, S. D. Osborne, K. R. Fox and T. Brown, Biochemistry, 2005, 44, 5884-5892.

348. C. Escudé, J.-C. François, J.-S. Sun, G. Ott, M. Sprinzl, T. Garestier and J.-C. Hélène, Nucleic Acids Res., 1993, 21, 5547-5553.

349. A. Biton, A. Ezra, J. Kasparkova, V. Brabec and E. Yavin Bioconjugate Chem., 2010, 21, 616-621.

350. W. B. Wan and P. P. Seth, J. Med. Chem., 2016, 59, 96459667.

351. A. Khvorova and J. K. Watts, Nat. Biotechnol., 2017, 35, 238-248.

352. T. C. Roberts, R. Langer and M. J. A. Wood, Nat. Rev. Drug Discov., 2020, 19, 673-694.

353. C. Chen, Z. Yang and X. Tang, Med. Res. Rev., 2018, 38, 829-869.

354. B. Hu, L. Zhong, Y. Weng, L. Peng, Y. Huang, Y. Zhao and X.-J. Liang, Signal Transduct. Target. Ther., 2020, 5, 101.

355. L. Kibler-Herzog, G. Zon, B. Uznanski, G. Whittier and W. D. Wilson, Nucleic Acids Res., 1991, 19, 2979-2986.
S. Agrawal and E. R. Kandimalla, Mol. Med. Today, 2000, 6, 72-81.

D. A. Braasch, S. Jensen, Y. Liu, K. Kaur, K. Arar, M. A. White and D. R. Corey, Biochemistry, 2003, 42, 79677975.

358. J. Alter, F. Lou, A. Rabinowitz, H. Yin, J. Rosenfeld, S. D. Wilton, T. A. Partridge and Q. L. Lu, Nat. Med., 2006, 12, 175-177.

359. D. F. Doyle, D. A. Braasch, B. A. Janowski and D. R. Corey, Biochemistry, 2001, 40, 53-64.

360. S. Shakeel, S. Karim and A. Ali, J. Chem. Technol. Biotechnol., 2006, 81, 892-899.

361. L. Du and R. A. Gatti, J. Immunol. Methods, 2011, 365, 1-7. 362. K. Albertshofer, A. M. Siwkowski, E. V. Wancewicz, C. C. Esau, T. Watanabe, K. C. Nishihara, G. A. Kinberger, L. Malik, A. B. Eldrup, M. Manoharan, R. S. Geary, B. P. Monia, E. E. Swayze, R. H. Griffey, C. F. Bennett and M. A. Maier, Journal of Medicinal Chemistry, 2005, 48, 67416749.

363. B. Wu, H. M. Moulton, P. L. Iversen, J. Jiang, J. Li, J. Li, C. F. Spurney, A. Sali, A. D. Guerron, K. Nagaraju, T. Doran, P. Lu, X. Xiao and Q. L. Lu, Proc. Natl. Acad. Sci. U.S.A., 2008, 105, 14814-14819.

364. E. V. Wancewicz, M. A. Maier, A. M. Siwkowski, K. Albertshofer, T. M. Winger, A. Berdeja, H. Gaus, T. A. Vickers, C. F. Bennett, B. P. Monia, R. H. Griffey, C. J. Nulf, J. Hu, D. R. Corey, E. E. Swayze and G. A. Kinberger, J. Med. Chem., 2010, 53, 3919-3926.

365. N. Potenza, L. Moggio, G. Milano, V. Salvatore, B. Di Blasio, A. Russo and A. Messere, Int. J. Mol. Sci., 2008, 9, 299-315.

366.

K. Pongracz and S. Gryaznov, Tetrahedron Lett., 1999, 40 7661-7664.

367. B.-S. Herbert, G. C. Gellert, A. Hochreiter, K. Pongracz, W. E. Wright, D. Zielinska, A. C. Chin, C. B. Harley, J. W. Shay and S. M. Gryaznov, Oncogene, 2005, 24, 5262-5268.

368. M. T. Migawa, W. Shen, W. B. Wan, G. Vasquez, M. E. Oestergaard, A. Low, C. L. De Hoyos, R. Gupta, S. Murray, M. Tanowitz, M. Bell, J. G. Nichols, H. Gaus, X.-h. Liang, E. E. Swayze, S. T. Crooke and P. P. Seth, Nucleic Acids Res. 2019, 47, 5465-5479.

369. B. R. Meade, K. Gogoi, A. S. Hamil, C. Palm-Apergi, A. v. d. Berg, J. C. Hagopian, A. D. Springer, A. Eguchi, A. D. Kacsinta, C. F. Dowdy, A. Presente, P. Lönn, M. Kaulich, N. Yoshioka, E. Gros, X.-S. Cui and S. F. Dowdy, Nat. Biotechnol., 2014, 32, 1256-1261.

370. T. P. Prakash, W. F. Lima, H. M. Murray, W. Li, G. A. Kinberger, A. E. Chappell, H. Gaus, P. P. Seth, B. Bhat, S. T. Crooke and E. E. Swayze, Nucleic Acids Res., 2015, 43, 2993-3011.

371. E. Elkayam, R. Parmar, C. R. Brown, J. L. Willoughby, C. S Theile, M. Manoharan and L. Joshua-Tor, Nucleic Acids Res., 2016, 45, 3528-3536.

372. R. A. Haraszti, L. Roux, A. H. Coles, A. A. Turanov, J. F. Alterman, D. Echeverria, B. M. D. C. Godinho, N. Aronin and A. Khvorova, Nucleic Acids Res., 2017, 45, 7581-7592. C. t. Altona and M. Sundaralingam, J. Am. Chem. Soc., $1972,94,8205-8212$

374

C. Thibaudeau and J. Chattopadhyaya, Stereoelectronic effects in nucleosides and nucleotides and their structural implications, Uppsala University Press Uppsala, 1999. 
375. Glen F. Deleavey and Masad J. Damha, Chem. Biol., 2012, 19, 937-954.

376. S. Obika, D. Nanbu, Y. Hari, J.-i. Andoh, K.-i. Morio, T. Doi and T. Imanishi, Tetrahedron Lett., 1998, 39, 5401-5404.

377. J. Kurreck, E. Wyszko, C. Gillen and V. A. Erdmann, Nucleic Acids Res., 2002, 30, 1911-1918.

378. R. Steffens and C. J. Leumann, J. Am. Chem. Soc., 1999, 121, 3249-3255.

379. C. J. Leumann, Bioorg. Med. Chem., 2002, 10, 841-854.

380. A. Goyenvalle, G. Griffith, A. Babbs, S. El Andaloussi, K. Ezzat, A. Avril, B. Dugovic, R. Chaussenot, A. Ferry, T. Voit, H. Amthor, C. Buhr, S. Schurch, M. J. A. Wood, K. E. Davies, C. Vaillend, C. Leumann and L. Garcia, Nat. Med., 2015, 21, 270-275.

381. M. Hollenstein and C. J. Leumann, ChemBioChem, 2014, 15, 1901-1904.

382. A. Yahara, A. R. Shrestha, T. Yamamoto, Y. Hari, T. Osawa, M. Yamaguchi, M. Nishida, T. Kodama and S. Obika, ChemBioChem, 2012, 13, 2513-2516.

383. S. K. Singh, R. Kumar and J. Wengel, J. Org. Chem., 1998, 63, 6078-6079.

384. K. Morihiro, T. Kodama, Y. Moai, R. N. Veedu and S. Obika, Angew. Chem. Int. Ed., 2013, 52, 5074-5078.

385. Y. Moai, H. Hiroaki, S. Obika and T. Kodama, Nucleosides, Nucleotides \& Nucleic Acids, 2020, 39, 131-140.

386. D. S. Pedersen and T. Koch, Synthesis, 2004, 2004, 578582.

387. A. R. Shrestha, Y. Hari, A. Yahara, T. Osawa and S. Obika, J. Org. Chem., 2011, 76, 9891-9899.

388. N. Albæk, J. Ravn, M. Freitag, H. Thomasen, N. K. Christensen, M. Petersen and P. Nielsen, Nucleosides, Nucleotides and Nucleic Acids, 2003, 22, 723-725.

389. P. H. Hagedorn, R. Persson, E. D. Funder, N. Albæk, S. L. Diemer, D. J. Hansen, M. R. Møller, N. Papargyri, H. Christiansen and B. R. Hansen, Drug Discov. Today, 2018, 23, 101-114.

390. H. Komine, S. Mori, K. Morihiro, K. Ishida, T. Okuda, Y. Kasahara, H. Aoyama, T. Yamaguchi and S. Obika, Molecules, 2020, 25, 1732.

391. W. F. Lima, J. G. Nichols, H. Wu, T. P. Prakash, M. T. Migawa, T. K. Wyrzykiewicz, B. Bhat and S. T. Crooke, J. Biol. Chem., 2004, 279, 36317-36326.

392. P. S. Pallan and M. Egli, Cell Cycle, 2008, 7, 2562-2569.

393. H. Inoue, Y. Hayase, S. Iwai and E. Ohtsuka, FEBS Lett., 1987, 215, 327-330.

394. W. Zhou and S. Agrawal, Bioorg. Med. Chem. Lett., 1998, 8, 3269-3274.

395. P. Martin, Helv. Chim. Acta, 1995, 78, 486-504.

396. M. Teplova, G. Minasov, V. Tereshko, G. B. Inamati, P. D. Cook, M. Manoharan and M. Egli, Nat. Struct. Biol., 1999, 6, 535-539.

397. Y. Hua, K. Sahashi, G. Hung, F. Rigo, M. A. Passini, C. F. Bennett and A. R. Krainer, Genes Dev., 2010, 24, 16341644.

398. Y. Hua, K. Sahashi, F. Rigo, G. Hung, G. Horev, C. F. Bennett and A. R. Krainer, Nature, 2011, 478, 123-126.

399. M. A. Passini, J. Bu, A. M. Richards, C. Kinnecom, S. P. Sardi, L. M. Stanek, Y. Hua, F. Rigo, J. Matson, G. Hung, E. M. Kaye, L. S. Shihabuddin, A. R. Krainer, C. F. Bennett and S. H. Cheng, Sci. Transl. Med., 2011, 3, 72ra18-72ra18.
400.

B. P. Monia, E. A. Lesnik, C. Gonzalez, W. F. Lima, D. McGee, C. J. Guinosso, A. M. Kawasaki, P. D. Cook and S. M. Freier, J. Biol. Chem., 1993, 268, 14514-14522.

401. F. Rigo, Y. Hua, S. J. Chun, T. P. Prakash, A. R. Krainer and C. F. Bennett, Nat. Chem. Biol., 2012, 8, 555-561.

402. C. R. Allerson, N. Sioufi, R. Jarres, T. P. Prakash, N. Naik, A. Berdeja, L. Wanders, R. H. Griffey, E. E. Swayze and B. Bhat, J. Med. Chem., 2005, 48, 901-904.

403. M. Manoharan, A. Akinc, R. K. Pandey, J. Qin, P. Hadwiger, M. John, K. Mills, K. Charisse, M. A. Maier, L. Nechev, E. M. Greene, P. S. Pallan, E. Rozners, K. G. Rajeev and M. Egli, Angew. Chem. Int. Ed., 2011, 50, 2284-2288.

404. A. L. Jackson, J. Burchard, D. Leake, A. Reynolds, J. Schelter, J. Guo, J. M. Johnson, L. Lim, J. Karpilow, K. Nichols, W. Marshall, A. Khvorova and P. S. Linsley, RNA, 2006, 12, 1197-1205.

405. T. L. Cuellar, D. Barnes, C. Nelson, J. Tanguay, S.-F. Yu, X. Wen, S. J. Scales, J. Gesch, D. Davis, A. van Brabant Smith, D. Leake, R. Vandlen and C. W. Siebel, Nucleic Acids Res., 2014, 43, 1189-1203.

406. H. Addepalli, Meena, C. G. Peng, G. Wang, Y. Fan, K. Charisse, K. N. Jayaprakash, K. G. Rajeev, R. K. Pandey, G. Lavine, L. Zhang, K. Jahn-Hofmann, P. Hadwiger, M. Manoharan and M. A. Maier, Nucleic Acids Res., 2010, 38, 7320-7331.

407. C. Matranga, Y. Tomari, C. Shin, D. P. Bartel and P. D. Zamore, Cell, 2005, 123, 607-620.

408. J.-F. Trempe, C. J. Wilds, A. Y. Denisov, R. T. Pon, M. J. Damha and K. Gehring, J. Am. Chem. Soc., 2001, 123, 4896-4903.

409. M. J. Damha, C. J. Wilds, A. Noronha, I. Brukner, G. Borkow, D. Arion and M. A. Parniak, J. Am. Chem. Soc., 1998, 120, 12976-12977.

410. K.-L. Min, E. Viazovkina, A. Galarneau, M. A. Parniak and M. J. Damha, Bioorg. Med. Chem. Lett., 2002, 12, 26512654.

411. A. Kalota, L. Karabon, C. R. Swider, E. Viazovkina, M. Elzagheid, M. J. Damha and A. M. Gewirtz, Nucleic Acids Res., 2006, 34, 451-461.

412. M. Fortin, H. D'Anjou, M. E. Higgins, J. Gougeon, P. Aube, K. Moktefi, S. Mouissi, S. Seguin, R. Seguin, P. M. Renzi, L. Paquet and N. Ferrari, Respir. Res., 2009, 10.

413. M. Takahashi, H. T. Li, J. H. Zhou, P. Chomchan, V. Aishwarya, M. J. Damha and J. J. Rossi, Mol. Ther.-Nucl. Acids, 2019, 17, 615-625.

414. T. Dowler, D. Bergeron, A.-L. Tedeschi, L. Paquet, N. Ferrari and M. J. Damha, Nucleic Acids Res., 2006, 34, 1669-1675.

415. G. F. Deleavey, J. K. Watts, T. Alain, F. Robert, A. Kalota, V. Aishwarya, J. Pelletier, A. M. Gewirtz, N. Sonenberg and M. J. Damha, Nucleic Acids Res., 2010, 38, 4547-4557.

416. S. Martínez-Montero, G. F. Deleavey, N. Martín-Pintado, J. F. Fakhoury, C. González and M. J. Damha, ACS Chem. Biol., 2015, 10, 2016-2023.

417. S. Martínez-Montero, G. F. Deleavey, A. Kulkarni, N. Martín-Pintado, P. Lindovska, M. Thomson, C. González, M. Götte and M. J. Damha, J. Org. Chem., 2014, 79, 56275635.

418. M. Burai Patrascu, E. Malek-Adamian, M. J. Damha and N. Moitessier, J. Am. Chem. Soc., 2017, 139, 13620-13623. 
419. E. Malek-Adamian, J. Fakhoury, A. E. Arnold, S. MartínezMontero, M. S. Shoichet and M. J. Damha, Nucleic Acid Ther., 2019, 29, 187-194.

420. J. M. Harp, D. C. Guenther, A. Bisbe, L. Perkins, S. Matsuda, G. R. Bommineni, I. Zlatev, D. J. Foster, N. Taneja, K. Charisse, M. A. Maier, K. G. Rajeev, M. Manoharan and M. Egli, Nucleic Acids Res., 2018, 46, 8090-8104.

421. A. A. Koshkin, S. K. Singh, P. Nielsen, V. K. Rajwanshi, R. Kumar, M. Meldgaard, C. E. Olsen and J. Wengel, Tetrahedron, 1998, 54, 3607-3630.

422. D. A. Braasch and D. R. Corey, Chem. Biol., 2001, 8, 1-7.

423. P. P. Seth, G. Vasquez, C. A. Allerson, A. Berdeja, H. Gaus, G. A. Kinberger, T. P. Prakash, M. T. Migawa, B. Bhat and E. E. Swayze, J. Org. Chem., 2010, 75, 1569-1581.

424. D. Hong, R. Kurzrock, Y. Kim, R. Woessner, A. Younes, J. Nemunaitis, N. Fowler, T. Zhou, J. Schmidt, M. Jo, S. J. Lee, M. Yamashita, S. G. Hughes, L. Fayad, S. Piha-Paul, M. V. P. Nadella, M. Mohseni, D. Lawson, C. Reimer, D. C. Blakey, X. Xiao, J. Hsu, A. Revenko, B. P. Monia and A. R. MacLeod, Sci. Transl. Med., 2015, 7, 314ra185-314ra185.

425. K. A. Lennox and M. A. Behlke, Pharm. Res., 2010, 27, 1788-1799.

426. R. N. Veedu and J. Wengel, Chem. Biodivers., 2010, 7, 536542.

427. K. Fluiter, O. R. F. Mook and F. Baas in siRNA and miRNA Gene Silencing: From Bench to Bedside, ed. M. Sioud, Humana Press, Totowa, NJ, 2009, DOI: 10.1007/978-160327-547-7_9, pp. 1-15.

428. H.-S. Lee, H. Seok, D. H. Lee, J. Ham, W. Lee, E. M. Youm, J. S. Yoo, Y.-S. Lee, E.-S. Jang and S. W. Chi, Nat. Commun., 2015, 6, 10154.

429. M. E. Østergaard, P. Kumar, J. Nichols, A. Watt, P. K. Sharma, P. Nielsen and P. P. Seth, Nucl. Acid Ther., 2015, 25, 266-274.

430. J. Liu, H. Pendergraff, K. J. Narayanannair, J. G. Lackey, S. Kuchimanchi, K. G. Rajeev, M. Manoharan, J. Hu and D. R. Corey, Nucleic Acids Res., 2013, 41, 8788-8801.

431. M. Jinek, K. Chylinski, I. Fonfara, M. Hauer, J. A. Doudna and E. Charpentier, Science, 2012, 337, 816-821.

432. Y. Cui, J. Xu, M. Cheng, X. Liao and S. Peng, Interdiscip. Sci., 2018, 10, 455-465.

433. D. A. Glazier, J. Z. Liao, B. L. Roberts, X. L. Li, K. Yang, C. M. Stevens and W. P. Tang, Bioconjugate Chem., 2020, 31, 1213-1233.

434. A. Latorre, A. Latorre and Á. Somoza, Angew. Chem. Int. Ed., 2016, 55, 3548-3550.

435. J. Filippova, A. Matveeva, E. Zhuravlev and G. Stepanov, Biochimie, 2019, 167, 49-60.

436. J. Wu and H. Yin, J. Genet. Genomics, 2019, 46, 523-529.

437. A. Hendel, R. O. Bak, J. T. Clark, A. B. Kennedy, D. E. Ryan, S. Roy, I. Steinfeld, B. D. Lunstad, R. J. Kaiser and A. B. Wilkens, Nat. Biotechnol., 2015, 33, nbt. 3290.

438. M. Rahdar, M. A. McMahon, T. P. Prakash, E. E. Swayze, C F. Bennett and D. W. Cleveland, Proc. Natl. Acad. Sci. U.S.A., 2015, 112, E7110-E7117.

439. A. Mir, J. F. Alterman, M. R. Hassler, A. J. Debacker, E. Hudgens, D. Echeverria, M. H. Brodsky, A. Khvorova, J. K. Watts and E. J. Sontheimer, Nat. Commun., 2018, 9, 1-9.

440. H. Yin, C.-Q. Song, S. Suresh, S.-Y. Kwan, Q. Wu, S. Walsh, J. Ding, R. L. Bogorad, L. J. Zhu and S. A. Wolfe, Nat. Chem. Biol., 2018, 14, 311.
441. F. O. Rueda, M. Bista, M. D. Newton, A. U. Goeppert, M. E. Cuomo, E. Gordon, F. Kröner, J. A. Read, J. D. Wrigley and D. Rueda, Nat. Commun., 2017, 8, 1-11.

442. D. O'Reilly, Z. J. Kartje, E. A. Ageely, E. Malek-Adamian, M. Habibian, A. Schofield, C. L. Barkau, K. J. Rohilla, L. B. DeRossett and A. T. Weigle, Nucleic Acids Res., 2019, 47, 546-558.

443. C. R. Cromwell, K. Sung, J. Park, A. R. Krysler, J. Jovel, S. K. Kim and B. P. Hubbard, Nat. Commun., 2018, 9, 1-11.

444. C. L. Barkau, D. O'Reilly, K. J. Rohilla, M. J. Damha and K. T. Gagnon, Nucleic Acid Ther., 2019, 29, 136-147.

445. C. M. Palumbo, J. M. Gutierrez-Bujari, H. O'Geen, D. J. Segal and P. A. Beal, ChemBioChem, 2020.

446. Y. Wang, Y. Liu, F. Xie, J. Lin and L. Xu, Chem. Sci., 2020, 11, 11478-11484.

447. S. Nahar, P. Sehgal, M. Azhar, M. Rai, A. Singh, S. Sivasubbu, D. Chakraborty and S. Maiti, Chem. Commun., 2018, 54, 2377-2380.

448. A. D. Ellington and J. W. Szostak, Nature, 1990, 346, 818822.

449. D. L. Robertson and G. F. Joyce, Nature, 1990, 344, 467468.

450. C. Tuerk and L. Gold, Science, 1990, 249, 505-510.

451. M. Hollenstein, Curr. Opin. Chem. Biol., 2019, 52, 93-101.

452. P. Röthlisberger and M. Hollenstein, Adv. Drug Deliv. Rev., 2018, 134, 3-21.

453. K. Duffy, S. Arangundy-Franklin and P. Holliger, BMC Biol., 2020, 18, 112.

454. F. Odeh, H. Nsairat, W. Alshaer, M. A. Ismail, E. Esawi, B. Qaqish, A. A. Bawab and S. I. Ismail, Molecules, 2020, 25, 3.

455. N. Klöcker, F. P. Weissenboeck and A. Rentmeister, Chem. Soc. Rev., 2020, 49, 8749-8773.

456. J. A. Latham, R. Johnson and J. J. Toole, Nucleic Acids Res. 1994, 22, 2817-2822.

457. D. Jellinek, L. S. Green, C. Bell, C. K. Lynott, N. Gill, C. Vargeese, G. Kirschenheuter, D. P. C. McGee, P. Abesinghe, W. A. Pieken, R. Shapiro, D. B. Rifkin, D. Moscatelli and N. Janjic, Biochemistry, 1995, 34, 1136311372.

458. S. Jhaveri, B. Olwin and A. D. Ellington, Bioorg. Med. Chem. Lett., 1998, 8, 2285-2290.

459. L. Gold, D. Ayers, J. Bertino, C. Bock, A. Bock, E. N. Brody, J. Carter, A. B. Dalby, B. E. Eaton, T. Fitzwater, D. Flather, A. Forbes, T. Foreman, C. Fowler, B. Gawande, M. Goss, M. Gunn, S. Gupta, D. Halladay, J. Heil, J. Heilig, B. Hicke, G. Husar, J. Janjic, T. Jarvis, S. Jennings, E. Katilius, T. R. Keeney, N. Kim, T. H. Koch, S. Kraemer, L. Kroiss, N. Le, D. Levine, W. Lindsey, B. Lollo, W. Mayfield, M. Mehan, R. Mehler, S. K. Nelson, M. Nelson, D. Nieuwlandt, M. Nikrad, U. Ochsner, R. M. Ostroff, M. Otis, T. Parker, S. Pietrasiewicz, D. I. Resnicow, J. Rohloff, G. Sanders, S. Sattin, D. Schneider, B. Singer, M. Stanton, A. Sterkel, A. Stewart, S. Stratford, J. D. Vaught, M. Vrkljan, J. J. Walker, M. Watrobka, S. Waugh, A. Weiss, S. K. Wilcox, A. Wolfson, S. K. Wolk, C. Zhang and D. Zichi, PLoS One, 2010, 5.

460. D. R. Davies, A. D. Gelinas, C. Zhang, J. C. Rohloff, J. D. Carter, D. O'Connell, S. M. Waugh, S. K. Wolk, W. S. Mayfield, A. B. Burgin, T. E. Edwards, L. J. Stewart, L. Gold, N. Janjic and T. C. Jarvis, Proc. Natl. Acad. Sci. U.S.A., 2012, 109, 19971-19976. 
461. J. Candia, F. Cheung, Y. Kotliarov, G. Fantoni, B. Sellers, T. Griesman, J. H. Huang, S. Stuccio, A. Zingone, B. M. Ryan, J. S. Tsang and A. Biancotto, Sci Rep, 2017, 7.

462. B. B. Sun, J. C. Maranville, J. E. Peters, D. Stacey, J. R. Staley, J. Blackshaw, S. Burgess, T. Jiang, E. Paige, P. Surendran, C. Oliver-Williams, M. A. Kamat, B. P. Prins, S. K. Wilcox, E. S. Zimmerman, A. Chi, N. Bansal, S. L. Spain, A. M. Wood, N. W. Morrell, J. R. Bradley, N. Janjic, D. J. Roberts, W. H. Ouwehand, J. A. Todd, N. Soranzo, K. Suhre, D. S. Paul, C. S. Fox, R. M. Plenge, J. Danesh, H. Runz and A. S. Butterworth, Nature, 2018, 558, 73-79.

463. M. Renders, E. Miller, C. H. Lam and D. M. Perrin, Org. Biomol. Chem., 2017, 15, 1980-1989.

464. Y. Imaizumi, Y. Kasahara, H. Fujita, S. Kitadume, H. Ozaki, T. Endoh, M. Kuwahara and N. Sugimoto, J. Am. Chem. Soc., 2013, 135, 9412-9419.

465. H. Minagawa, K. Onodera, H. Fujita, T. Sakamoto, J. Akitomi, N. Kaneko, I. Shiratori, M. Kuwahara, K. Horii and I. Waga, Sci Rep, 2017, 7, 9.

466. M. Rosenthal, F. Pfeiffer and G. Mayer, Angew. Chem. Int. Ed., 2019, 58, 10752-10755.

467. M. Y. Li, N. Lin, Z. Huang, L. P. Du, C. Altier, H. Fang and B. H. Wang, J. Am. Chem. Soc., 2008, 130, 12636-12638.

468. V. T. Dien, M. Holcomb, A. W. Feldman, E. C. Fischer, T. J. Dwyer and F. E. Romesberg, J. Am. Chem. Soc., 2018, 140, 16115-16123.

469. M. Kimoto, Y. W. S. Lim and I. Hirao, Nucleic Acids Res., 2019, 47, 8362-8374.

470. S. Moran, R. X. F. Ren and E. T. Kool, Proc. Natl. Acad. Sci. U.S.A., 1997, 94, 10506-10511.

471. M. P. Ledbetter, J. M. Craig, R. J. Karadeema, M. T. Noakes, H. C. Kim, S. J. Abell, J. R. Huang, B. A. Anderson, R. Krishnamurthy, J. H. Gundlach and F. E. Romesberg, J. Am. Chem. Soc., 2020, 142, 2110-2114.

472. D. A. Malyshev, K. Dhami, T. Lavergne, T. J. Chen, N. Dai, J. M. Foster, I. R. Correa and F. E. Romesberg, Nature, 2014, 509, 385-388.

473. M. Kimoto, R. Kawai, T. Mitsui, S. Yokoyama and I. Hirao, Nucleic Acids Res., 2009, 37, 9.

474. K. Matsunaga, M. Kimoto and I. Hirao, J. Am. Chem. Soc., 2017, 139, 324-334.

475. J. Müller, Coord. Chem. Rev., 2019, 393, 37-47.

476. M. Flamme, F. Levi-Acobas, S. Hensel, S. Naskar, P. Röthlisberger, I. Sarac, G. Gasser, J. Müller and M. Hollenstein, ChemBioChem, 2020, 21, 3398-3409.

477. C. Kaul, M. Müller, M. Wagner, S. Schneider and T. Carell, Nat. Chem., 2011, 3, 794-800.

478. T. Kobayashi, Y. Takezawa, A. Sakamoto and M. Shionoya, Chem. Commun., 2016, 52, 3762-3765.

479. M. Flamme, P. Röthlisberger, F. Levi-Acobas, M. Chawla, R. Oliva, L. Cavallo, G. Gasser, P. Marlière, P. Herdewijn and M. Hollenstein, ACS Chem. Biol., 2020, 15, 2872-2884.

480. T. Nakama, Y. Takezawa, D. Sasaki and M. Shionoya, J. Am. Chem. Soc., 2020, 142, 10153-10162.

481. Y. Takezawa, T. Nakama and M. Shionoya, J. Am. Chem. Soc., 2019, 141, 19342-19350.

482. Y. Takezawa, L. Hu, T. Nakama and M. Shionoya, Angew. Chem. Int. Ed., 2020, DOI: 10.1002/anie.202009579, 10.1002/anie.202009579.

483. F. Levi-Acobas, P. Röthlisberger, I. Sarac, P. Marliere, P. Herdewijn and M. Hollenstein, ChemBioChem, 2019, 20, 3032-3040.
484.

P. Röthlisberger, F. Levi-Acobas, I. Sarac, P. Marliere, P. Herdewijn and M. Hollenstein, Org. Biomol. Chem., 2017, 15, 4449-4455.

485. P. Röthlisberger, F. Levi-Acobas, I. Sarac, P. Marliere, P. Herdewijn and M. Hollenstein, J. Inorg. Biochem., 2019, 191, 154-163.

486. T. Funai, C. Tagawa, O. Nakagawa, S.-i. Wada, A. Ono and H. Urata, Chem. Commun., 2020, DOI: 10.1039/DOCC04423G, 10.1039/D1030CC04423G.

487. V. B. Pinheiro, A. I. Taylor, C. Cozens, M. Abramov, M. Renders, S. Zhang, J. C. Chaput, J. Wengel, S. Peak-Chew, S. H. McLaughlin, P. Herdewijn and P. Holliger, Science, 2012, 336, 341-344.

488.

K. M. Rose, I. A. Ferreira-Bravo, M. Li, R. Craigie, M. A. Ditzler, P. Holliger and J. J. DeStefano, ACS Chem. Biol., 2019, 14, 2166-2175.

489.

E. Eremeeva, A. Fikatas, L. Margamuljana, M. Abramov, D. Schols, E. Groaz and P. Herdewijn, Nucleic Acids Res., 2019, 47, 4927-4939.

490.

A. E. Rangel, Z. Chen, T. M. Ayele and J. M. Heemstra, Nucleic Acids Res., 2018, 46, 8057-8068.

491. L. Zhang and J. C. Chaput, Molecules, 2020, 25, 4194.

492. Z. X. Liu, T. J. Chen and F. E. Romesberg, Chem. Sci., 2017, 8, 8179-8182.

493. Q. Shao, T. J. Chen, K. Sheng, Z. X. Liu, Z. C. Zhang and F. E. Romesberg, J. Am. Chem. Soc., 2020, 142, 2125-2128.

494. N. Minakawa, M. Sanji, Y. Kato and A. Matsuda, Bioorg. Med. Chem., 2008, 16, 9450-9456.

B. E. Young, N. Kundu and J. T. Sczepanski, Chem.-Eur. J., 2019, 25, 7981-7990.

496. S. Helmling, C. Maasch, D. Eulberg, K. Buchner, W. Schroder, C. Lange, S. Vonhoff, B. Wlotzka, M. H. Tschop, S. Rosewicz and S. Klussmann, Proc. Natl. Acad. Sci. U.S.A., 2004, 101, 13174-13179.

L. Yatime, C. Maasch, K. Hoehlig, S. Klussmann, G. R. Andersen and A. Vater, Nat. Commun., 2015, 6, 13.

498. S. Dey and J. T. Sczepanski, Nucleic Acids Res., 2020, 48, 1669-1680.

499. J. An, J. Choi, D. Hwang, J. Park, C. W. Pemble, T. H. M. Duong, K. R. Kim, H. Ahn, H. S. Chung and D. R. Ahn, Chem. Commun., 2020, 56, 2186-2189.

500. A. Pech, J. Achenbach, M. Jahnz, S. Schulzchen, F. Jarosch, F. Bordusa and S. Klussmann, Nucleic Acids Res., 2017, 45, 3997-4005.

501. M. Wang, W. J. Jiang, X. Y. Liu, J. X. Wang, B. C. Zhang, C. Y. Fan, L. Liu, G. Pena-Alcantara, J. J. Ling, J. Chen and T. F. Zhu, Chem, 2019, 5, 848-857.

502. J. Weidmann, M. Schnolzer, P. E. Dawson and J. D. Hoheisel, Cell Chem. Biol., 2019, 26, 645-651.e643.

K. F. Tjhung, J. T. Sczepanski, E. R. Murtfeldt and G. F. Joyce, J. Am. Chem. Soc., 2020, 142, 15331-15339.

504. C. Liu, C. Cozens, F. Jaziri, J. Rozenski, A. Marechal, S. Dumbre, V. Pezo, P. Marliere, V. B. Pinheiro, E. Groaz and P. Herdewijn, J. Am. Chem. Soc., 2018, 140, 6690-6699.

505. S. M. Lato, N. D. S. Ozerova, K. Z. He, Z. Sergueeva, B. R. Shaw and D. H. Burke, Nucleic Acids Res., 2002, 30, 14011407.

506. D. J. King, D. A. Ventura, A. R. Brasier and D. G. Gorenstein, Biochemistry, 1998, 37, 16489-16493.

507. J. P. Elskens, J. M. Elskens and A. Madder, Int. J. Mol. Sci., 2020, 21, 31. 
508. K. Yamasaki, Y. Akutsu, T. Yamasaki, M. Miyagishi and T. Kubota, Nucleic Acids Res., 2020, 48, 4551-4561.

509. C. Wang, Y. Sun and Q. Zhao, Talanta, 2020, 207, 6.

510. A. Okruszek, M. Olesiak and J. Balzarini, J. Med. Chem., 1994, 37, 3850-3854.

511. V. Zelikman, J. Pelletier, L. Simhaev, A. Sela, F. P. Gendron, G. Arguin, H. Senderowitz, J. Sevigny and B. Fischer, J. Med. Chem., 2018, 61, 3939-3951.

512. K. W. Porter, J. D. Briley and B. R. Shaw, Nucleic Acids Res., 1997, 25, 1611-1617.

513. H. Li, C. Hardin and B. R. Shaw, J. Am. Chem. Soc., 1996, 118, 6606-6614.

514. R. I. Hara, T. Saito, T. Kogure, Y. Hamamura, N. Uchiyama, Y. Nukaga, N. Iwamoto and T. Wad, J. Org. Chem., 2019, 84, 7971-7983.

515. D. Kaniowski, K. Ebenryter-Olbinska, K. Kulik, S. Janczak, A. Maciaszek, K. Bednarska-Szczepaniak, B. Nawrot and Z. Lesnikowski, Nanoscale, 2020, 12, 103-114.

516. M. A. Dineva, S. Chakurov, E. K. Bratovanova, I. Devedjiev and D. D. Petkov, Bioorg. Med. Chem., 1993, 1, 411-414.

517. H. Higuchi, T. Endo and A. Kaji, Biochemistry, 1990, 29, 8747-8753.

518. R. R. Breaker, ACS Chem. Biol., 2020, 15, 2020-2030.

519. S. W. Santoro, G. F. Joyce, K. Sakthivel, S. Gramatikova and C. F. Barbas, J. Am. Chem. Soc., 2000, 122, 2433-2439.

520. T. M. Tarasow, S. L. Tarasow and B. E. Eaton, Nature, 1997, 389, 54-57.

521. P.-J. J. Huang and J. Liu, ChemistryOpen, 2020, 9, 10461059.

522. D. M. Perrin, T. Garestier and C. Helene, J. Am. Chem. Soc., 2001, 123, 1556-1563.

523. A. V. Sidorov, J. A. Grasby and D. M. Williams, Nucleic Acids Res., 2004, 32, 1591-1601.

524. Y. J. Wang, E. K. Liu, C. H. Lam and D. M. Perrin, Chem. Sci., 2018, 9, 1813-1821.

525. M. Hollenstein, C. J. Hipolito, C. H. Lam and D. M. Perrin, ACS Comb. Sci., 2013, 15, 174-182.

526. M. Hollenstein, C. J. Hipolito, C. H. Lam and D. M. Perrin, ChemBioChem, 2009, 10, 1988-1992.

527. X. C. Dai, A. Demesmaeker and G. F. Joyce, Science, 1995, 267, 237-240.

528. M. Chandra, A. Sachdeva and S. K. Silverman, Nat. Chem Biol., 2009, 5, 718-720.

529. C. Zhou, J. L. Avins, P. C. Klauser, B. M. Brandsen, Y. Lee and S. K. Silverman, J. Am. Chem. Soc., 2016, 138, 21062109.

530. A. I. Taylor, V. B. Pinheiro, M. J. Smola, A. S. Morgunov, S. Peak-Chew, C. Cozens, K. M. Weeks, P. Herdewijn and P. Holliger, Nature, 2015, 518, 427-430.

531. Y. J. Wang, A. K. Ngor, A. Nikoomanzar and J. C. Chaput, Nat. Commun., 2018, 9.

532. Y. J. Wang, A. Vorperian, M. Shehabat and J. C. Chaput, ChemBioChem, 2020, 21, 1001-1006.

533. S. K. Wolk, W. S. Mayfield, A. D. Gelinas, D. Astling, J. Guillot, E. N. Brody, N. Janjic and L. Gold, Proc. Natl. Acad. Sci. U.S.A., 2020, 117, 8236-8242.

534. A. Espinasse, H. K. Lembke, A. A. Cao and E. E. Carlson, RSC Chem. Biol., 2020, DOI: 10.1039/D0CB00078G.

535. M. Hocek, J. Org. Chem., 2014, 79, 9914-9921.

536. I. Ivancová, D.-L. Leone and M. Hocek, Curr. Opin. Chem. Biol., 2019, 52, 136-144.
537

B. Y. Michel, D. Dziuba, R. Benhida, A. P. Demchenko and A. Burger, Front. Chem., 2020, 8, 112.

538. J. Balintova, M. Welter and A. Marx, Chem. Sci., 2018, 9, 7122-7125.

539. A. R. Rovira, A. Fin and Y. Tor, Chem. Sci., 2017, 8, 29832993.

540. Y. Li, A. Fin, L. McCoy and Y. Tor, Angew. Chem. Int. Ed. 2017, 56, 1303-1307.

541. C. Steinmetzger, C. Bauerlein and C. Hobartner, Angew. Chem. Int. Ed., 2020, 59, 6760-6764.

H. Mei, C. H. Shi, R. M. Jimenez, Y. J. Wang, M. Kardouh and J. C. Chaput, Nucleic Acids Res., 2017, 45, 5629-5638.

P. Sandin, G. Stengel, T. Ljungdahl, K. Borjesson, B. Macao and L. M. Wilhelmsson, Nucleic Acids Res., 2009, 37, 39243933.

544. M. Krömer, M. Brunderová, I. Ivancová, L. Poštová Slavětínská and M. Hocek, ChemPlusChem, 2020, 85, 1164-1170.

545. M. Krömer, K. Bártová, V. Raindlová and M. Hocek, Chem. Eur. J., 2018, 24, 11890-11894.

546. T. Gerard-Hirne, F. Thiebaut, E. Sachon, A. Desert, T. Drujon, V. Guerineau, B. Y. Michel, R. Benhida, S. Coulon, C. Saintome and D. Guianvarc'h, Biochimie, 2018, 154, 164-175.

547. A. Olszewska, R. Pohl, M. Brázdová, M. Fojta and M. Hocek, Bioconjugate Chem., 2016, 27, 2089-2094.

548. C. C. Smith, M. Hollenstein and C. J. Leumann, RSC Adv., 2014, 4, 48228-48235.

549. M. Winnacker, S. Breeger, R. Strasser and T. Carell, ChemBioChem, 2009, 10, 109-118.

550. S. Fodor, J. Read, M. Pirrung, L. Stryer, A. Lu and D. Solas, Science, 1991, 251, 767-773.

551. A. C. Pease, D. Solas, E. J. Sullivan, M. T. Cronin, C. P. Holmes and S. P. Fodor, Proc. Natl. Acad. Sci. U.S.A., 1994, 91, 5022-5026.

552. S. Singh-Gasson, R. D. Green, Y. Yue, C. Nelson, F. Blattner, M. R. Sussman and F. Cerrina, Nat. Biotechnol., 1999, 17, 974-978.

553. C.-C. Chou, C.-H. Chen, T.-T. Lee and K. Peck, Nucleic Acids Res., 2004, 32, e99-e99.

554. J. Lietard and M. M. Somoza, Comp. Struct. Biotechnol. J., 2019, 17, 862-868.

555. J. Tian, H. Gong, N. Sheng, X. Zhou, E. Gulari, X. Gao and G. Church, Nature, 2004, 432, 1050-1054.

556. N. Berthet, I. Leclercq, A. Dublineau, S. Shigematsu, A. M. Burguière, C. Filippone, A. Gessain and J.-C. Manuguerra, Nat. Biotechnol., 2010, 28, 25-27.

557. J. D. Hoheisel, Nat. Rev. Genet., 2006, 7, 200-210.

558. R. Bumgarner, Curr. Prot. Mol. Biol., 2013, 101, 22.21.2122.21.11.

559. L. Ceze, J. Nivala and K. Strauss, Nat. Rev. Genet., 2019, 20, 456-466.

560. Y. Dong, F. Sun, Z. Ping, Q. Ouyang and L. Qian, Natl. Sci. Rev., 2020, 7, 1092-1107.

561. S. M. H. T. Yazdi, R. Gabrys and O. Milenkovic, Sci Rep, 2017, 7, 5011.

562. R. N. Grass, R. Heckel, C. Dessimoz and W. J. Stark, Angew. Chem. Int. Ed., 2020, 59, 8476-8480.

563. J. Koch, S. Gantenbein, K. Masania, W. J. Stark, Y. Erlich and R. N. Grass, Nat. Biotechnol., 2020, 38, 39-43.

564. M. C. Pirrung, L. Fallon and G. McGall, J. Org. Chem., 1998, 63, 241-246. 
565. G. H. McGall, A. D. Barone, M. Diggelmann, S. P. A. Fodor, E. Gentalen and N. Ngo, J. Am. Chem. Soc., 1997, 119, 5081-5090.

566. M. Beier and J. D. Hoheisel, Nucleic Acids Res., 2000, 28, e11-e11.

567. M. Sack, K. Hölz, A.-K. Holik, N. Kretschy, V. Somoza, K.-P. Stengele and M. M. Somoza, J. Nanobiotechnol., 2016, 14, 14.

568. N. Kretschy, A.-K. Holik, V. Somoza, K.-P. Stengele and M. M. Somoza, Angew. Chem. Int. Ed., 2015, 54, 8555-8559.

569. K. Hölz, J. K. Hoi, E. Schaudy, V. Somoza, J. Lietard and M. M. Somoza, Sci Rep, 2018, 8, 15099.

570. F. Yang, B. Dong, K. Nie, H. Shi, Y. Wu, H. Wang and Z. Liu, ACS Comb. Sci., 2015, 17, 608-614.

571. J. Lackey, M. Somoza, D. Mitra, F. Cerrina and M. J. Damha, Chim. Oggi-Chem. Today, 2009, 27, 30-33.

572. J. Lietard, D. Ameur, M. J. Damha and M. M. Somoza, Angew. Chem. Int. Ed., 2018, 57, 15257-15261.

573. J. Lietard, H. Abou Assi, I. Gómez-Pinto, C. González, M. M. Somoza and M. J. Damha, Nucleic Acids Res., 2017, 45, 1619-1632.

574. N. Pardi, M. J. Hogan, F. W. Porter and D. Weissman, Nat. Rev. Drug Discov., 2018, 17, 261-279. 